\title{
Selective Loading of Xylene Isomers in Self-Assembled Triphenylamine bis-Urea Macrocycles
}

\author{
Dustin W. Goodlett, ${ }^{\dagger}$ Ammon J. Sindt, ${ }^{\dagger}$ Md Faizul Islam, ${ }^{\dagger}$ Mark D. Smith, ${ }^{\dagger}$ and Linda S. \\ Shimizu ${ }^{\dagger *}$ \\ tDepartment of Chemistry and Biochemistry, University of South Carolina, Columbia, South Carolina \\ 29208, United States
}

\section{Contents}

General Experimental $\quad$ S2

$\begin{array}{lr}\text { Guest Loading } & \text { S2 } \\ 1 & \text { S3 }\end{array}$

$\begin{array}{ll}{ }^{1} \mathrm{H} \text { NMR data for } \mathbf{1} & \mathbf{S 3}\end{array}$

Table of crystallographic data for single crystals of host:guest complexes of $\mathbf{1} \quad$ S4

SCXRD data of $\mathbf{1} \cdot\left(\mathrm{CH}_{2} \mathrm{Cl}_{2}\right)_{0.52(1)} \quad \mathbf{S 6}$

$\begin{array}{lr}\text { SCXRD data of } \mathbf{1} \cdot(o \text {-xylene })_{0.5} & \text { S7 }\end{array}$

$\begin{array}{lr}\text { SCXRD data of } \mathbf{1} \cdot(m \text {-xylene })_{0.5} & \mathbf{S 8}\end{array}$

SCXRD data of $\mathbf{1} \cdot(p \text {-xylene })_{0.5} \quad$ S9

$\begin{array}{lr}\text { SCXRD data of } \mathbf{1} \cdot(E B)_{0.45} & \mathbf{S 9}\end{array}$

Tabulated results from GC/MS data for selective loading of xylene binary mixtures $\quad$ S11

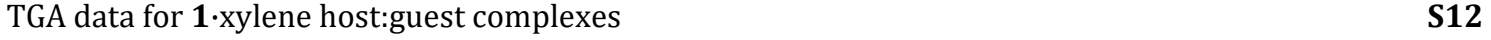

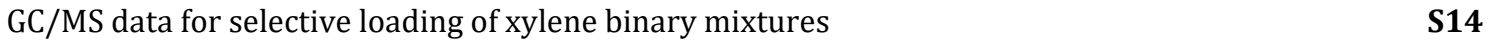

${ }^{1}$ H NMR data for selective loading of xylene binary mixtures using extracted guests $\quad \mathbf{S 5 1}$

${ }^{1} \mathrm{H}$ NMR data for selective loading of xylene binary mixtures using dissolved host:guest complexes $\quad$ S59 
General Experimental. Macrocycle 1 was synthesized as reported. ${ }^{1}$ NMR spectra were recorded on Bruker 300 or $400 \mathrm{MHz}$ spectrometers. Chemical shifts are reported in $\mathrm{ppm}(\delta)$ and were internally referenced with the solvent peak. All GC/MS data was collected using a VG705 magnetic sector mass spectrometer with HP 5890 gas chromatograph using a Restek Stabilwax-DA (30 meter capillary) column and an oven program of $40^{\circ} \mathrm{C}$ for $3 \mathrm{~min}$ then $4{ }^{\circ} \mathrm{C} / \mathrm{min}$ to $70^{\circ} \mathrm{C}$ followed by $10^{\circ} \mathrm{C} / \mathrm{min}$ to $180^{\circ} \mathrm{C}$. All chemicals were purchased from chemical suppliers and were used as received unless otherwise noted. All other instrument protocols are described in their own sections hereafter.

Guest Loading. Host 1 was crystallized via vapor diffusion of 1,2-dimethoxyethane (DME) into a dimethyl sulfoxide (DMSO) solution of $\mathbf{1}(\sim 2.5 \mathrm{mg} / \mathrm{mL}) .{ }^{1}$ The crystals $(5 \mathrm{mg})$ were activated by heating to $80^{\circ} \mathrm{C}$ under vacuum overnight, then cooled under vacuum to room temperature. Next, vials of activated host $\mathbf{1}$ were removed from vacuum and placed inside larger vials containing prepared binary xylene mixtures in for competition experiments or in pure xylene samples for SC-SC transformation studies (Figure S1). Binary mixtures were made by mixing xylenes in 7 different ratios (99:1, 4:1, 3:1, 2:1, 1:1, 1:3, 1:99). In all cases, xylene guests were allowed to vapor load into the activated host 1 crystals overnight and crystals remained colorless throughout all the studies. Each experiment was done three times and error bars were calculated for the separation (Table S2). A total of 63 competition studies and 4 single component sorption experiments were done using the same batch of crystals. Similar binary competition experiment was done using different batch of host $\mathbf{1}$ crystals with 3 trials. For the ternary competition experiment, a ternary xylene mixture (1:1:1) was made using the xylene isomers ( $1 \mathrm{~mL}$ each). $5 \mathrm{mg}$ of activated host $\mathbf{1}$ was placed inside the larger vial containing the ternary mixture. Same batch of crystals were used for three trials. Finally, for the quaternary mixture $(4 \mathrm{~mL})$, the three xylene isomers and ethyl benzene $(1: 1: 1: 1)$ was used. The guests were subsequently extracted from the complexes using $\mathrm{CH}_{2} \mathrm{Cl}_{2}$.

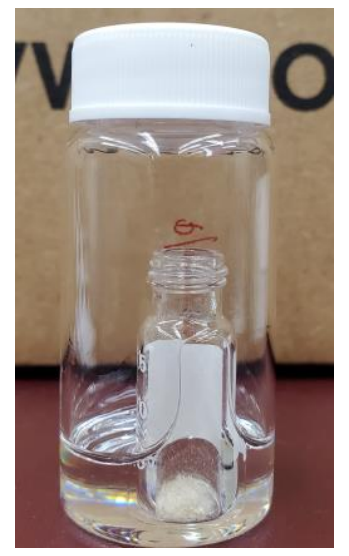

Figure S1. Guest loading setup for selective separation of xylene isomers and ethyl benzene using host 1. 
1H NMR data for host 1
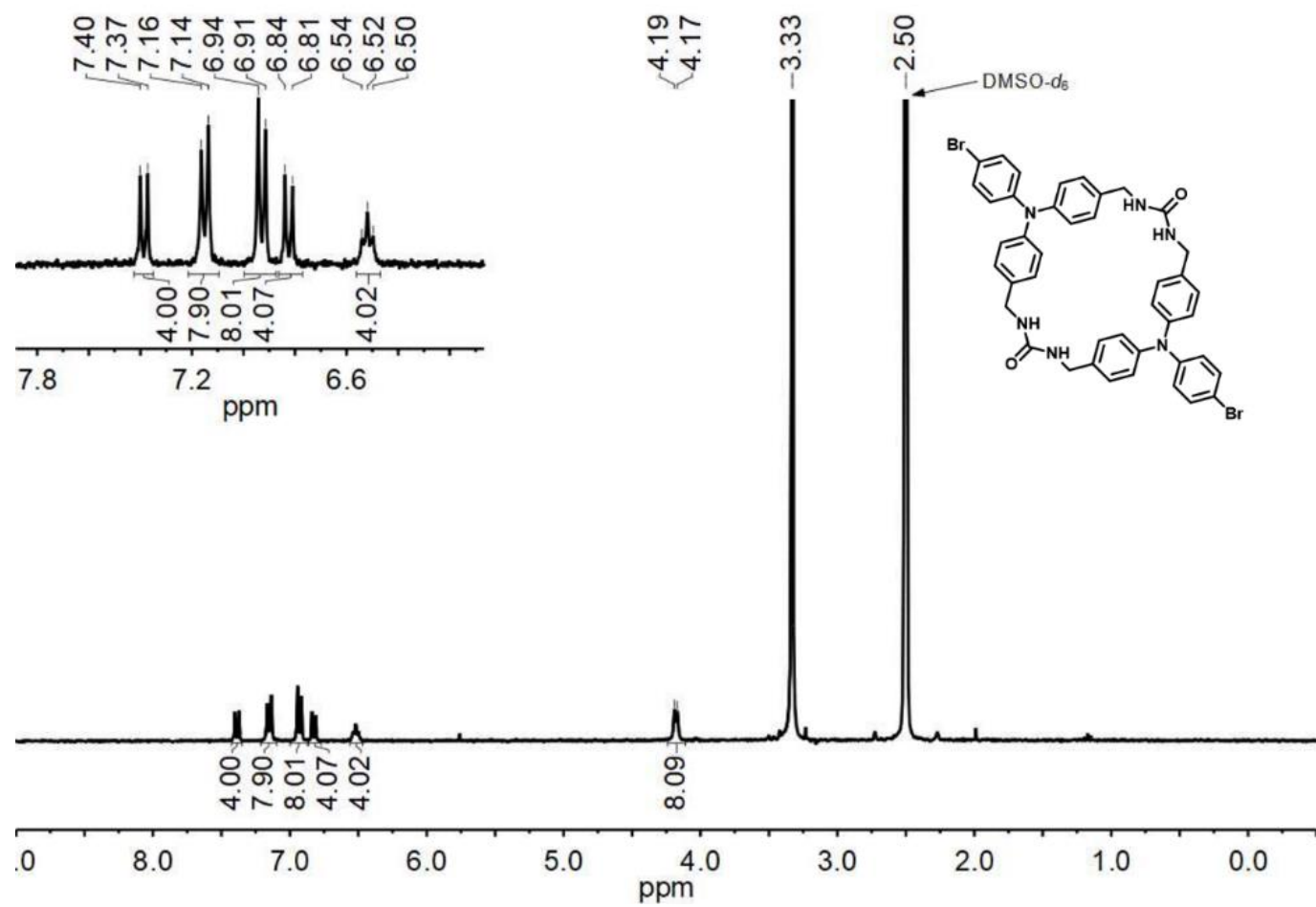

Figure S2. ${ }^{1} \mathrm{H}$ NMR of $1\left(300 \mathrm{MHz}\right.$; $\left.\left(\mathrm{CD}_{3}\right)_{2} \mathrm{SO}\right) \delta 7.39(\mathrm{~d}, J=8.8 \mathrm{~Hz}, 4 \mathrm{H}), 7.15(\mathrm{~d}, J=8.3 \mathrm{~Hz}, 8 \mathrm{H}), 6.93(\mathrm{~d}, J$ $=8.4 \mathrm{~Hz}, 8 \mathrm{H}), 6.82(\mathrm{~d}, J=8.8 \mathrm{~Hz}, 4 \mathrm{H}), 6.52(\mathrm{t}, J=6.5 \mathrm{~Hz}, 4 \mathrm{H}), 4.18(\mathrm{~d}, J=5.8 \mathrm{~Hz}, 8 \mathrm{H})$. 
Table S1. Crystallographic data for single crystals of host:guest complexes of $\mathbf{1}$.

\begin{tabular}{|c|c|c|c|c|c|}
\hline & $\mathbf{1 \cdot}\left(\mathrm{CH}_{2} \mathrm{Cl}_{2}\right)_{0.52(1)}$ & $\mathbf{1} \cdot(o \text {-xylene })_{0.5}$ & $\mathbf{1} \cdot(m \text {-xylene })_{0.5}$ & $\mathbf{1} \cdot(p \text {-xylene })_{0.5}$ & $\mathbf{1} \cdot(\mathrm{EB})_{0.45}$ \\
\hline $\begin{array}{l}\text { Empirical } \\
\text { formula }\end{array}$ & $\begin{array}{c}\mathrm{C}_{42.52} \mathrm{H}_{37.05} \mathrm{Br}_{2} \mathrm{Cl}_{1.04} \\
\mathrm{~N}_{6} \mathrm{O}_{2}\end{array}$ & $\mathrm{C}_{42} \mathrm{H}_{41} \mathrm{Br}_{2} \mathrm{~N}_{6} \mathrm{O}_{2}$ & $\mathrm{C}_{42} \mathrm{H}_{41} \mathrm{Br}_{2} \mathrm{~N}_{6} \mathrm{O}_{2}$ & $\mathrm{C}_{42} \mathrm{H}_{41} \mathrm{Br}_{2} \mathrm{~N}_{6} \mathrm{O}_{2}$ & $\mathrm{C}_{45.62} \mathrm{H}_{40.52} \mathrm{Br}_{2} \mathrm{~N}_{6} \mathrm{O}_{2}$ \\
\hline Formula weight & 860.93 & 869.67 & 869.67 & 869.67 & 864.55 \\
\hline Temperature/K & $100(2)$ & $100(2)$ & $100(2)$ & $100(2)$ & $100(2)$ \\
\hline Crystal system & monoclinic & monoclinic & monoclinic & monoclinic & monoclinic \\
\hline Space group & $\mathrm{P} 2_{1} / \mathrm{c}$ & $\mathrm{P} 2{ }_{1} / \mathrm{c}$ & $\mathrm{P} 2{ }_{1} / \mathrm{c}$ & $\mathrm{P} 2{ }_{1} / \mathrm{c}$ & $\mathrm{P} 21 / \mathrm{c}$ \\
\hline$a / \AA ̊$ & $15.8563(6)$ & $15.8607(9)$ & $15.8344(9)$ & $15.8867(8)$ & $15.8526(5)$ \\
\hline$b / \AA ̊ ̊$ & $4.6189(2)$ & $4.6458(3)$ & $4.6623(3)$ & $4.6344(3)$ & $4.6403(2)$ \\
\hline$c / \AA ̊ \AA$ & 26.7954(9) & $26.7519(14)$ & $26.8179(15)$ & 26.7064(13) & $26.8125(9)$ \\
\hline$\alpha /{ }^{\circ}$ & 90 & 90 & 90 & 90 & 90 \\
\hline$\beta /{ }^{\circ}$ & $100.0478(13)$ & $99.863(2)$ & 100.0238(17) & $99.589(2)$ & $100.0690(10)$ \\
\hline$\gamma /{ }^{\circ}$ & 90 & 90 & 90 & 90 & 90 \\
\hline Volume $/ \AA^{3} 3$ & $1932.36(13)$ & 1942.1(2) & $1949.6(2)$ & 1938.79(19) & 1941.97(12) \\
\hline $\mathbf{z}$ & 2 & 2 & 2 & 2 & 2 \\
\hline$\rho_{\text {calc }} \mathrm{g} / \mathrm{cm}^{3}$ & 1.480 & 1.487 & 1.481 & 1.490 & 1.479 \\
\hline$\mu / \mathbf{m m}^{-1}$ & 2.215 & 2.136 & 2.127 & 2.139 & 2.135 \\
\hline$F(000)$ & 876.0 & 890.0 & 890.0 & 890.0 & 884.0 \\
\hline $\begin{array}{c}\text { Crystal } \\
\text { size } / \mathbf{m m}^{3}\end{array}$ & $0.4 \times 0.04 \times 0.03$ & $0.22 \times 0.08 \times 0.04$ & $0.16 \times 0.03 \times 0.02$ & $0.16 \times 0.05 \times 0.02$ & $0.18 \times 0.07 \times 0.03$ \\
\hline Radiation & $\begin{array}{c}\operatorname{MoK} \alpha(\lambda= \\
0.71073)\end{array}$ & $\begin{array}{c}\operatorname{MoK} \alpha(\lambda= \\
0.71073)\end{array}$ & $\begin{array}{c}\operatorname{MoK} \alpha(\lambda= \\
0.71073)\end{array}$ & $\operatorname{MoK} \alpha(\lambda=0.71073)$ & $\operatorname{MoK} \alpha(\lambda=0.71073)$ \\
\hline $\begin{array}{c}2 \Theta \text { range for } \\
\text { data } \\
\text { collection/ }\end{array}$ & 4.376 to 52.85 & 3.686 to 54.986 & 3.678 to 50.086 & 4.36 to 50.064 & 4.376 to 56.628 \\
\hline Index ranges & $\begin{array}{l}-19 \leq \mathrm{h} \leq 19,-5 \leq \\
\mathrm{k} \leq 5,-33 \leq \mathrm{l} \leq 33\end{array}$ & $\begin{array}{l}-20 \leq \mathrm{h} \leq 20,-6 \leq \\
\mathrm{k} \leq 6,-34 \leq \mathrm{l} \leq 34\end{array}$ & $\begin{array}{l}-18 \leq h \leq 18,-5 \leq \\
k \leq 5,-31 \leq l \leq 31\end{array}$ & $\begin{array}{c}-18 \leq \mathrm{h} \leq 18,-5 \leq \mathrm{k} \leq \\
5,-29 \leq \mathrm{l} \leq 31\end{array}$ & $\begin{array}{c}-21 \leq \mathrm{h} \leq 21,-6 \leq \mathrm{k} \leq \\
6,-35 \leq \mathrm{l} \leq 35\end{array}$ \\
\hline
\end{tabular}




\begin{tabular}{|c|c|c|c|c|c|}
\hline $\begin{array}{c}\text { Reflections } \\
\text { collected }\end{array}$ & 38814 & 41228 & 22622 & 25380 & 67694 \\
\hline $\begin{array}{l}\text { Independent } \\
\text { reflections }\end{array}$ & $\begin{array}{c}3965[\text { Rint }= \\
0.0399, \text { Rsigma }= \\
0.0203]\end{array}$ & $\begin{array}{c}4434[\text { Rint }= \\
0.0510, \text { Rsigma }= \\
0.0308]\end{array}$ & $\begin{array}{c}3456[\text { Rint }= \\
0.0671, \text { Rsigma }= \\
0.0433]\end{array}$ & $\begin{array}{c}3406[\text { Rint }=0.0692, \\
\left.R_{\text {sigma }}=0.0400\right]\end{array}$ & $\begin{array}{c}4828[\text { Rint }=0.0479, \\
\left.R_{\text {sigma }}=0.0198\right]\end{array}$ \\
\hline $\begin{array}{l}\text { Data/restraints } \\
\text { /parameters }\end{array}$ & $3965 / 11 / 272$ & $4434 / 40 / 271$ & $3456 / 10 / 261$ & $3406 / 2 / 258$ & $4828 / 8 / 264$ \\
\hline $\begin{array}{c}\text { Goodness-of-fit } \\
\text { on } F^{2}\end{array}$ & 1.090 & 1.073 & 1.143 & 1.139 & 1.049 \\
\hline $\begin{array}{c}\text { Final } R \text { indexes } \\
{[I \geq 2 \sigma(I)]}\end{array}$ & $\begin{aligned} \mathrm{R} 1= & 0.0370, \mathrm{wR} 2 \\
& =0.0869\end{aligned}$ & $\begin{aligned} \mathrm{R} 1= & 0.0493, \mathrm{wR} 2 \\
& =0.1123\end{aligned}$ & $\begin{aligned} \mathrm{R} 1 & =0.0546, \mathrm{wR} 2 \\
& =0.0957\end{aligned}$ & $\begin{array}{c}\mathrm{R} 1=0.0557, \mathrm{wR} 2= \\
0.1013\end{array}$ & $\begin{array}{c}\mathrm{R} 1=0.0338, w \mathrm{R} 2= \\
0.0801\end{array}$ \\
\hline $\begin{array}{c}\text { Final } R \text { indexes } \\
\text { [all data] }\end{array}$ & $\begin{aligned} \mathrm{R} 1= & 0.0428, \mathrm{wR} 2 \\
& =0.0895\end{aligned}$ & $\begin{aligned} \mathrm{R} 1= & 0.0637, \mathrm{wR} 2 \\
& =0.1186\end{aligned}$ & $\begin{aligned} \mathrm{R} 1 & =0.0737, \mathrm{wR} 2 \\
& =0.1010\end{aligned}$ & $\begin{array}{c}\mathrm{R} 1=0.0702, \mathrm{wR} 2= \\
0.1062\end{array}$ & $\begin{array}{c}\mathrm{R} 1=0.0420, \mathrm{wR} 2= \\
0.0841\end{array}$ \\
\hline $\begin{array}{c}\text { Largest diff. } \\
\text { peak/hole/eÅ }\end{array}$ & $0.54 /-0.43$ & $1.10 /-0.59$ & $0.77 /-0.54$ & $0.38 /-0.59$ & $0.84 /-0.55$ \\
\hline
\end{tabular}




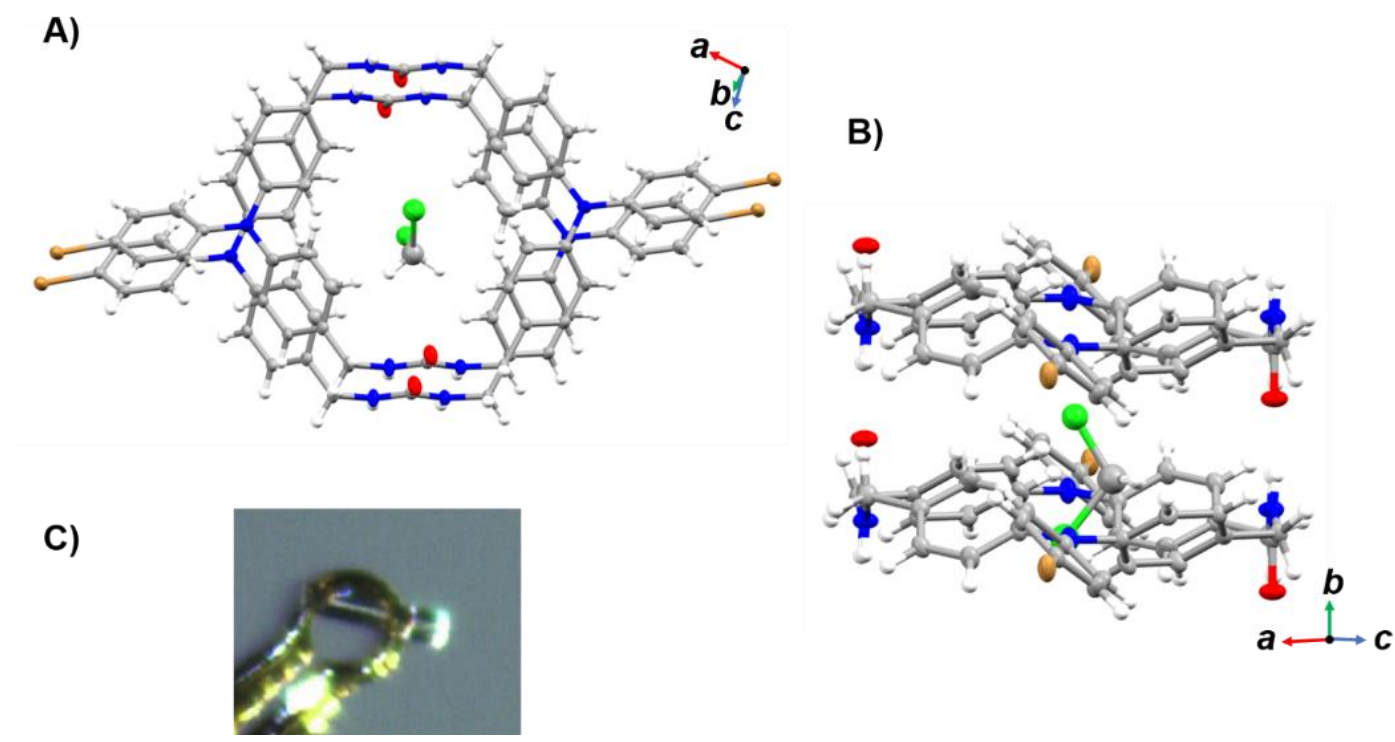

Figure S3. SC-XRD determined structure of $\mathbf{1} \cdot\left(\mathrm{CH}_{2} \mathrm{Cl}_{2}\right)_{0.52(1)}$ viewed along the crystallographic $b$ axis $(\mathrm{A})$ with an alternate view of the host:guest complex (B). Thermal ellipsoids were drawn at the $50 \%$ probability level. The mounted single crystal is shown (C) Mounted single crystal, $0.4 \times 0.04 \times 0.03 \mathrm{~mm}^{3}$.

X-ray intensity data from a colorless needle were collected at 100(2) K using a Bruker D8 QUEST diffractometer equipped with a PHOTON-100 CMOS area detector and an Incoatec microfocus source (Mo K $\alpha$ radiation, $\lambda=0.71073 \AA$ ). The raw area detector data frames were reduced and corrected for absorption effects using the Bruker APEX3, SAINT+ and SADABS programs. ${ }^{2,3}$ The structure was solved with SHELXT. ${ }^{4}$ Subsequent difference Fourier calculations and full-matrix least-squares refinement against $F^{3}$ were performed with SHELXL-2018 ${ }^{3}$ using OLEX2. ${ }^{5}$

The compound crystallizes in the space group $P 2_{1} / c$ of the monoclinic system. The asymmetric unit consists of half of one $\mathrm{C}_{42} \mathrm{H}_{36} \mathrm{Br}_{2} \mathrm{~N}_{6} \mathrm{O}_{2}$ cycle located on a crystallographic inversion center and several electron density peaks located inside the tubular channels created by the cycle columns. The residual difference electron density in the channel region is highly disordered, but arranged in a planar zigzag planar fashion along the crystallographic $b$ axis direction. Two peaks refined to significantly greater than or near $100 \%$ carbon occupancy. These were initially modeled as chlorine atoms from dichloromethane but were subsequently split. Ultimately three independent, partially occupied $\mathrm{CH}_{2} \mathrm{Cl}_{2}$ molecules were modeled. Both are further disordered about crystallographic inversion centers. Distance restraints of $d(\mathrm{C}-\mathrm{Cl})=1.75(2) \AA$ and $d(\mathrm{Cl}-\mathrm{Cl})=2.90(2) \AA$ were applied. Occupancies refined to: $\mathrm{C} 1 \mathrm{~S}=0.175(2), \mathrm{C} 2 \mathrm{~S}=0.030(2)$ and $\mathrm{C} 3 \mathrm{~S}=0.055(2)$, generating a $\mathrm{CH}_{2} \mathrm{Cl}_{2}$ composition per cycle of $0.52(1)$. All non-hydrogen atoms were refined with anisotropic displacement parameters except for the disordered dichloromethane atoms (isotropic). Hydrogen atoms bonded to carbon were placed in geometrically idealized positions and included as riding atoms with $d(\mathrm{C}-\mathrm{H})=0.95 \AA$ and $\operatorname{Uiso}(\mathrm{H})=1.2$ Ueq(C) for aromatic hydrogen atoms and $d(\mathrm{C}-\mathrm{H})=0.99 \AA$ and $U$ iso $(\mathrm{H})=1.2 U \mathrm{eq}(\mathrm{C})$ for methylene hydrogen atoms. The two urea hydrogen atoms were located and refined with $d(\mathrm{~N}-\mathrm{H})=0.85(2) \AA$ distance restraints and a common displacement parameter. The largest residual electron density peak in the final difference map is $0.54 \mathrm{e}^{-} / \AA^{3}$, located $0.95 \AA$ from $\mathrm{Br} 1$. 

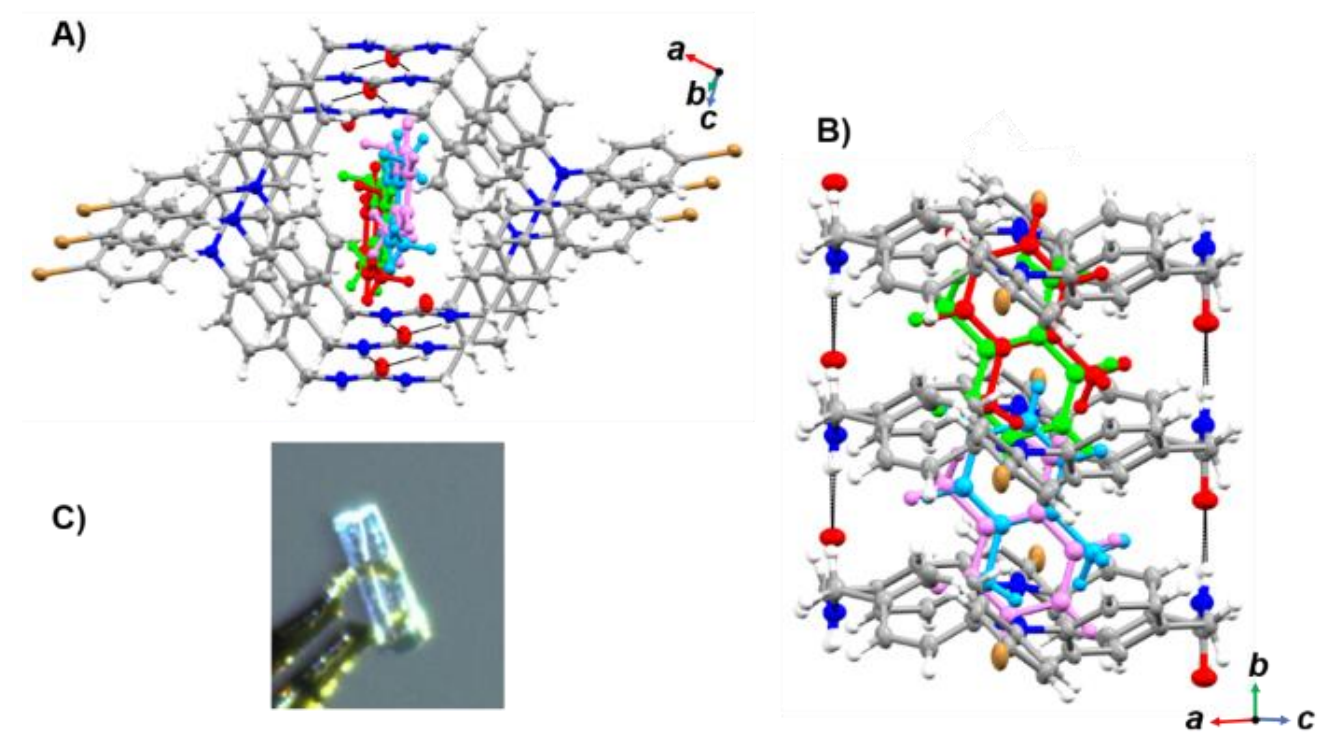

Figure S4. SC-XRD determined structure of $\mathbf{1} \cdot(o \text {-xylene })_{0.5}$ viewed along the crystallographic $b$ axis $(A)$ with an alternate view of the host:guest complex (B). Molecules of the disordered guest are colored for better visibility. Thermal ellipsoids were drawn at the $50 \%$ probability level. The mounted single crystal is shown (C) Mounted single crystal, $0.22 \times 0.08 \times 0.04 \mathrm{~mm}^{3}$.

X-ray intensity data from a colorless needle were collected at 100(2) K using a Bruker D8 QUEST diffractometer equipped with a PHOTON-100 CMOS area detector and an Incoatec microfocus source (Mo K $\alpha$ radiation, $\lambda=0.71073 \AA$ A). The raw area detector data frames were reduced, scaled and corrected for absorption effects using the Bruker APEX3, SAINT+ and SADABS programs. ${ }^{2.3}$ The structure was solved with SHELXT. ${ }^{4}$ Subsequent difference Fourier calculations and full-matrix least-squares refinement against $F^{2}$ were performed with SHELXL-2018 3 using OLEX2. ${ }^{5}$

The compound crystallizes in the monoclinic system. The pattern of systematic absences in the intensity data was uniquely consistent with the space group $P 2_{1} / c$, which was confirmed by structure solution. The ordered part of the asymmetric unit consists of half of one $\mathrm{C}_{42} \mathrm{H}_{36} \mathrm{Br}_{2} \mathrm{~N}_{6} \mathrm{O}_{2}$ cycle located on a crystallographic inversion center. Additional severely disordered electron density peaks were observed inside the tubular channels created by columns of $\mathrm{C}_{42} \mathrm{H}_{36} \mathrm{Br}_{2} \mathrm{~N}_{6} \mathrm{O}_{2}$ molecules. The residual electron density in the channel region is arranged in a planar, tapelike fashion along the crystallographic $b$ axis direction. These peaks, all of roughly the same magnitude, were eventually modeled reasonably as two partially occupied ortho-xylene components. The two $o$-xylene components are located near a crystallographic inversion center, and also are close to two other equivalents. The maximum allowable total group occupancy is therefore $1 / 4$ per asymmetric unit. For the final refinement cycles, the $o$-xylene component total occupancy was restrained to sum to 0.25 . To maintain a chemically reasonable geometry, the six-membered ring was refined as a rigid hexagon with $d(\mathrm{C}-\mathrm{C})=1.39 \AA$ and appropriate 1,2 - and 1,3-C-C distance restraints were applied to the two methyl carbons. All non-hydrogen atoms were refined with anisotropic displacement parameters except for atoms of the disordered $o$-xylene guest, which were refined with a common isotropic displacement parameter for each component. Hydrogen atoms bonded to carbon placed in geometrically idealized positions and included as riding atoms with $d(\mathrm{C}-\mathrm{H})=0.95 \AA$ and $U$ iso $(\mathrm{H})=1.2 U$ eq $(\mathrm{C})$ for arene hydrogen atoms, $d(\mathrm{C}-\mathrm{H})=0.99 \AA$ and Uiso $(\mathrm{H})=1.2 \mathrm{Ueq}(\mathrm{C})$ for methylene hydrogen atoms, and $d(\mathrm{C}-\mathrm{H})=0.98 \AA$ and $U$ iso $(\mathrm{H})=1.5 \mathrm{Ueq}(\mathrm{C})$ for methyl hydrogens. The methyl hydrogens were allowed to rotate as a rigid group to the orientation of maximum observed electron density. The two urea hydrogen atoms were located in difference maps and refined isotropically with $d(\mathrm{~N}-\mathrm{H})=0.85(2)$ A distance restraints. The largest residual electron density peak in the final difference map is $1.10 \mathrm{e}^{-} / \AA^{3}$, located $0.42 \AA$ from C11S. 

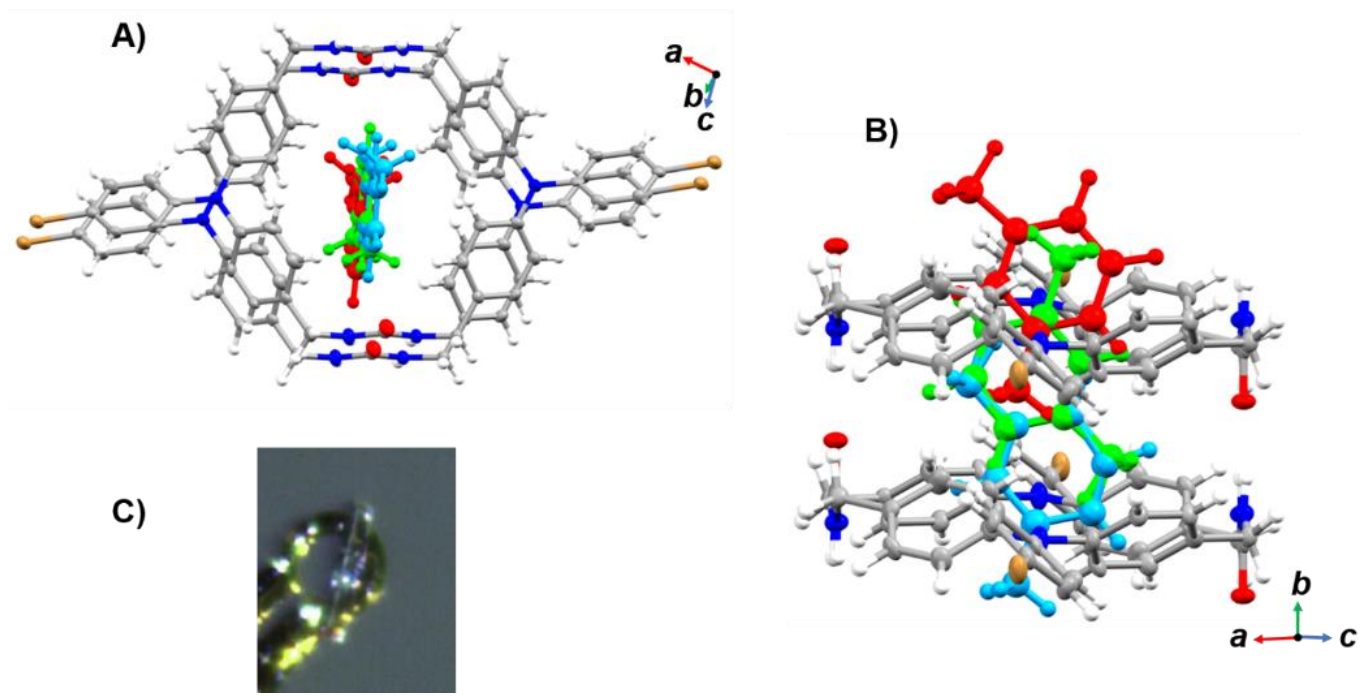

Figure S5. SC-XRD determined structure of $\mathbf{1} \cdot(m \text {-xylene })_{0.5}$ viewed along the crystallographic $b$ axis (A) with an alternate view of the host:guest complex (B). Molecules of the disordered guest are colored for better visibility. Thermal ellipsoids were drawn at the $50 \%$ probability level. The mounted single crystal is shown (C) Mounted single crystal, $0.16 \times 0.03 \times 0.02 \mathrm{~mm}^{3}$.

X-ray intensity data from a colorless needle were collected at 100(2) K using a Bruker D8 QUEST diffractometer equipped with a PHOTON-100 CMOS area detector and an Incoatec microfocus source (Mo K $\alpha$ radiation, $\lambda=0.71073 \AA$ ). The raw area detector data frames were reduced, scaled and corrected for absorption effects using the Bruker APEX3, SAINT+ and SADABS programs. ${ }^{2,3}$ The structure was solved with SHELXT. ${ }^{4}$ Subsequent difference Fourier calculations and full-matrix least-squares refinement against $F^{2}$ were performed with SHELXL-2018 ${ }^{3}$ using OLEX2.5

The compound crystallizes in the monoclinic system. The pattern of systematic absences in the intensity data was uniquely consistent with the space group $P 2_{1} / c$, which was confirmed by structure solution. The ordered part of the asymmetric unit consists of half of one $\mathrm{C}_{42} \mathrm{H}_{36} \mathrm{Br}_{2} \mathrm{~N}_{6} \mathrm{O}_{2}$ cycle located on a crystallographic inversion center. Additional electron density peaks were observed inside the tubular channels created by columns of $\mathrm{C}_{42} \mathrm{H}_{36} \mathrm{Br}_{2} \mathrm{~N}_{6} \mathrm{O}_{2}$ molecules. The residual electron density in the channel region is arranged in a planar, tapelike fashion along the crystallographic $b$ axis direction. These peaks, all of roughly the same magnitude, modeled well as a partially occupied meta-xylene molecule. The $m$-xylene is also located near a crystallographic inversion center, and close to two other translationally related equivalents. The maximum allowable group occupancy is therefore $1 / 4$. Refinement of the $m$-xylene group occupancy parameter gave $0.257(3)$, within experimental error of 0.25 . For the final refinement cycles, the $m$-xylene occupancy was fixed at 0.25 . To maintain a chemically reasonable geometry, the six-membered ring was refined as a rigid hexagon with $d(\mathrm{C}-\mathrm{C})=1.39 \AA$ and appropriate $1,2-$ and 1,3-C-C distance restraints were applied to the two methyl carbons. All non-hydrogen atoms were refined with anisotropic displacement parameters except for atoms of the disordered $m$-xylene guest, which were refined isotropically. Hydrogen atoms bonded to carbon placed in geometrically idealized positions and included as riding atoms with $d(\mathrm{C}-\mathrm{H})=0.95 \AA$ and $\operatorname{Uiso}(\mathrm{H})=1.2 \operatorname{Ueq}(\mathrm{C})$ for arene hydrogen atoms, $d(\mathrm{C}-\mathrm{H})=0.99 \AA$ and $U$ iso $(\mathrm{H})=1.2 U \mathrm{eq}(\mathrm{C})$ for methylene hydrogen atoms, and $d(\mathrm{C}-\mathrm{H})=0.98 \AA$ and $U$ iso $(\mathrm{H})=1.5 \mathrm{Ueq}(\mathrm{C})$ for methyl hydrogens. The methyl hydrogens were allowed to rotate as a rigid group to the orientation of maximum observed electron density. The two urea hydrogen atoms were located in difference maps and refined isotropically with $d(\mathrm{~N}-\mathrm{H})=0.85(2) \AA$ distance restraints. The largest residual electron density peak in the final difference map is $0.77 \mathrm{e}-/ \AA^{3}$, located $0.27 \AA$ from H37C. 


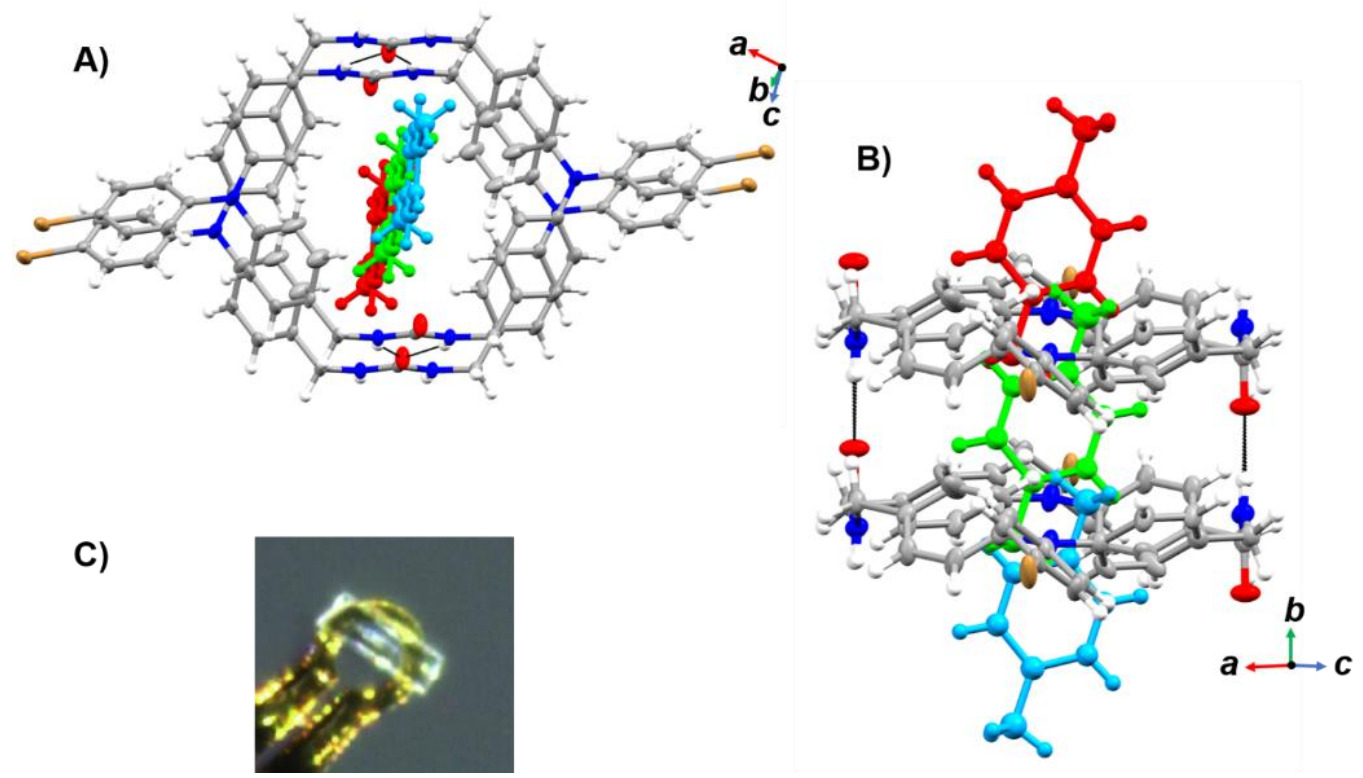

Figure S6. SC-XRD determined structure of 1·( $p$-xylene $)_{0.5}$ viewed along the crystallographic $b$ axis $(A)$ with an alternate view of the host:guest complex (B). Molecules of the disordered guest are colored for better visibility. Thermal ellipsoids were drawn at the $50 \%$ probability level. (C) The mounted single crystal is shown, $0.16 \mathrm{x} 0.05 \mathrm{x}$ $0.02 \mathrm{~mm}^{3}$.

X-ray intensity data from a colorless needle were collected at 100(2) K using a Bruker D8 QUEST diffractometer equipped with a PHOTON-100 CMOS area detector and an Incoatec microfocus source (Mo K $\alpha$ radiation, $\lambda=0.71073 \AA$ ). The raw area detector data frames were reduced, scaled and corrected for absorption effects using the Bruker APEX3, SAINT+ and SADABS programs. ${ }^{2,3}$ The structure was solved with SHELXT. ${ }^{4}$ Subsequent difference Fourier calculations and full-matrix least-squares refinement against $F^{2}$ were performed with SHELXL-2018 ${ }^{3}$ using OLEX2. ${ }^{5}$

The compound crystallizes in the monoclinic system. The pattern of systematic absences in the intensity data was uniquely consistent with the space group $P 2_{1} / c$, which was confirmed by structure solution. The ordered part of the asymmetric unit consists of half of one $\mathrm{C}_{42} \mathrm{H}_{36} \mathrm{Br}_{2} \mathrm{~N}_{6} \mathrm{O}_{2}$ cycle located on a crystallographic inversion center. Additional electron density peaks were observed inside the tubular channels created by columns of $\mathrm{C}_{42} \mathrm{H}_{36} \mathrm{Br}_{2} \mathrm{~N}_{6} \mathrm{O}_{2}$ molecules. The residual electron density in the channel region is arranged in a planar, tapelike fashion along the crystallographic $b$ axis direction. Four primary peaks were located, all of roughly the same magnitude, which were reasonably modeled as half of a partially occupied para-xylene molecule. The $p$-xylene is located on a crystallographic inversion center, and is also close to another translationally related equivalent. The maximum allowable group occupancy is therefore $1 / 2$. Free refinement of the $p$-xylene group occupancy parameter gave $0.505(5)$, within experimental error of 0.5 . For the final refinement cycles, the $p$-xylene occupancy was fixed at 0.5 . The four unique $p$-xylene atoms could be refined freely without the need for restraints to maintain a chemically reasonable geometry. All non-hydrogen atoms were refined with anisotropic displacement parameters except for atoms of the disordered $p$-xylene guest, which were refined isotropically. Hydrogen atoms bonded to carbon placed in geometrically idealized positions and included as riding atoms with $d(\mathrm{C}-\mathrm{H})=0.95 \AA$ and $U$ iso $(\mathrm{H})=1.2 U$ eq $(\mathrm{C})$ for arene hydrogen atoms, $d(\mathrm{C}-\mathrm{H})=0.99 \AA$ and $U$ iso $(\mathrm{H})=1.2 U$ eq $(\mathrm{C})$ for methylene hydrogen atoms, and $d(\mathrm{C}-\mathrm{H})=0.98 \AA$ and $U$ iso $(\mathrm{H})=$ $1.5 \mathrm{Ueq}(\mathrm{C})$ for methyl hydrogens. The methyl hydrogens were allowed to rotate as a rigid group to the orientation of maximum observed electron density. The two urea hydrogen atoms were located in difference maps and refined isotropically with $d(\mathrm{~N}-$ $\mathrm{H})=0.85(2) \AA$ distance restraints. The largest residual electron density peak in the final difference map is $0.38 \mathrm{e}^{-} / \AA^{3}$, located $1.18 \AA$ from Br1. 


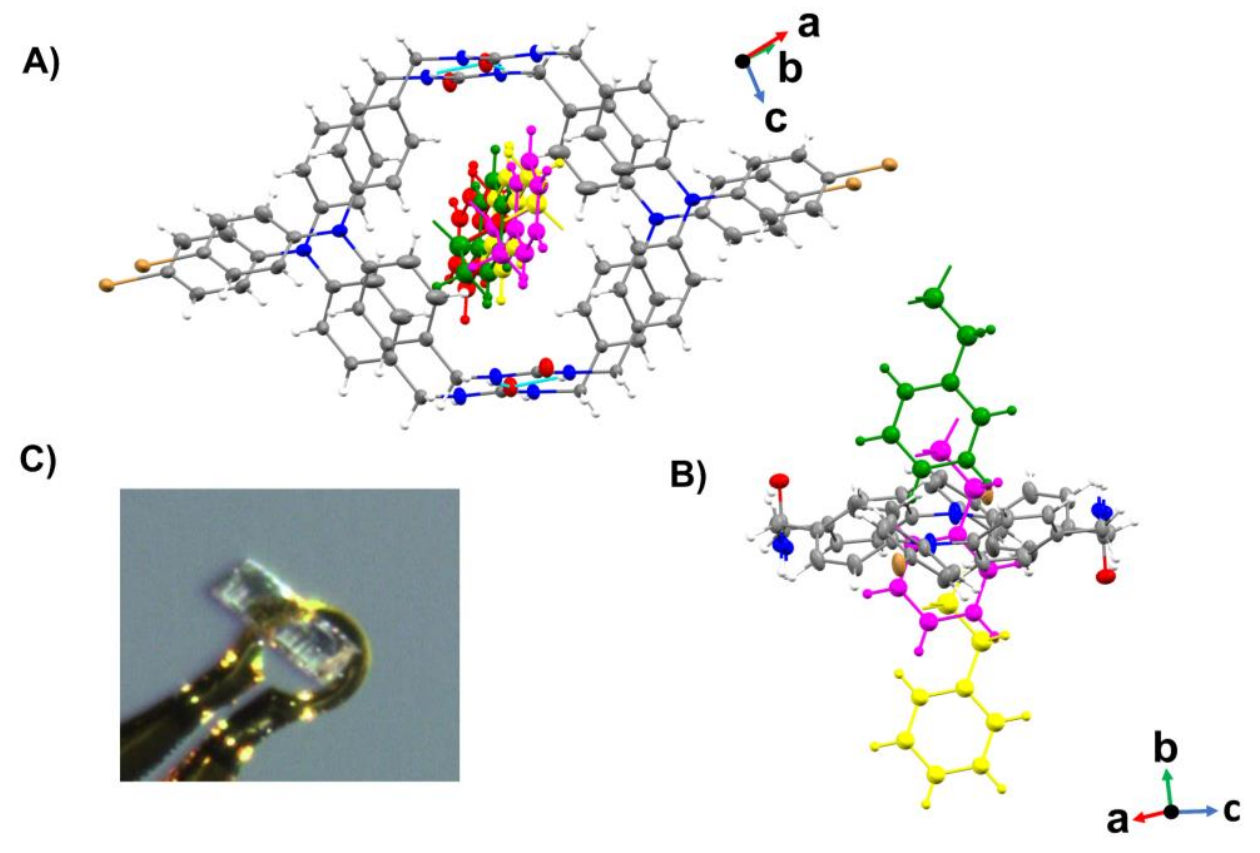

Figure S7. SC-XRD determined structure of 1-(EB) $)_{0.45}$ viewed along the crystallographic $b$ axis (A) with an alternate view of the host:guest complex (B). Molecules of the disordered guest are colored for better visibility. Thermal ellipsoids were drawn at the $50 \%$ probability level. (C) Mounted single crystal, $0.18 \times 0.07 \times 0.03 \mathrm{~mm}^{3}$.

X-ray intensity data from a colorless needle were collected at 100(2) K using a Bruker D8 QUEST diffractometer equipped with a PHOTON-100 CMOS area detector and an Incoatec microfocus source (Mo Ka radiation, $\lambda=0.71073 \AA$ ). The raw area detector data frames were reduced, scaled and corrected for absorption effects using the Bruker APEX3, SAINT+ and SADABS programs. ${ }^{2,3}$ The structure was solved with SHELXT. ${ }^{4}$ Subsequent difference Fourier calculations and full-matrix least-squares refinement against $F^{2}$ were performed with SHELXL-2018 ${ }^{3}$ using OLEX2. ${ }^{5}$

The compound crystallizes in the monoclinic system. The pattern of systematic absences in the intensity data was uniquely consistent with the space group $P 2_{1} / c$, which was confirmed by structure solution. The ordered part of the asymmetric unit consists of half of one $\mathrm{C}_{42} \mathrm{H}_{36} \mathrm{Br}_{2} \mathrm{~N}_{6} \mathrm{O}_{2}$ cycle located on a crystallographic inversion center. Additional electron density peaks were observed inside the tubular channels created by columns of $\mathrm{C}_{42} \mathrm{H}_{36} \mathrm{Br}_{2} \mathrm{~N}_{6} \mathrm{O}_{2}$ molecules. The residual electron density in the channel region is arranged in a planar, tapelike fashion along the crystallographic $b$ axis direction. These peaks, all of roughly the same magnitude, modeled well as a partially occupied ethylbenzene molecule. The ethylbenzene is also located near crystallographic inversion centers, and close to other translationally related equivalents. Refinement of the ethylbenzene group occupancy parameter gave $0.226(2)$. To maintain a chemically reasonable geometry, the six-membered ring was refined as a rigid hexagon with $d(\mathrm{C}-\mathrm{C})=1.39 \AA$ and appropriate $1,2-$ and $1,3-\mathrm{C}-\mathrm{C}$ distance restraints were applied to the two ethyl group carbons. All non-hydrogen atoms were refined with anisotropic displacement parameters except for atoms of the disordered ethylbenzene guest, which were refined isotropically. Hydrogen atoms bonded to carbon placed in geometrically idealized positions and included as riding atoms with $d(\mathrm{C}-\mathrm{H})=0.95 \AA$ and $U$ iso $(\mathrm{H})=$ $1.2 U$ eq $(\mathrm{C})$ for arene hydrogen atoms, $d(\mathrm{C}-\mathrm{H})=0.99 \AA$ and $U$ iso $(\mathrm{H})=1.2 U \mathrm{eq}(\mathrm{C})$ for methylene hydrogen atoms, and $d(\mathrm{C}-\mathrm{H})=$ $0.98 \AA$ and $U$ iso $(\mathrm{H})=1.5 U$ eq $(\mathrm{C})$ for methyl hydrogens. The two urea hydrogen atoms were located in difference maps and refined isotropically with $d(\mathrm{~N}-\mathrm{H})=0.87(2) \AA$ distance restraints. The largest residual electron density peak in the final difference map is $0.84 \mathrm{e}^{-} / \AA^{3}$, located $1.00 \AA$ from $\mathrm{Br} 1$. 
A)

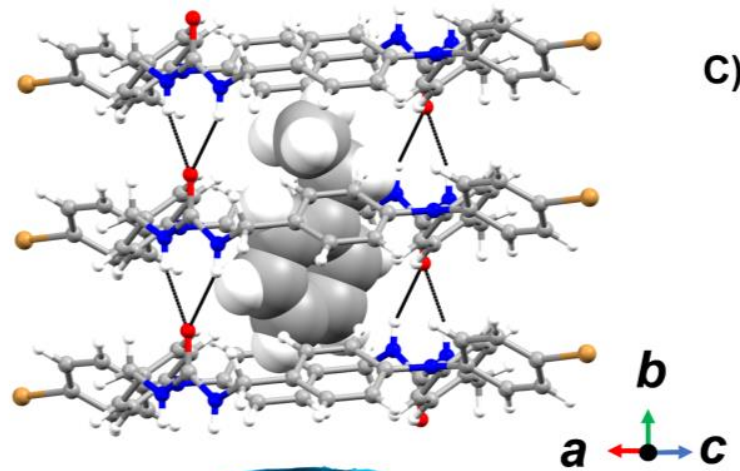

B)
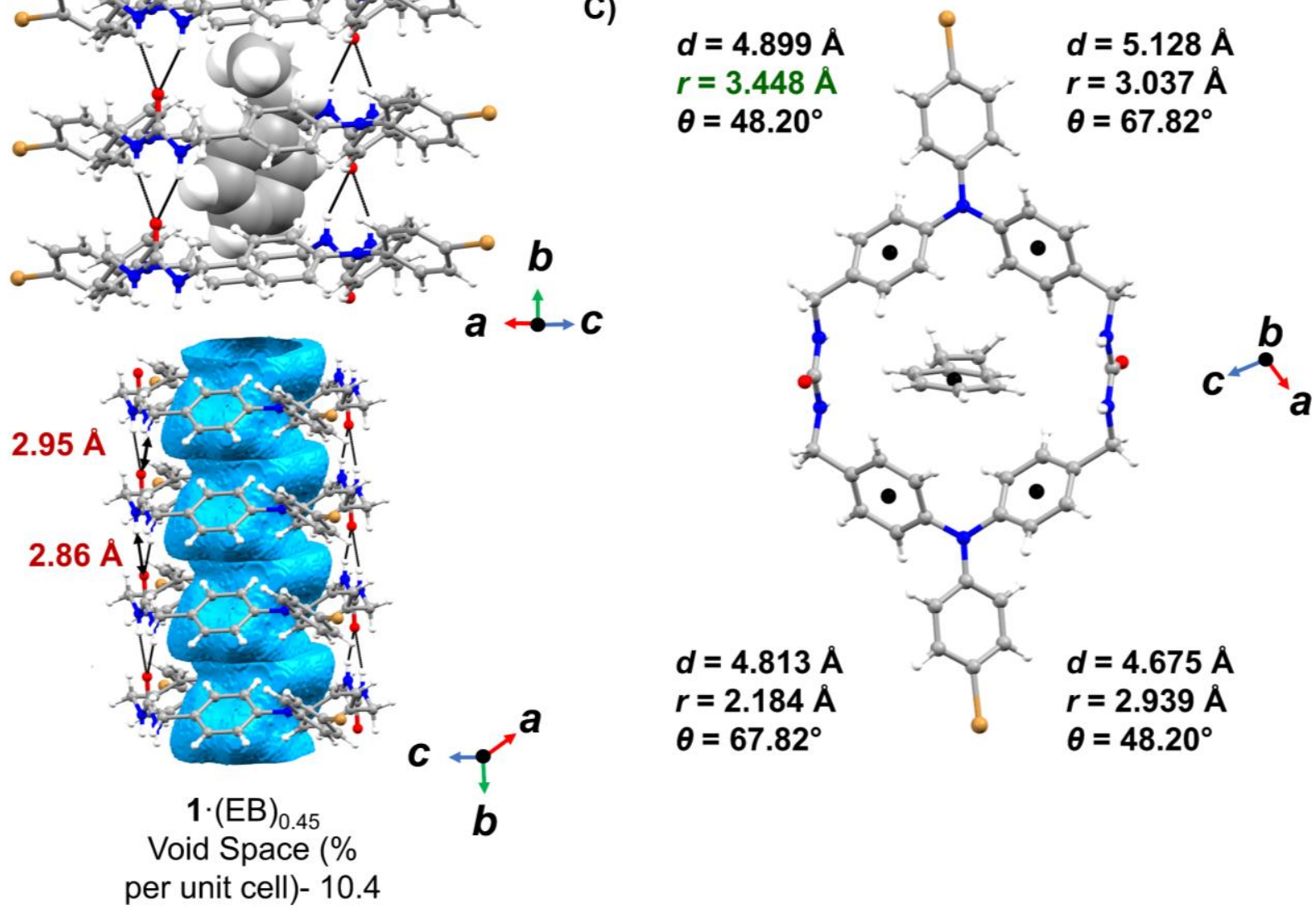

Figure S8. A) B) C) Schematic diagram illustrating key attributes for $\pi-\pi$ interactions for 1.(EB) 0.45 : centroid-centroid distance (d), centroid-centroid offset (r), and interplanar angle $(\theta)$. B) The xylene guest and nearest macrocycle from each of the complexes. Key attributes for $\pi-\pi$ interactions are listed beside the aryl rings making up the inner pore of host $\mathbf{1}$. (d) distance between the host and guest. Offset values (r) that fall within the most commonly reported range are highlighted in green.

Table S2. Tabulated average results from GC/MS data for selective loading of xylene binary mixtures across three trails.

\begin{tabular}{|c|c|c|c|c|c|}
\hline \multicolumn{2}{|c|}{$o$-xylene/m-xylene } & \multicolumn{2}{|c|}{$m$-xylene $/ p$-xylene } & \multicolumn{2}{|c|}{$o$-xylene $/ p$-xylene } \\
\hline $\begin{array}{l}\% m \text {-xylene } \\
\text { in solution }\end{array}$ & $\begin{array}{l}\% \text { m-xylene } \\
\text { in crystals }\end{array}$ & $\begin{array}{l}\% p \text {-xylene in } \\
\text { solution }\end{array}$ & $\begin{array}{l}\% p \text {-xylene in } \\
\text { crystals }\end{array}$ & $\begin{array}{c}\% p \text {-xylene in } \\
\text { solution }\end{array}$ & $\begin{array}{l}\% p \text {-xylene in } \\
\text { crystals }\end{array}$ \\
\hline 1.00 & $11.3 \pm 1.1$ & 1.00 & $33.3 \pm 27.3$ & 1.00 & $38.4 \pm 32.9$ \\
\hline 20.0 & $55.6 \pm 4.7$ & 20.0 & $61.3 \pm 19.6$ & 20.0 & $58.9 \pm 10.4$ \\
\hline 25.0 & $64.0 \pm 2.2$ & 25.0 & $57.6 \pm 8.8$ & 25.0 & $59.9 \pm 12.2$ \\
\hline 33.3 & $66.0 \pm 5.3$ & 33.3 & $67.7 \pm 8.0$ & 33.3 & $69.2 \pm 7.2$ \\
\hline 50.0 & $79.7 \pm 11.1$ & 50.0 & $69.4 \pm 8.3$ & 50.0 & $70.7 \pm 6.4$ \\
\hline 75.0 & $87.0 \pm 1.4$ & 75.0 & $88.6 \pm 4.0$ & 75.0 & $91.3 \pm 6.2$ \\
\hline 99.0 & $99.4 \pm 0.2$ & 99.0 & $98.9 \pm 0.5$ & 99.0 & $99.5 \pm 0.2$ \\
\hline
\end{tabular}



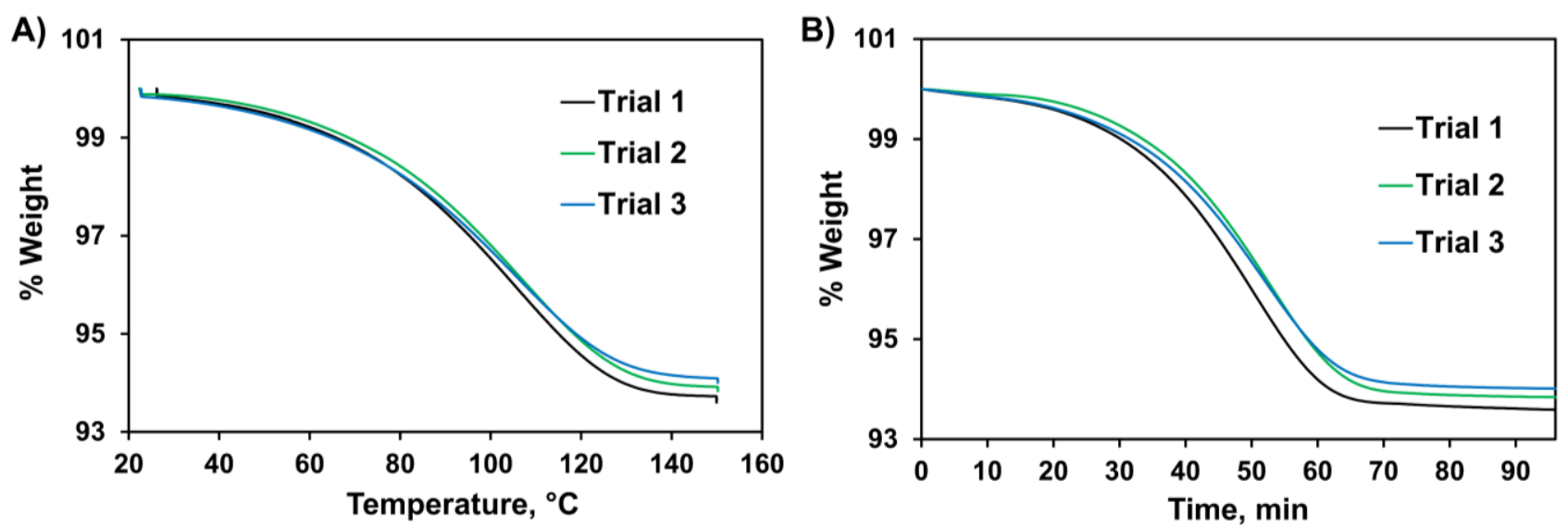

Figure S9. TGA of $p$-xylene A) \% weight loss plotted against temperature $\left.\left({ }^{\circ} \mathrm{C}\right), \mathrm{B}\right) \%$ weight loss plotted against time (min), Compound was kept into isotherm at $25^{\circ} \mathrm{C}$ for 10 minutes. Then temperature was ramped up to $150^{\circ} \mathrm{C}(\mathrm{rate}$ $\left.=2^{\circ} \mathrm{C} / \mathrm{min}\right)$.

A)

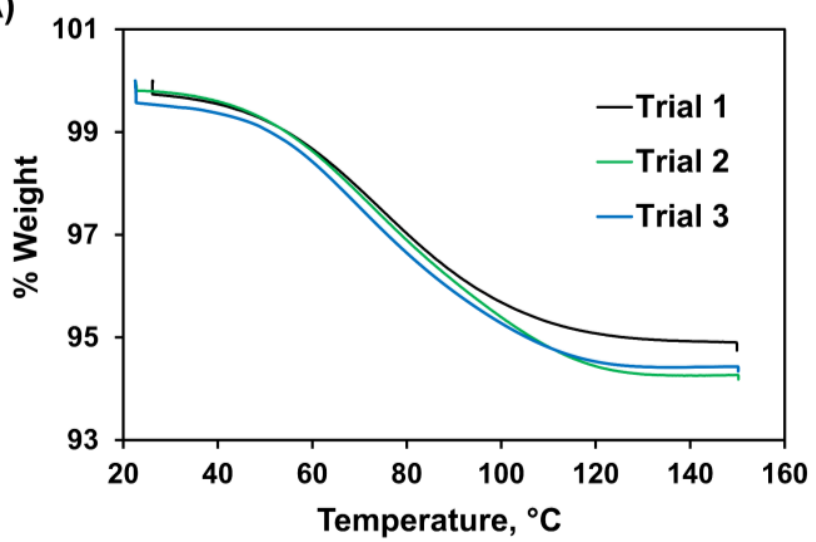

B)

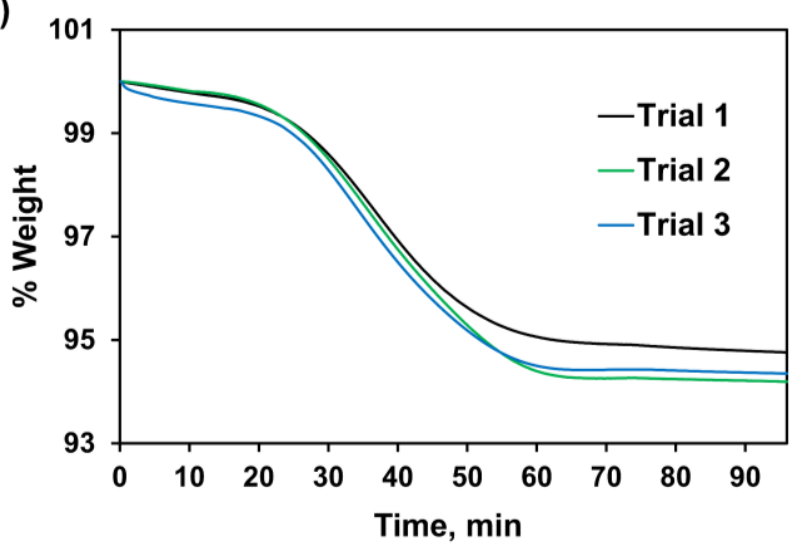

Figure S10. TGA of $o$-xylene A) \% weight loss plotted against temperature $\left.\left({ }^{\circ} \mathrm{C}\right), \mathrm{B}\right) \%$ weight loss plotted against time (min), Compound was kept into isotherm at $25^{\circ} \mathrm{C}$ for 10 minutes. Then temperature was ramped up to $150^{\circ} \mathrm{C}$ (rate $\left.=2^{\circ} \mathrm{C} / \mathrm{min}\right)$. 
A)

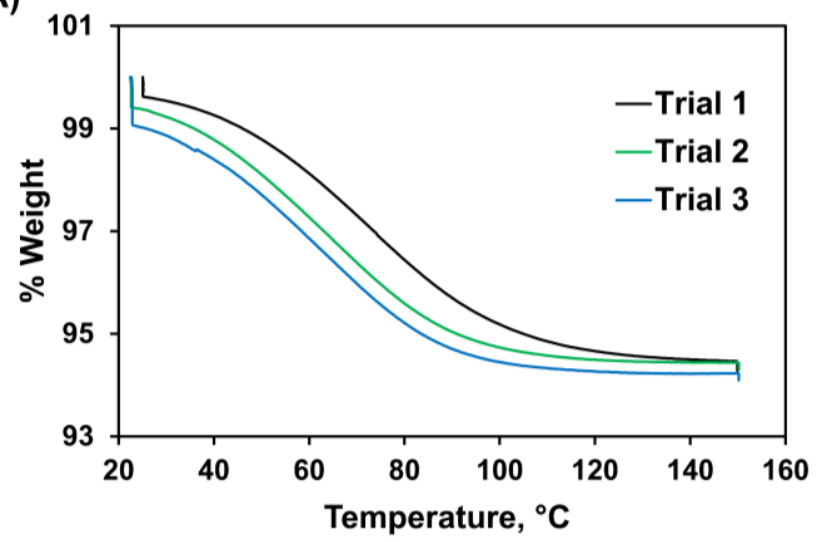

B)

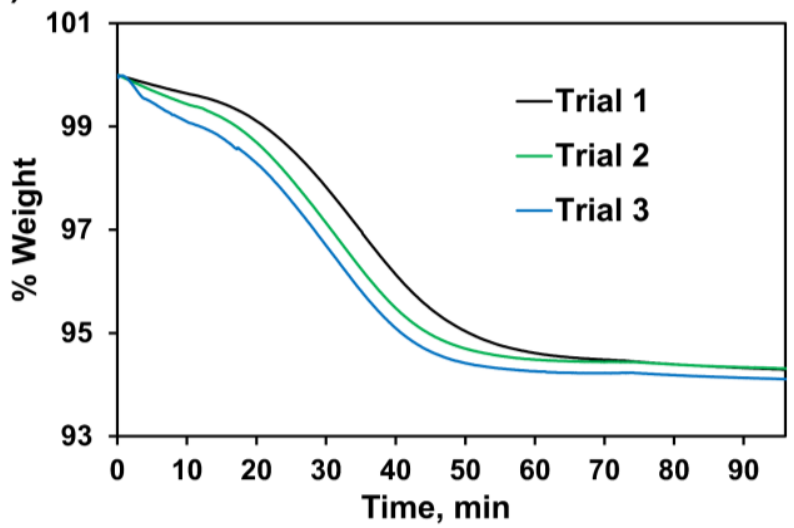

Figure S11. TGA of $m$-xylene A) \% weight loss plotted against temperature $\left.\left({ }^{\circ} \mathrm{C}\right), \mathrm{B}\right) \%$ weight loss plotted against time (min), Compound was kept into isotherm at $25^{\circ} \mathrm{C}$ for 10 minutes. Then temperature was ramped up to $150^{\circ} \mathrm{C}$ (rate $=2^{\circ} \mathrm{C} / \mathrm{min}$ ).
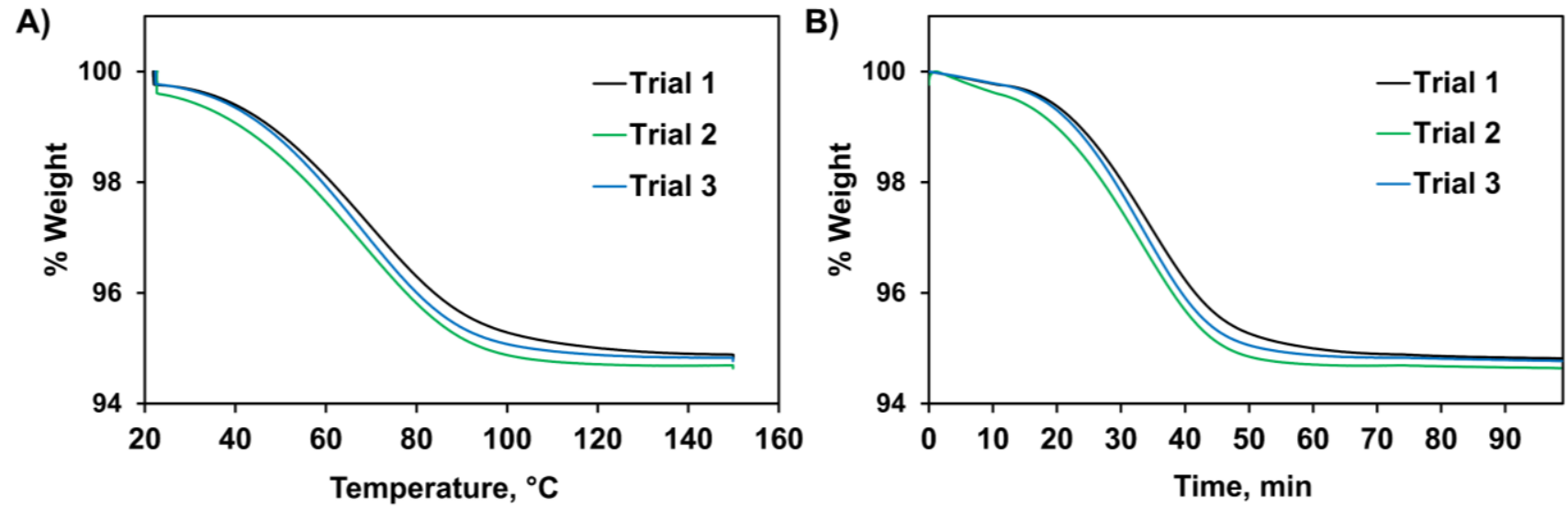

Figure S12. TGA of ethyl benzene A) \% weight loss plotted against temperature $\left.\left({ }^{\circ} \mathrm{C}\right), \mathrm{B}\right) \%$ weight loss plotted against time (min), Compound was kept into isotherm at $25^{\circ} \mathrm{C}$ for 10 minutes. Then temperature was ramped up to $150^{\circ} \mathrm{C}$ (rate $=2^{\circ} \mathrm{C} / \mathrm{min}$ ). 

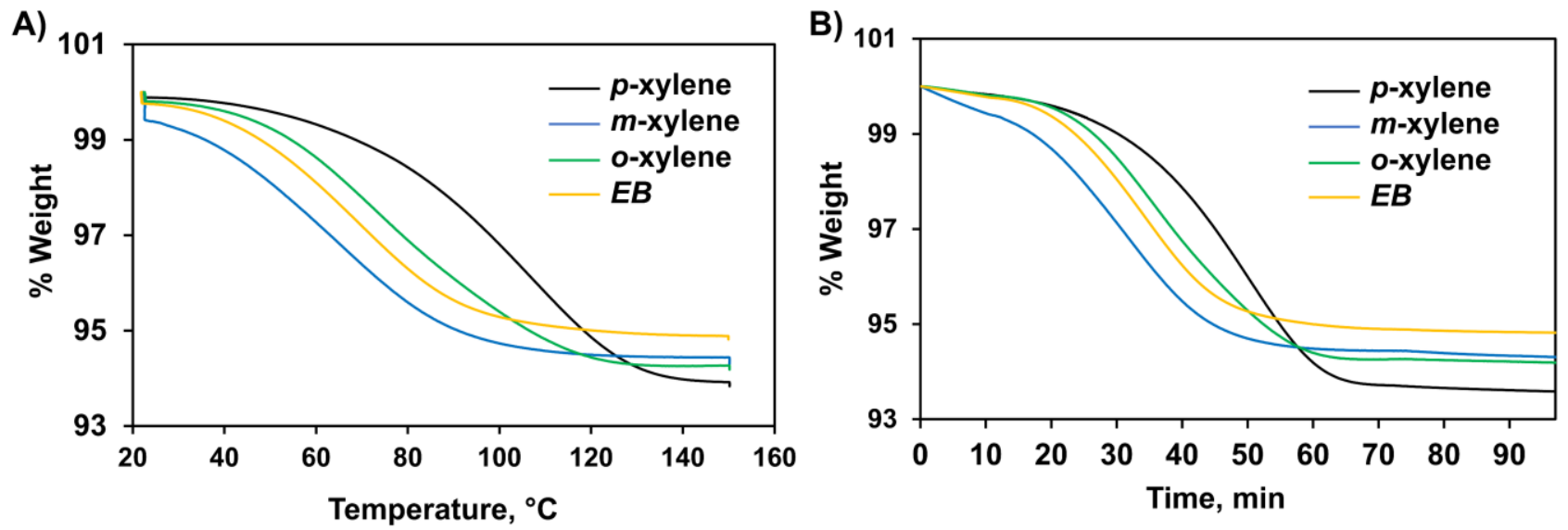

Figure S13. Combined TGA of $p$-xylene, $m$-xylene. $o$-xylene and ethyl benzene A) \% weight loss plotted against temperature $\left.\left({ }^{\circ} \mathrm{C}\right), \mathrm{B}\right) \%$ weight loss plotted against time (min),

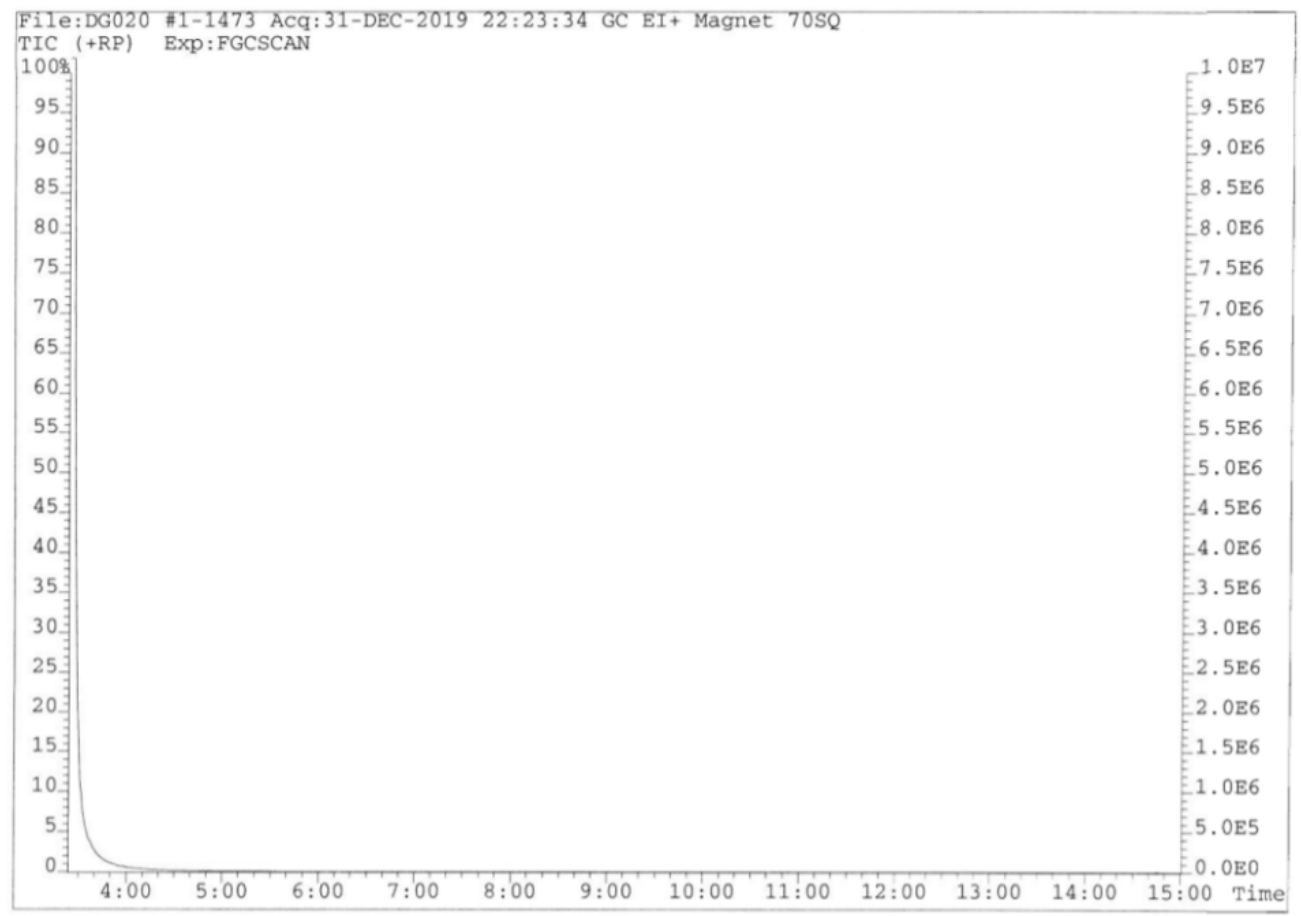

Figure S14. Gas chromatogram from GC/MS data taken on the $\mathrm{CH}_{2} \mathrm{Cl}_{2}$ used in sample preparation for all selective loading experiments. 


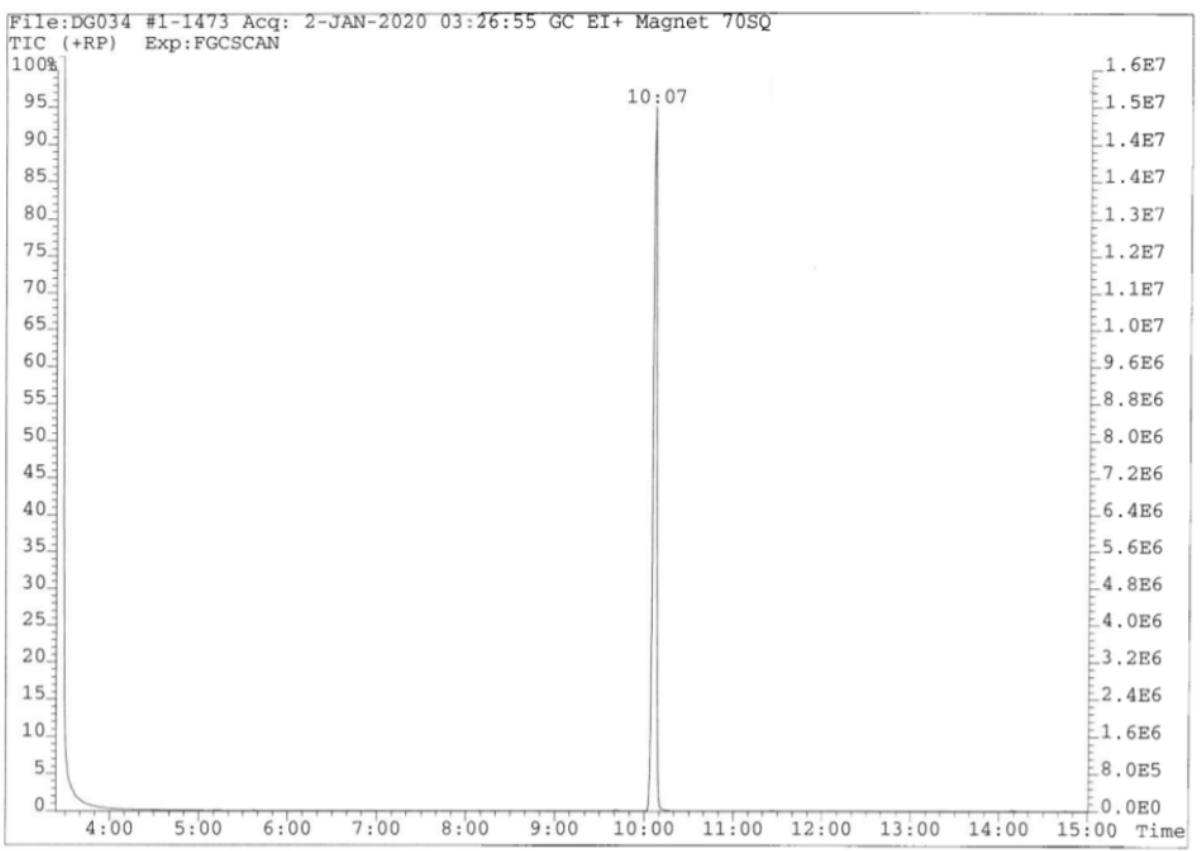

Figure S15. Gas chromatogram from GC/MS data taken on the $o$-xylene used in sample preparation for selective loading experiments.

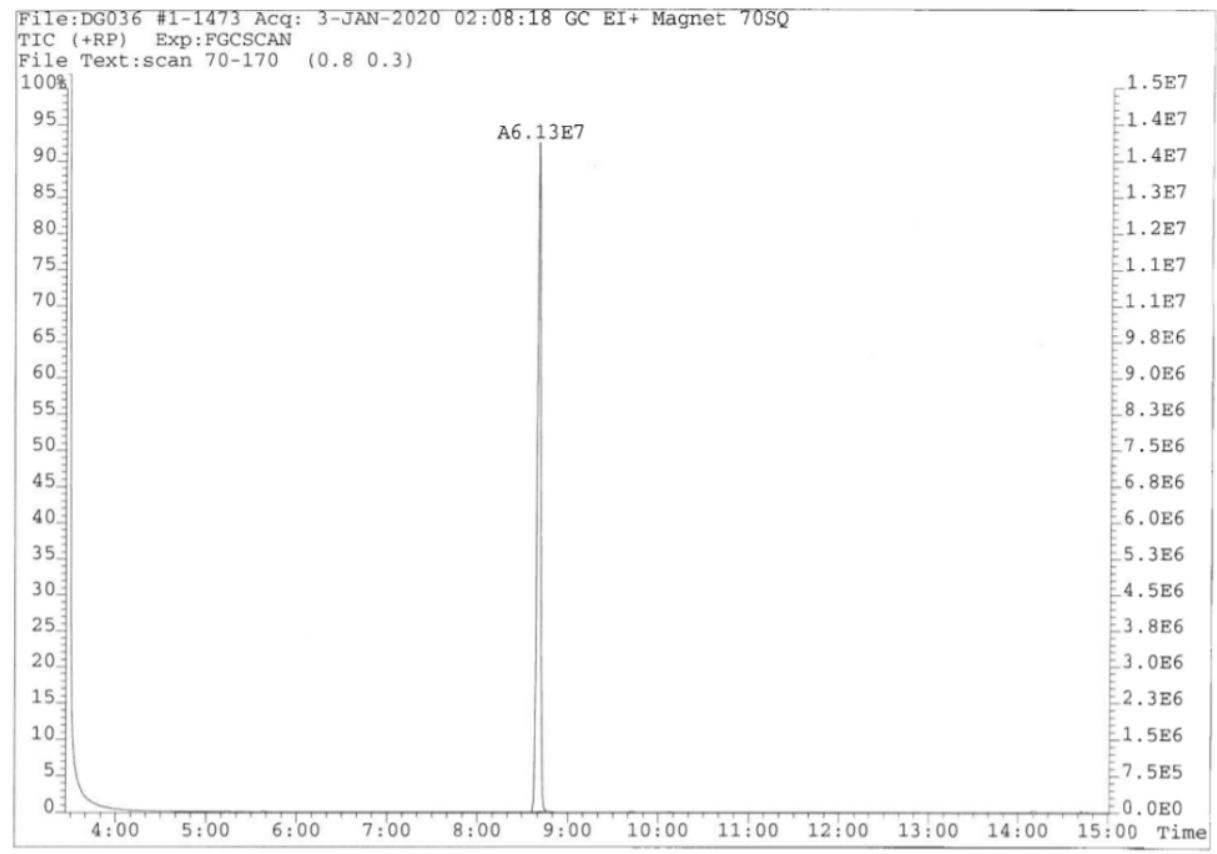

Figure S16. Gas chromatogram from GC/MS data taken on the $m$-xylene used in sample preparation for selective loading experiments. 


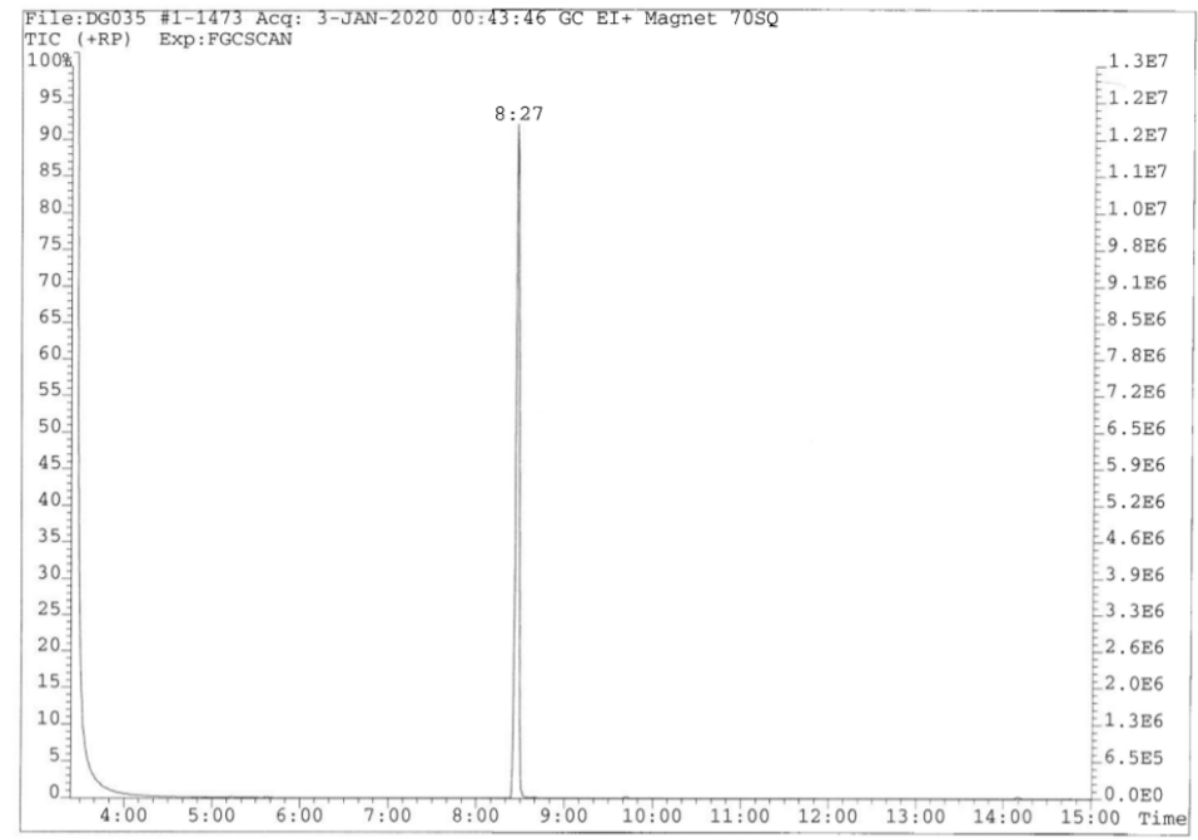

Figure S17. Gas chromatogram from GC/MS data taken on the p-xylene used in sample preparation for selective loading experiments.

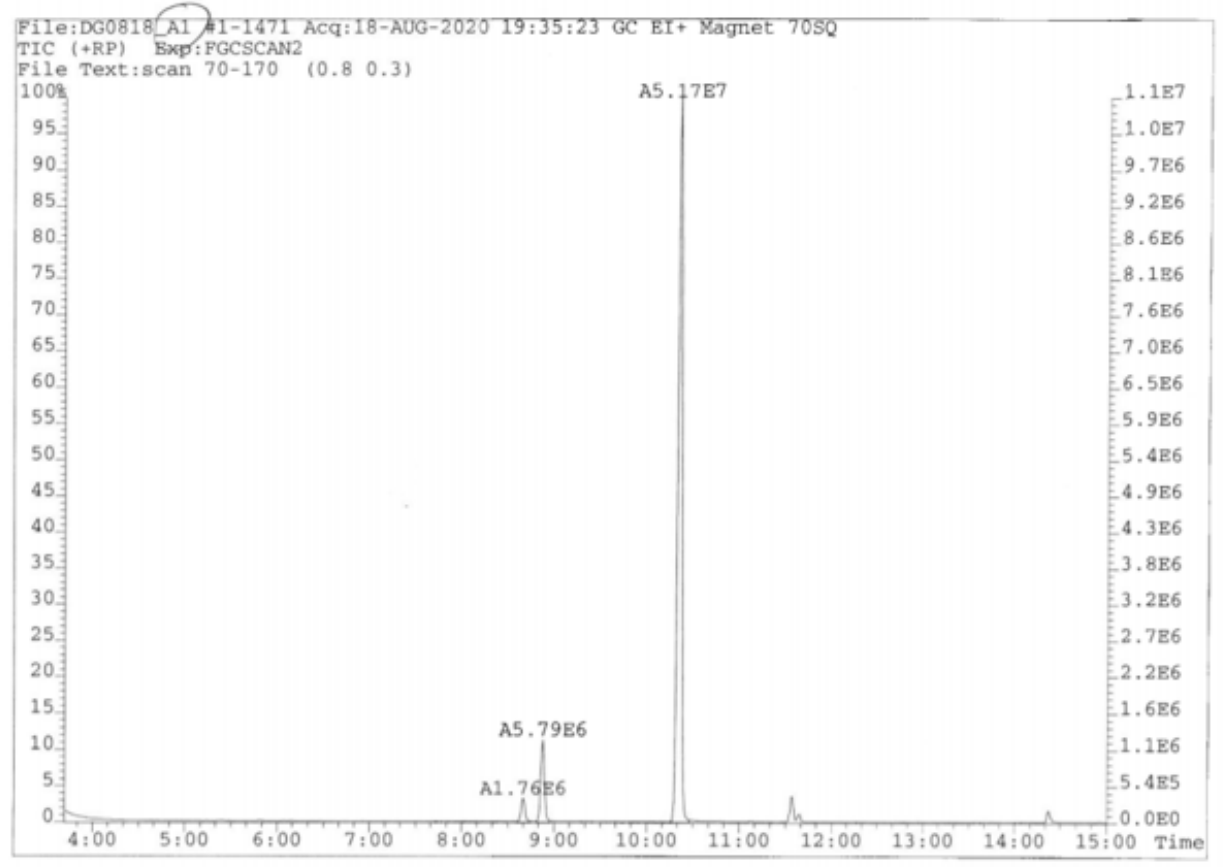

Figure S18. Gas chromatogram from GC/MS data taken on selective loading from a 99 to $1 \mathrm{o}$-xylene $/ \mathrm{m}$-xylene mixture (4 mL) using $5 \mathrm{mg}$ of crystalline $\mathbf{1}$ (trial 1). 


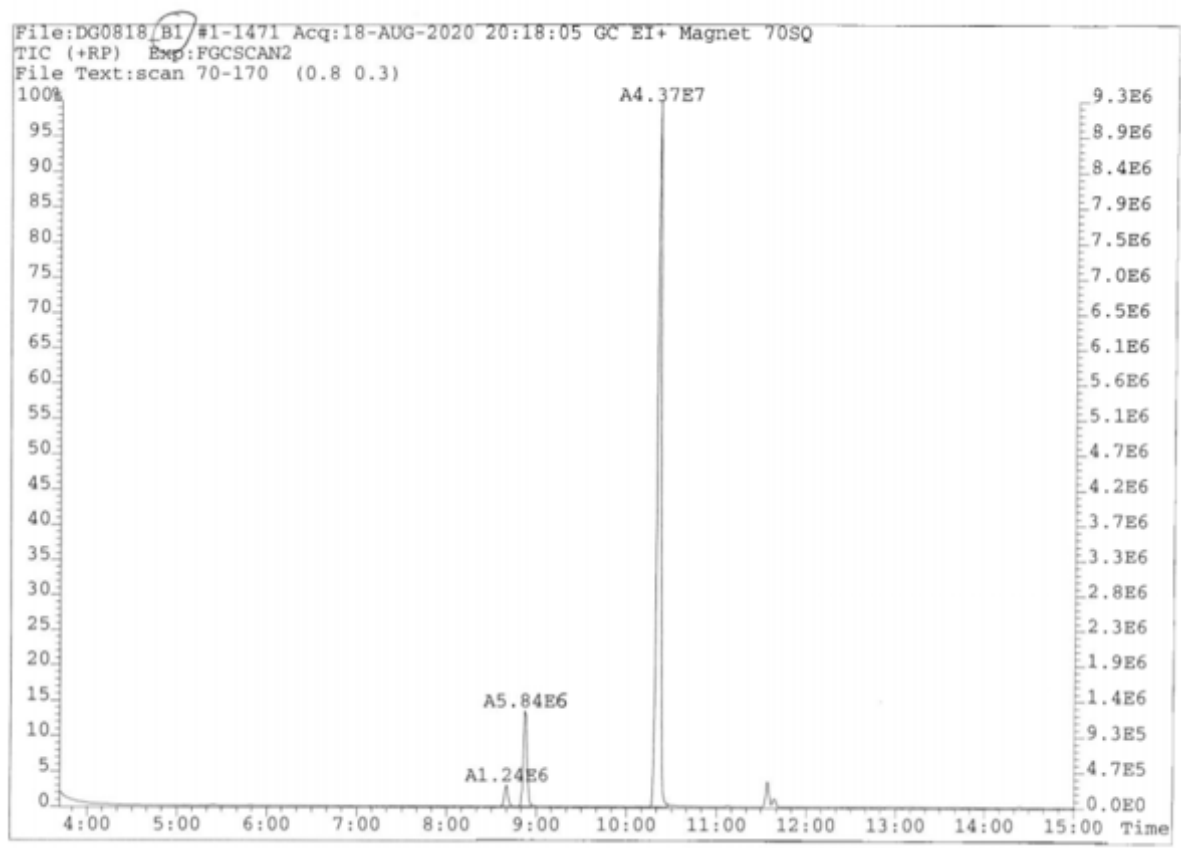

Figure S19. Gas chromatogram from GC/MS data taken on selective loading from a 99 to $1 o$-xylene $/ m$-xylene mixture ( $4 \mathrm{~mL}$ ) using $5 \mathrm{mg}$ of crystalline $\mathbf{1}$ (trial 2).

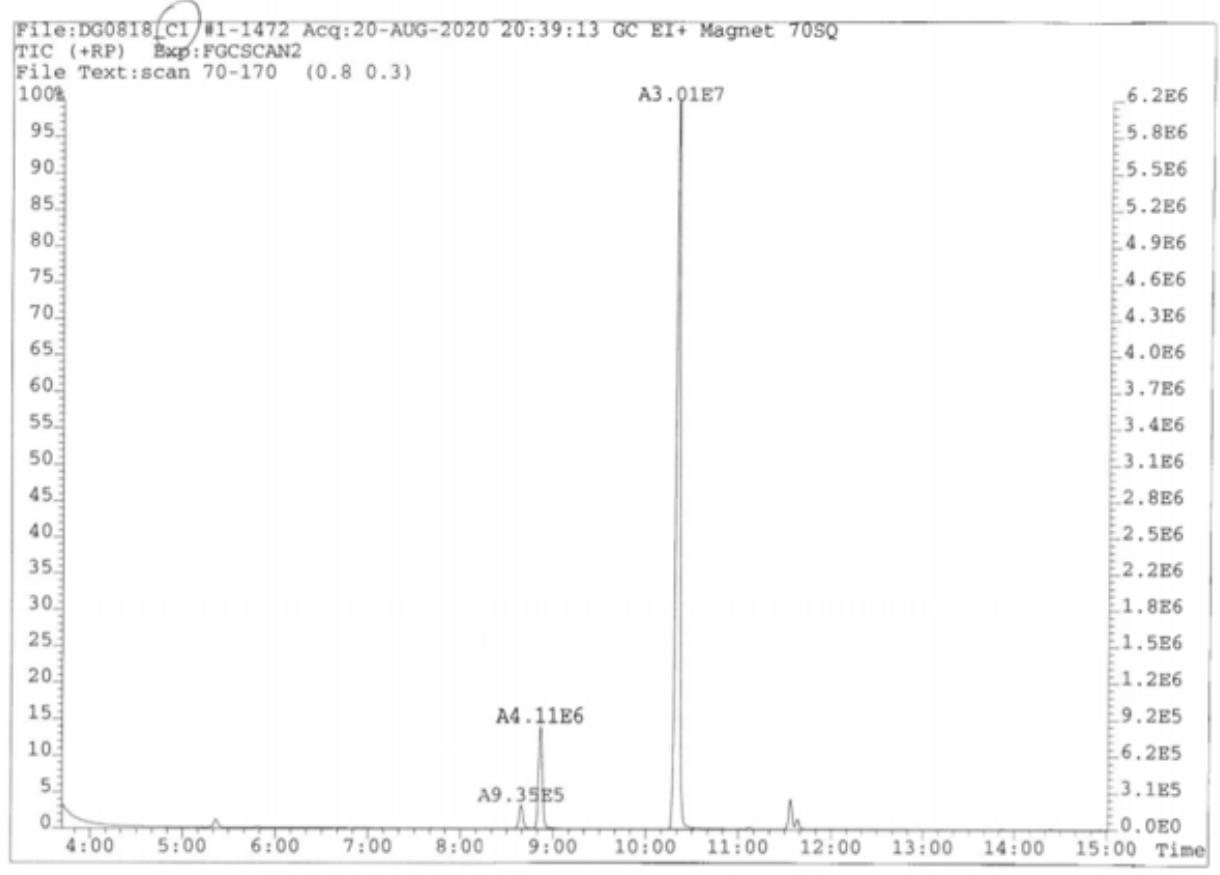

Figure S20. Gas chromatogram from GC/MS data taken on selective loading from a 99 to $1 o$-xylene $/ m$-xylene mixture (4 mL) using $5 \mathrm{mg}$ of crystalline $\mathbf{1}$ (trial 3 ). 


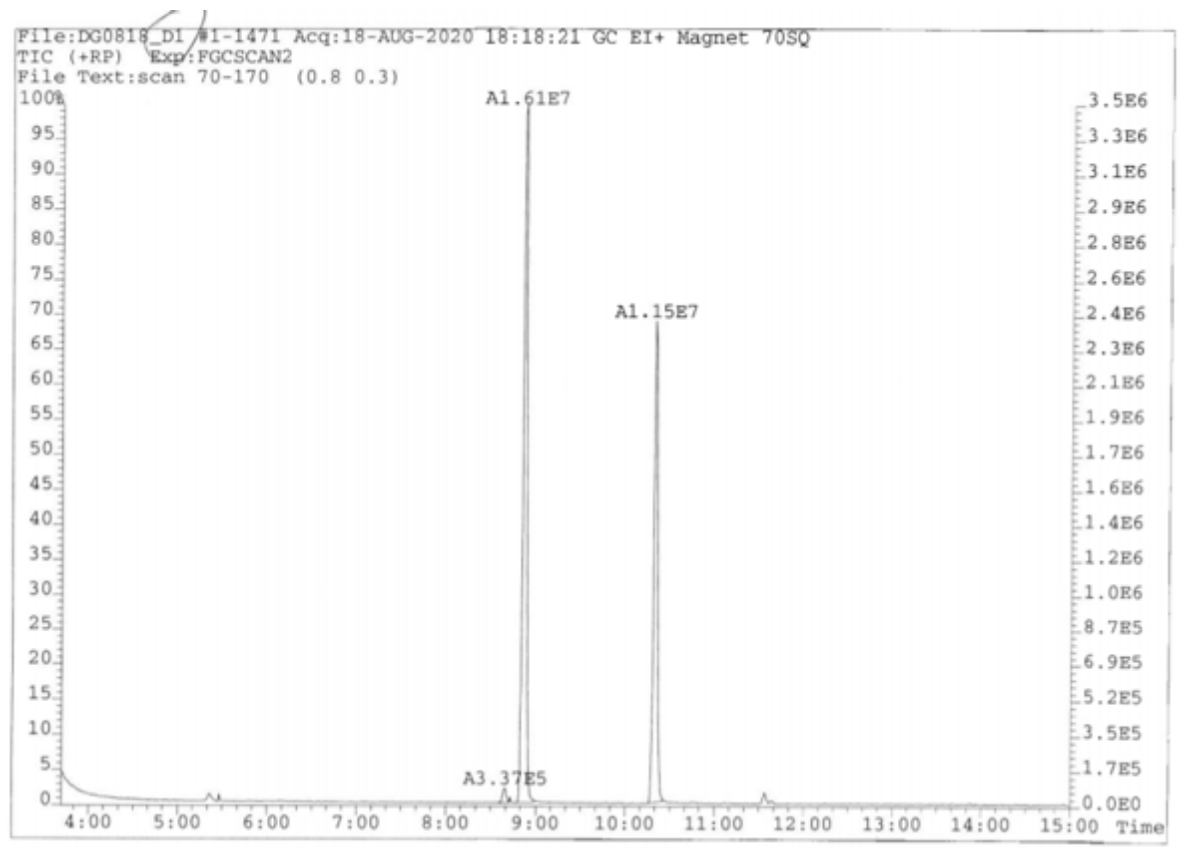

Figure S21. Gas chromatogram from GC/MS data taken on selective loading from a 4 to $1 \mathrm{o}$-xylene $/ \mathrm{m}$-xylene mixture (4 mL) using $5 \mathrm{mg}$ of crystalline $\mathbf{1}$ (trial 1 ).

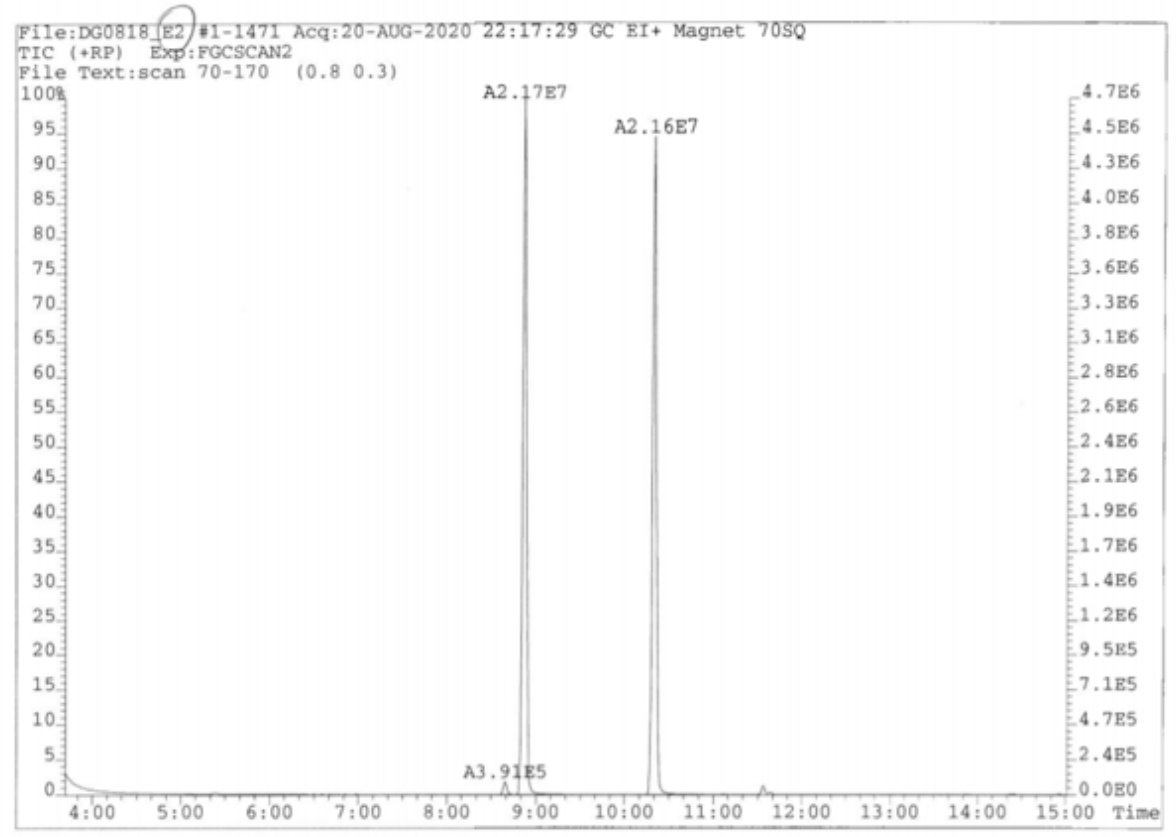

Figure S22. Gas chromatogram from GC/MS data taken on selective loading from a 4 to $1 \mathrm{o}$-xylene $/ \mathrm{m}$-xylene mixture (4 mL) using $5 \mathrm{mg}$ of crystalline $\mathbf{1}$ (trial 2). 


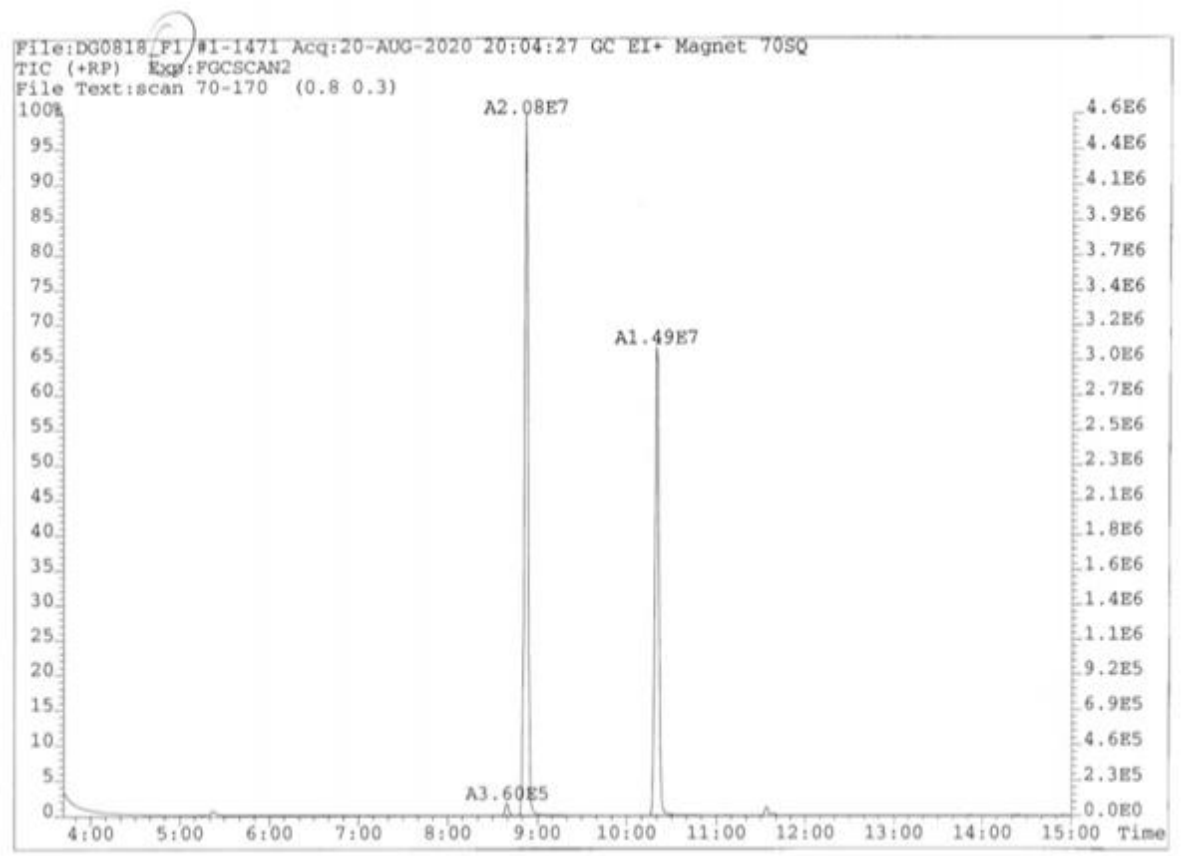

Figure S23. Gas chromatogram from GC/MS data taken on selective loading from a 4 to $1 o$-xylene/ $m$-xylene mixture (4 mL) using $5 \mathrm{mg}$ of crystalline $\mathbf{1}$ (trial 3).

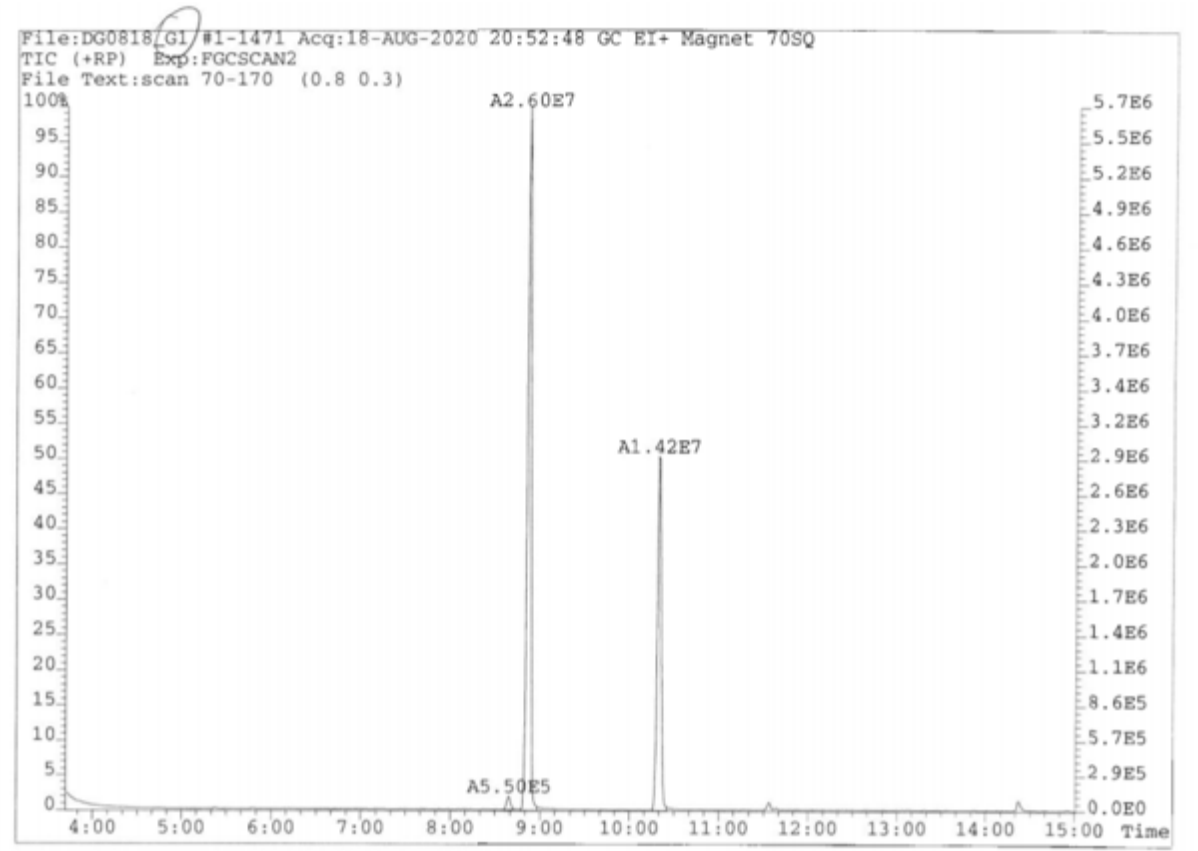

Figure S24. Gas chromatogram from GC/MS data taken on selective loading from a 3 to $1 o$-xylene $/ m$-xylene mixture (4 mL) using $5 \mathrm{mg}$ of crystalline $\mathbf{1}$ (trial 1). 


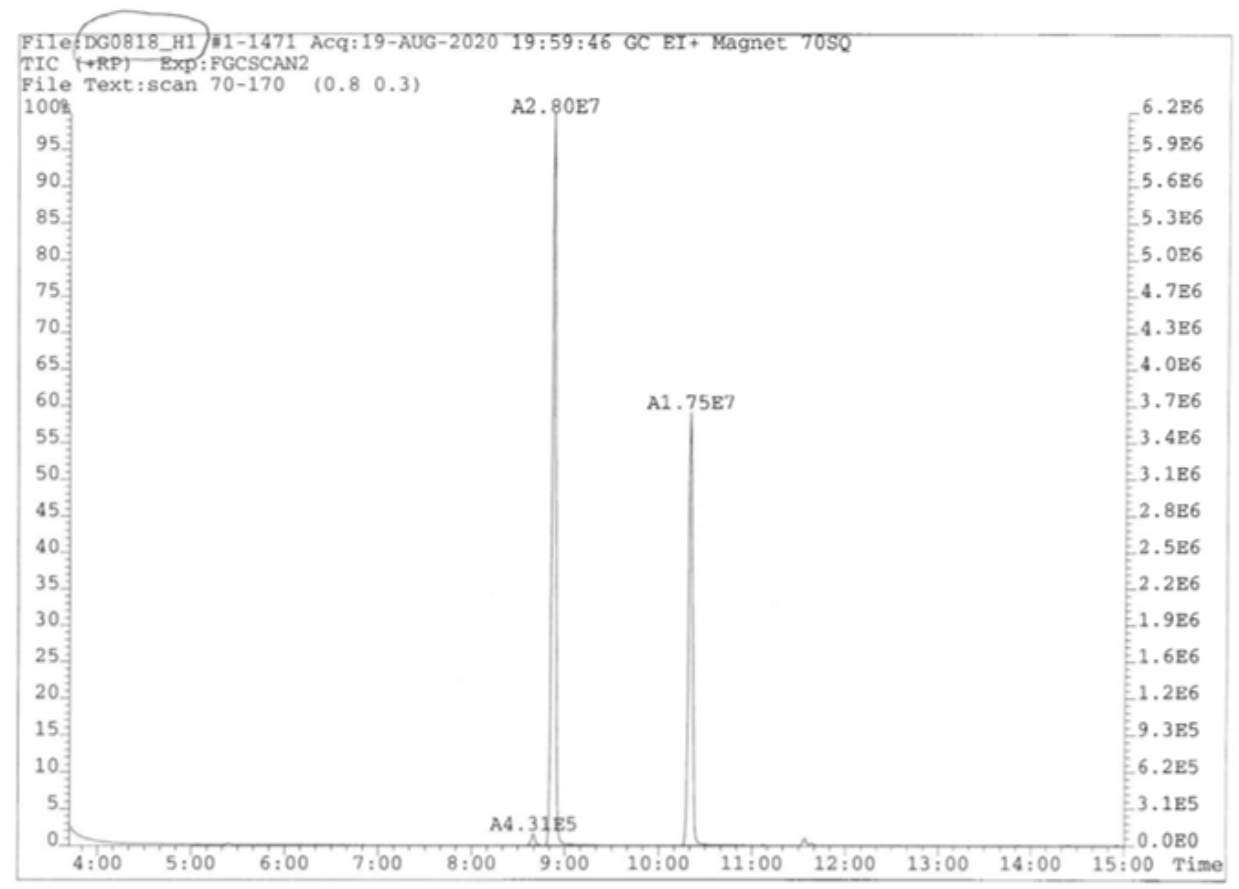

Figure S25. Gas chromatogram from GC/MS data taken on selective loading from a 3 to $1 o$-xylene/m-xylene mixture (4 mL) using $5 \mathrm{mg}$ of crystalline 1 (trial 2).

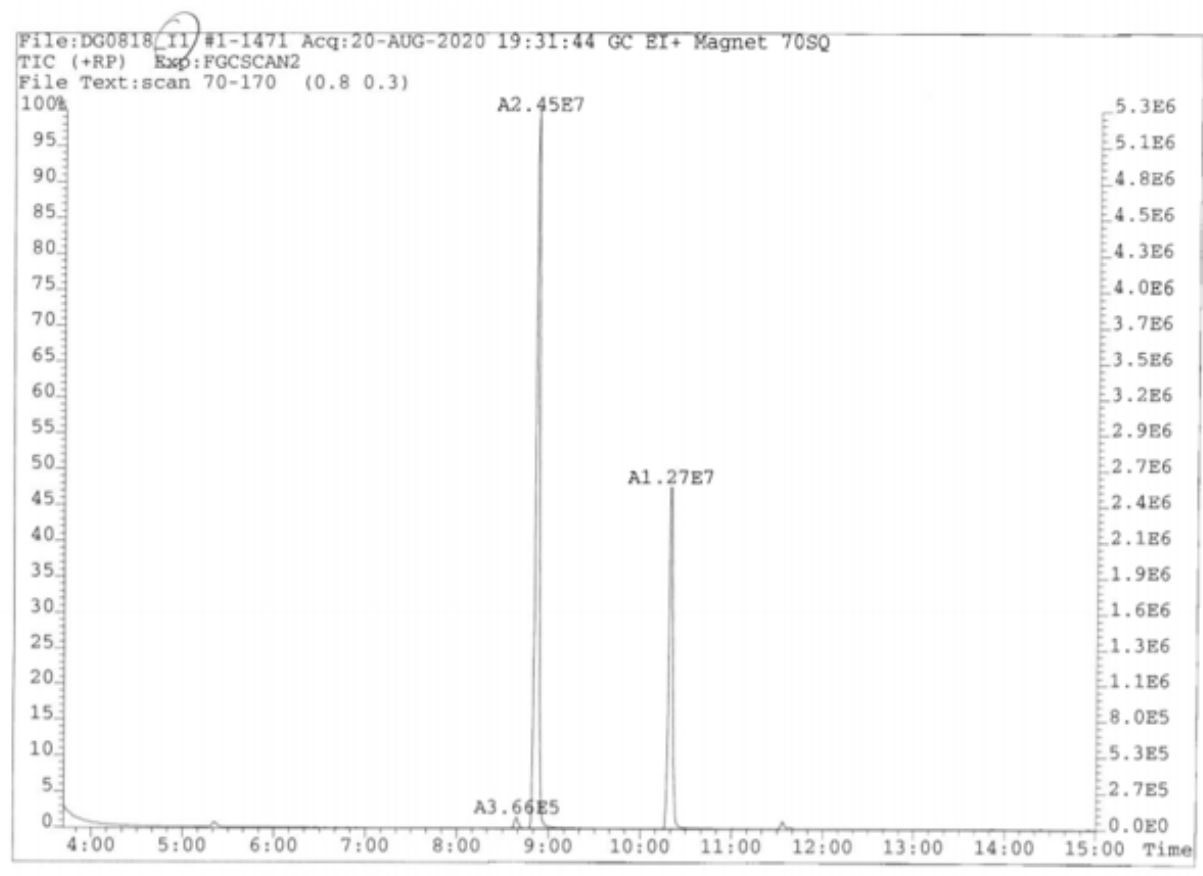

Figure S26. Gas chromatogram from GC/MS data taken on selective loading from a 3 to $1 o$-xylene/m-xylene mixture (4 mL) using $5 \mathrm{mg}$ of crystalline $\mathbf{1}$ (trial 3). 


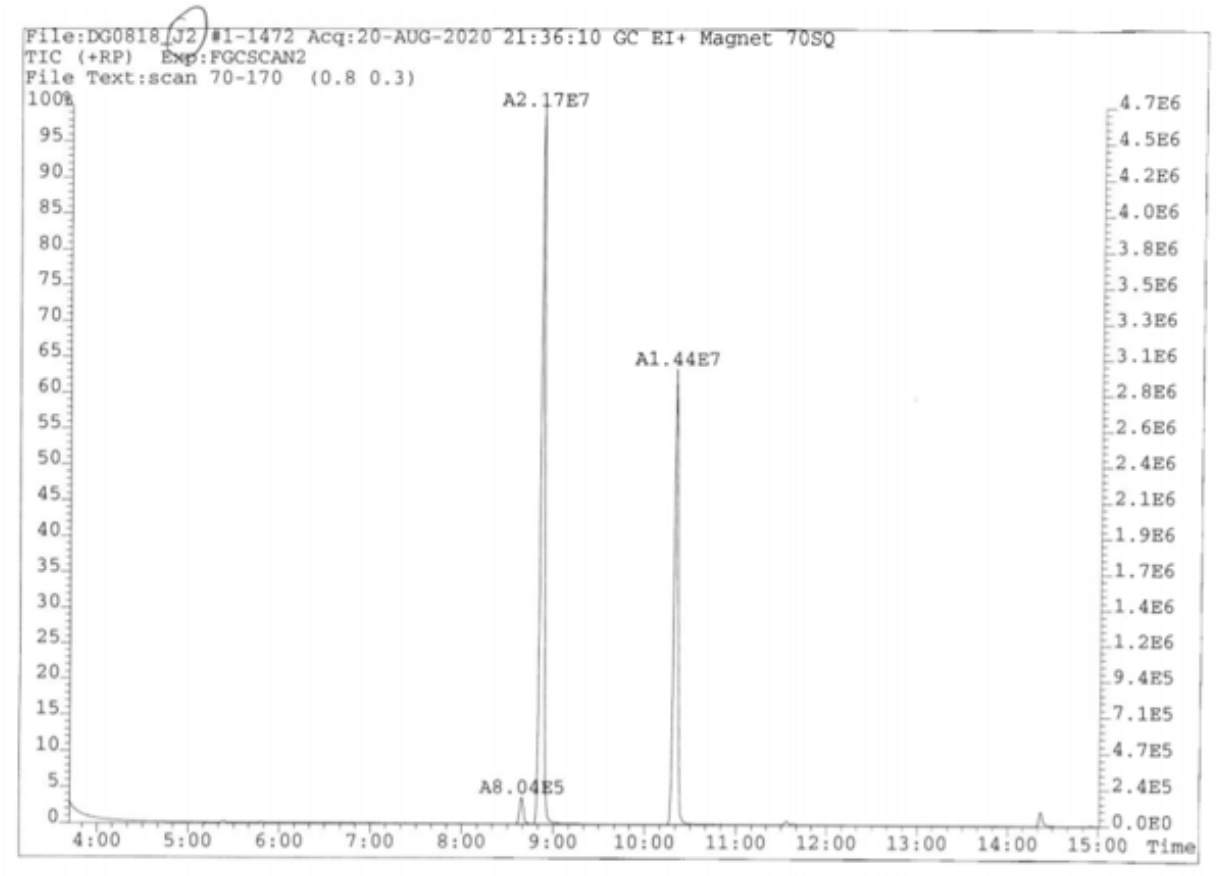

Figure S27. Gas chromatogram from GC/MS data taken on selective loading from a 2 to $1 o$-xylene $/ m$-xylene mixture (4 mL) using $5 \mathrm{mg}$ of crystalline $\mathbf{1}$ (trial 1).

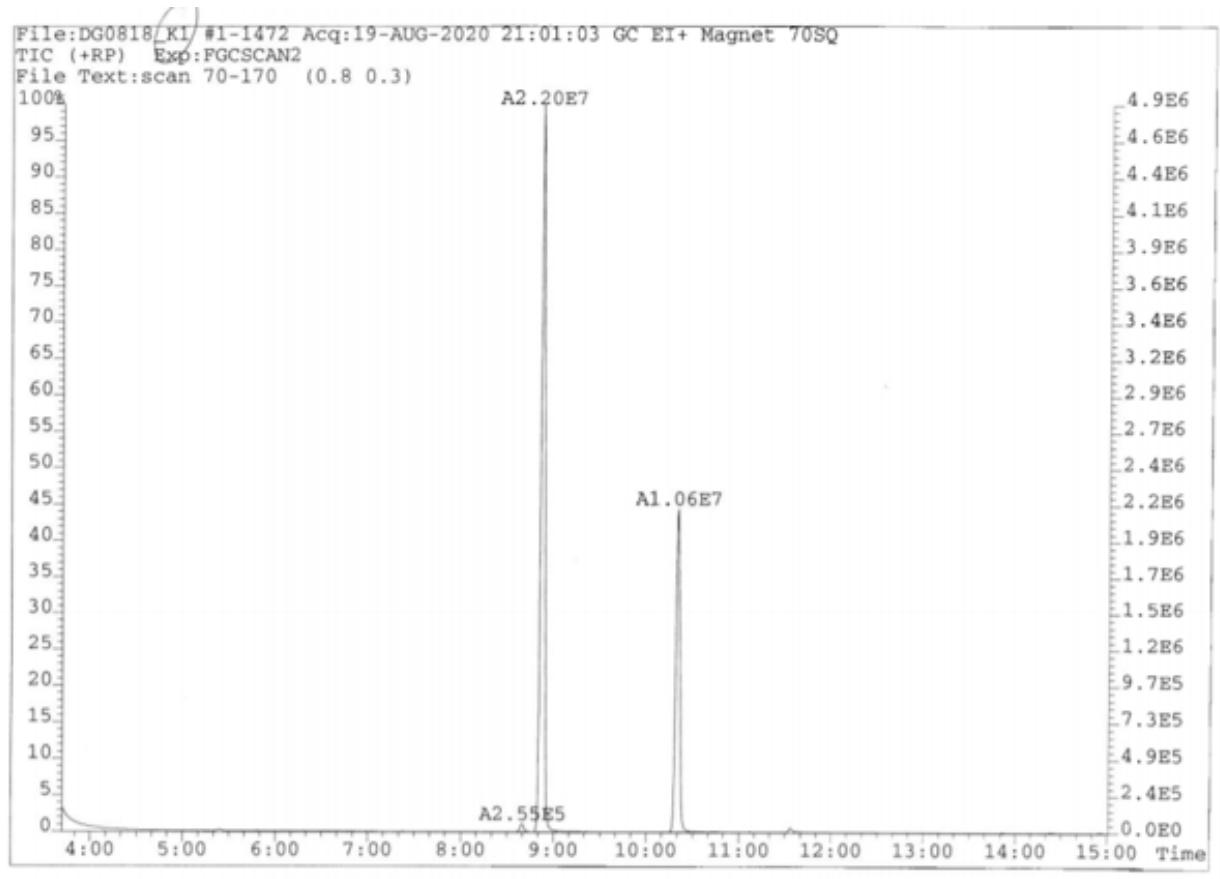

Figure S28. Gas chromatogram from GC/MS data taken on selective loading from a 2 to $1 o$-xylene $/ m$-xylene mixture (4 mL) using $5 \mathrm{mg}$ of crystalline $\mathbf{1}$ (trial 2). 


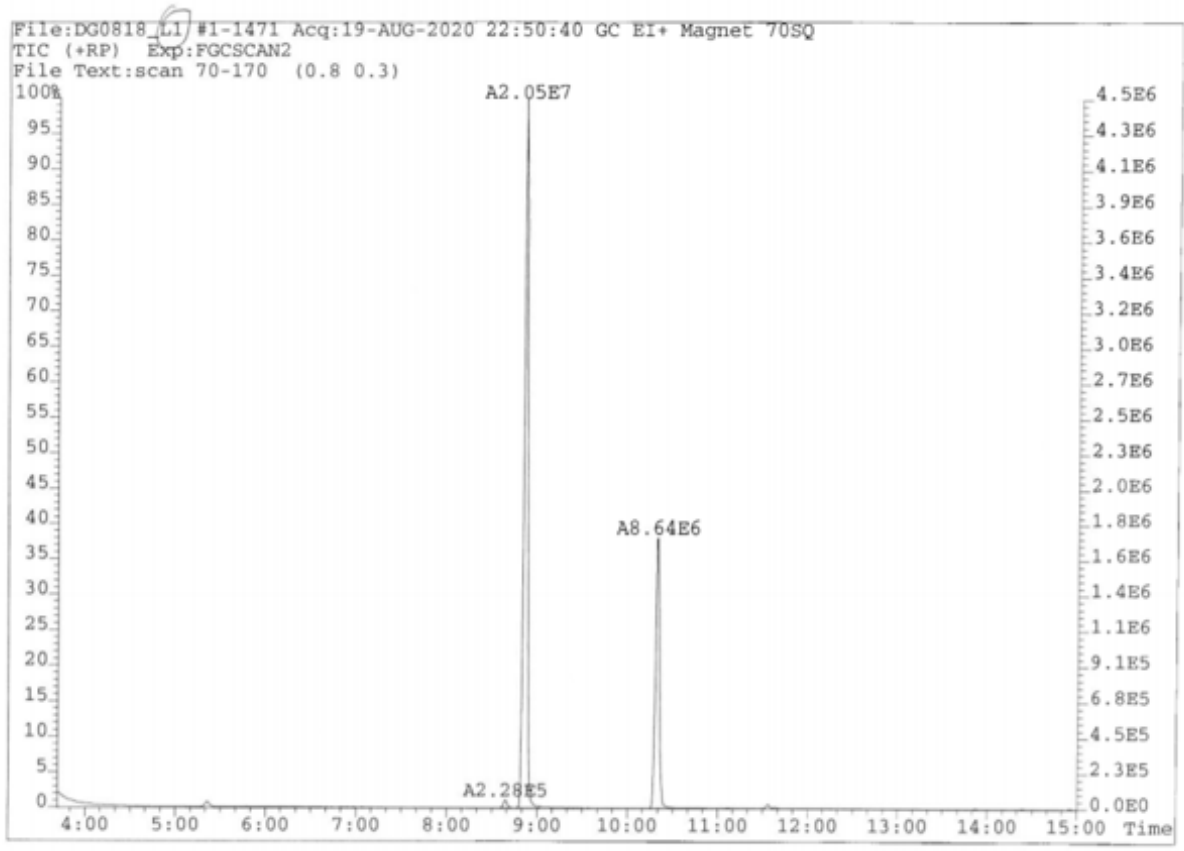

Figure S29. Gas chromatogram from GC/MS data taken on selective loading from a 2 to $1 \mathrm{o}$-xylene/ $\mathrm{m}$-xylene mixture (4 mL) using $5 \mathrm{mg}$ of crystalline $\mathbf{1}$ (trial 3 ).

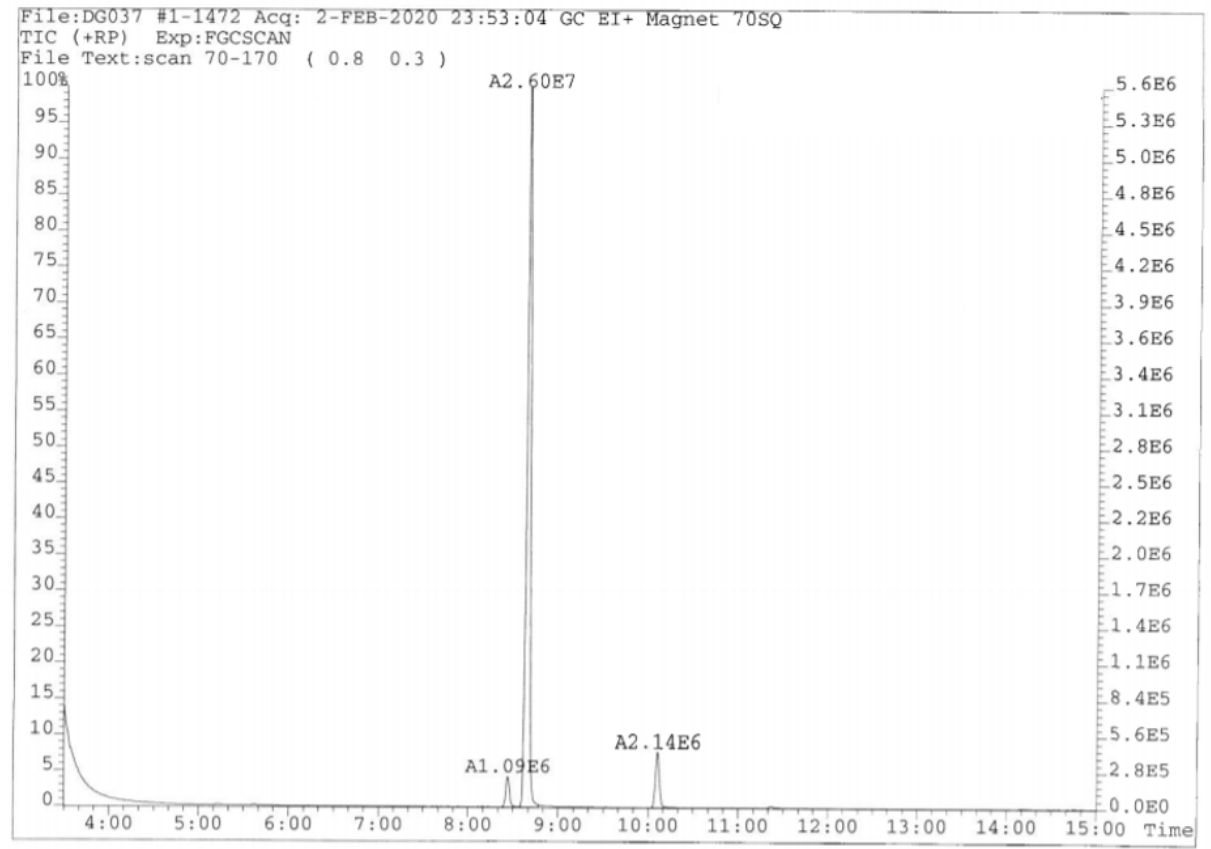

Figure S30. Gas chromatogram from GC/MS data taken on selective loading from a 1 to $1 o$-xylene $/ m$-xylene mixture (4 mL) using $5 \mathrm{mg}$ of crystalline $\mathbf{1}$ (trial 1). 


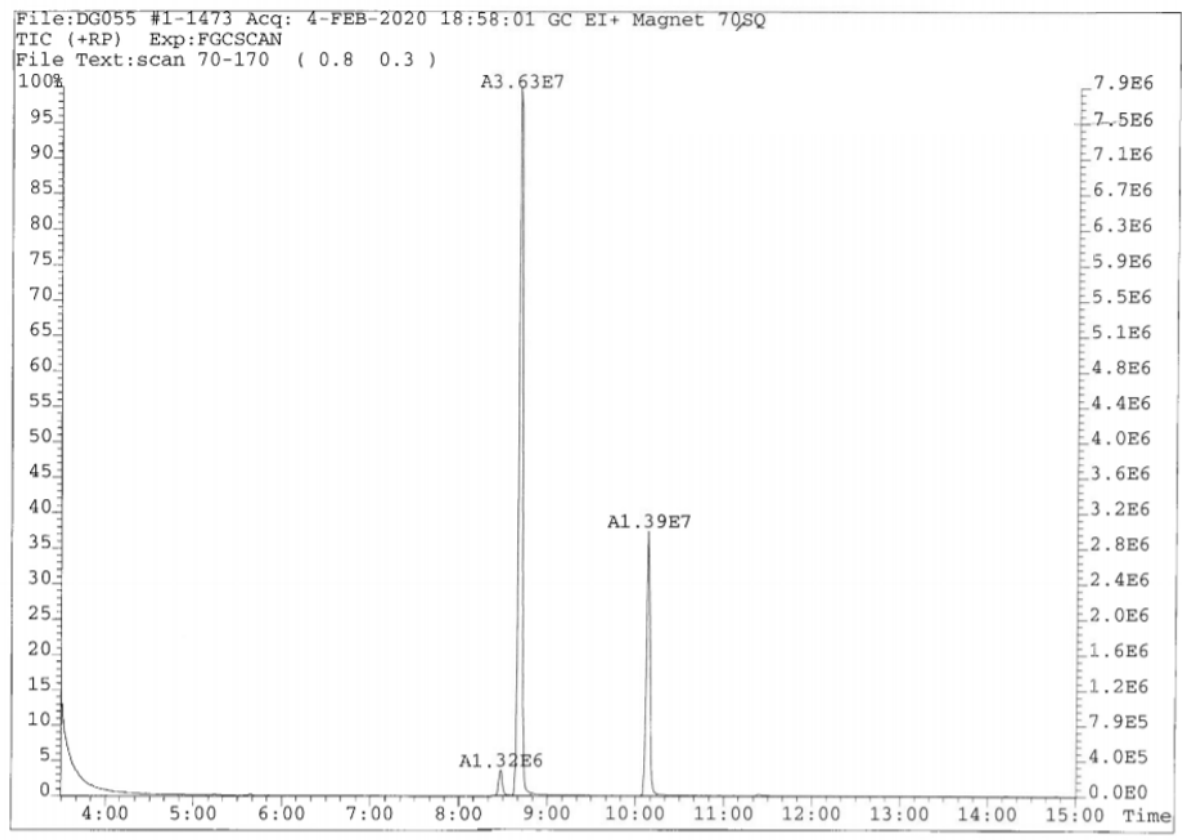

Figure S31. Gas chromatogram from GC/MS data taken on selective loading from a 1 to $1 \mathrm{o}$-xylene $/ \mathrm{m}$-xylene mixture (4 mL) using $5 \mathrm{mg}$ of crystalline $\mathbf{1}$ (trial 2).

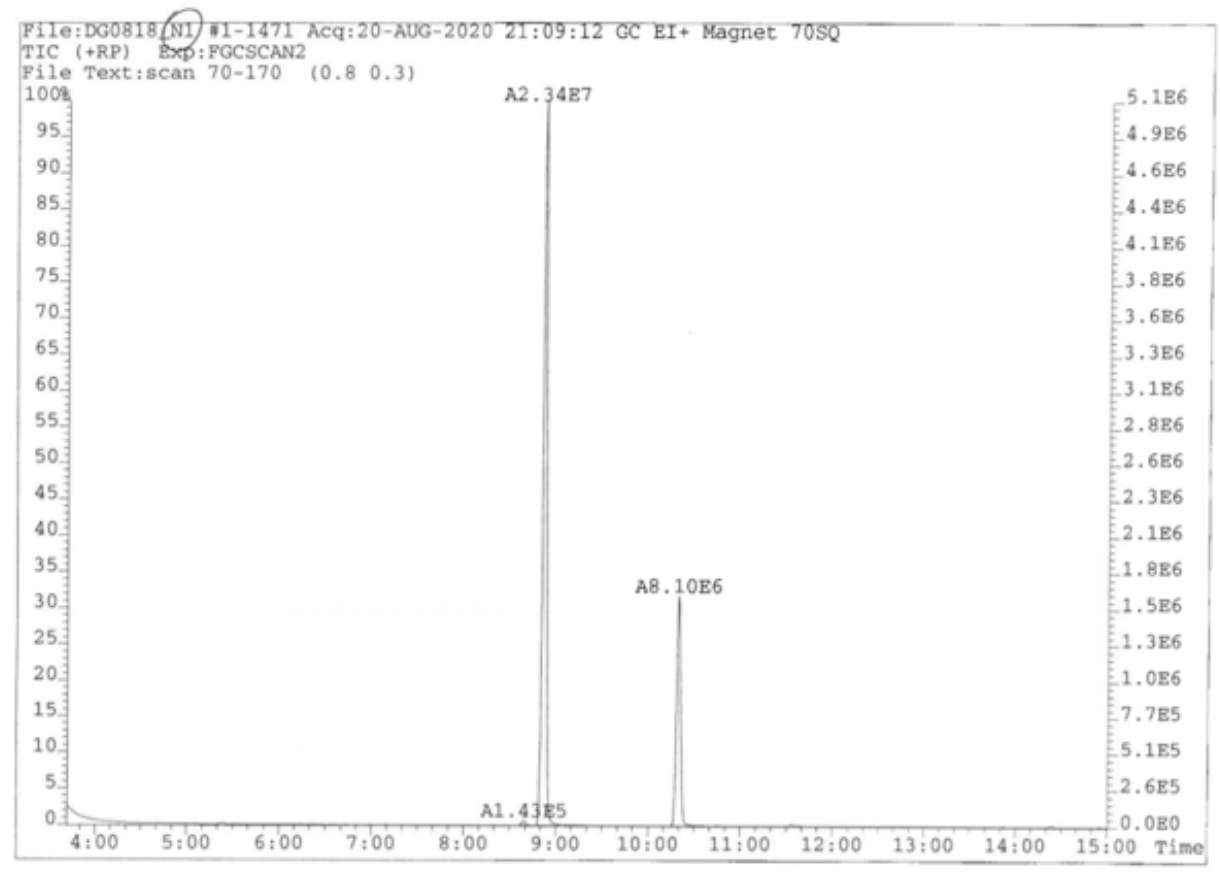

Figure S32. Gas chromatogram from GC/MS data taken on selective loading from a 1 to $1 \mathrm{o}$-xylene/m-xylene mixture (4 mL) using $5 \mathrm{mg}$ of crystalline $\mathbf{1}$ (trial 3 ). 


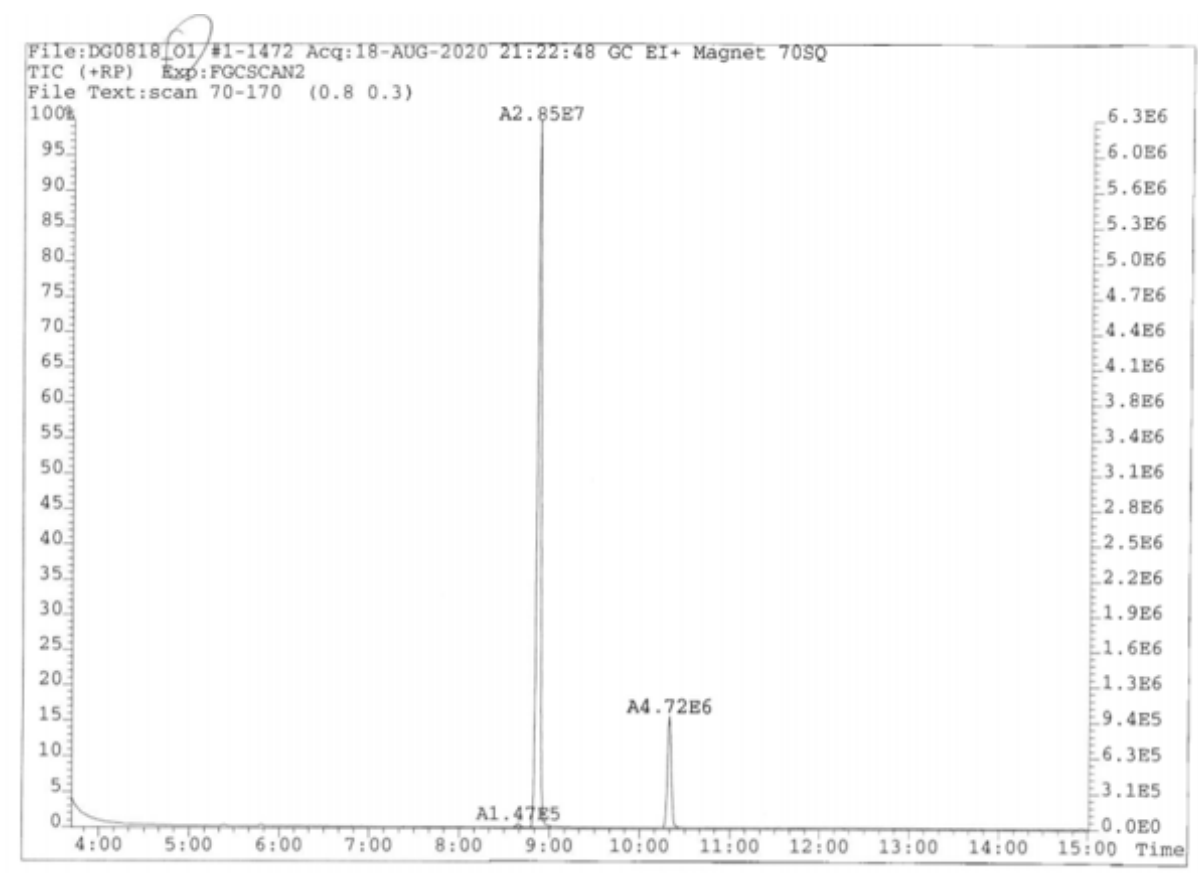

Figure S33. Gas chromatogram from GC/MS data taken on selective loading from a 1 to $3 o$-xylene $/ m$-xylene mixture (4 mL) using $5 \mathrm{mg}$ of crystalline $\mathbf{1}$ (trial 1 ).

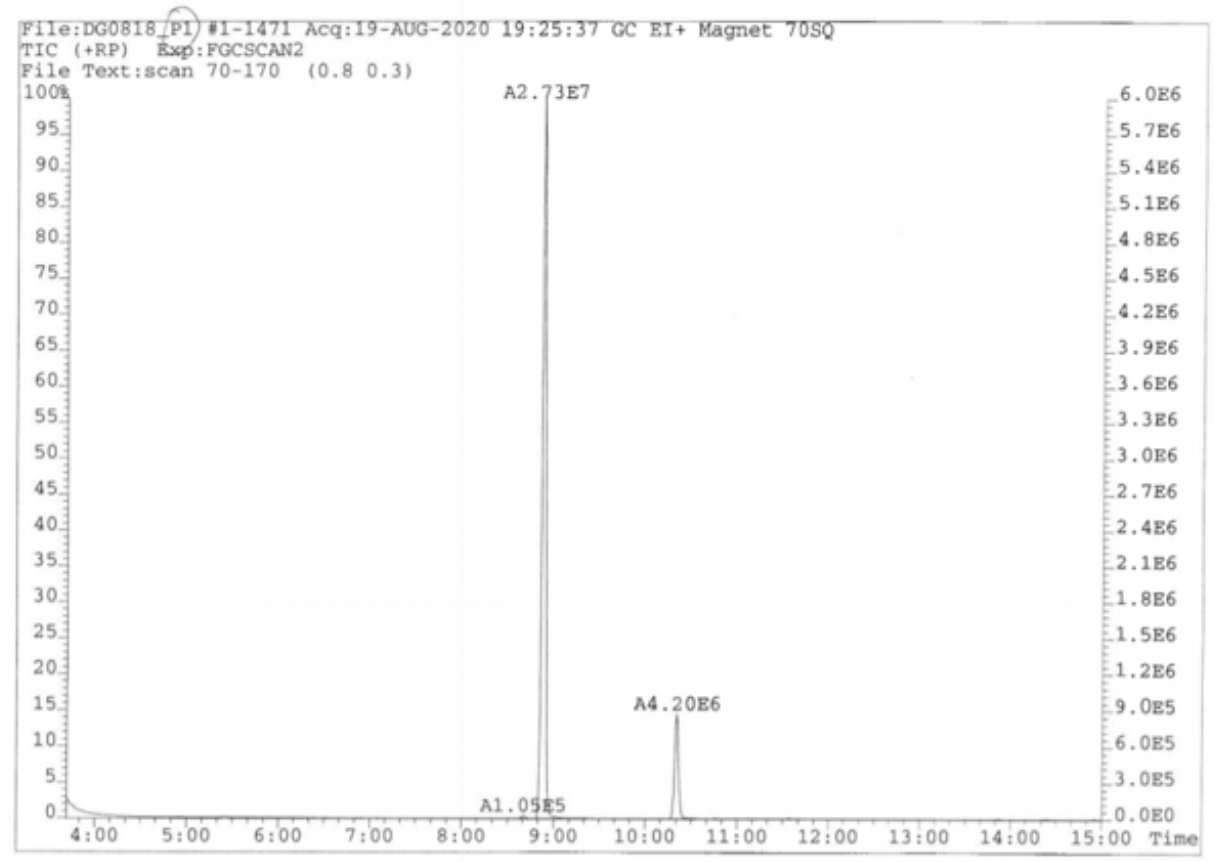

Figure S34. Gas chromatogram from GC/MS data taken on selective loading from a 1 to $3 o$-xylene $/ m$-xylene mixture (4 mL) using $5 \mathrm{mg}$ of crystalline $\mathbf{1}$ (trial 2). 


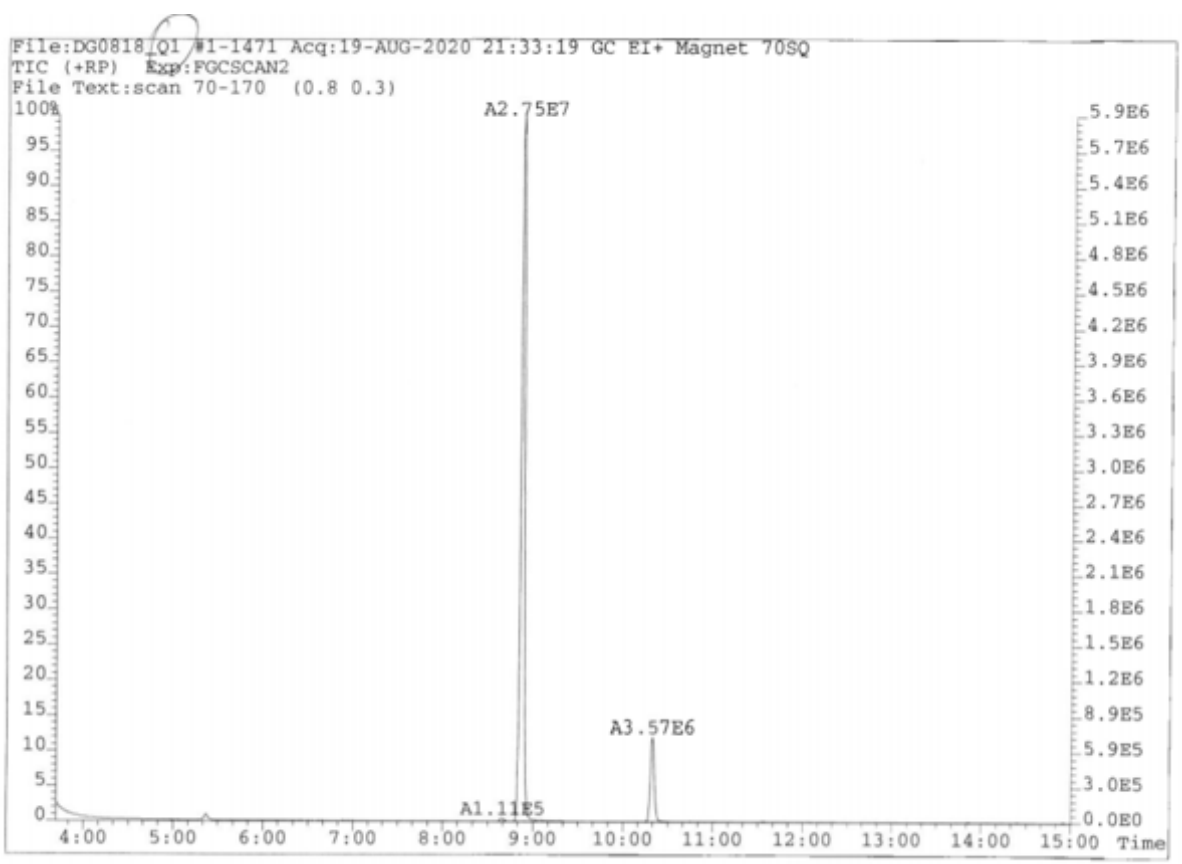

Figure S35. Gas chromatogram from GC/MS data taken on selective loading from a 1 to $3 o$-xylene $/ m$-xylene mixture (4 mL) using $5 \mathrm{mg}$ of crystalline $\mathbf{1}$ (trial 3 ).

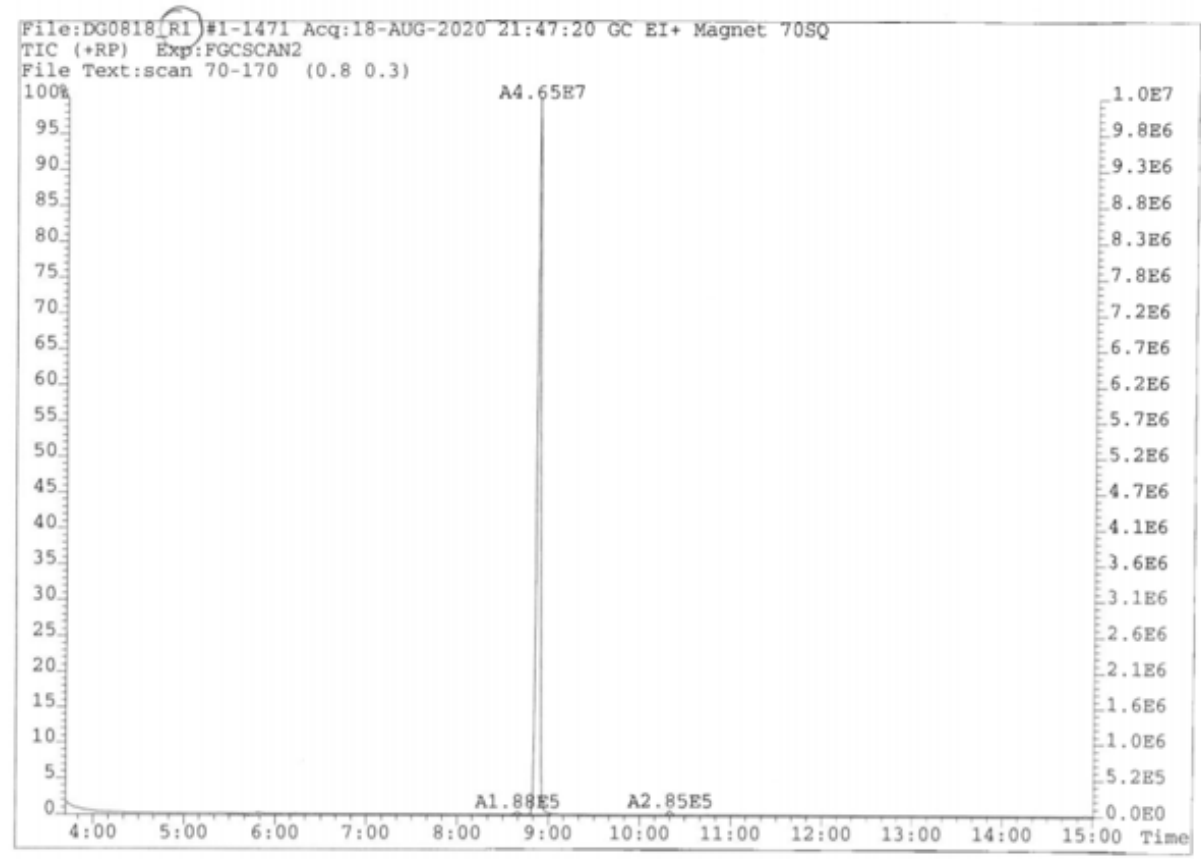

Figure S36. Gas chromatogram from GC/MS data taken on selective loading from a 1 to $99 o$-xylene $/ m$-xylene mixture (4 mL) using $5 \mathrm{mg}$ of crystalline $\mathbf{1}$ (trial 1). 


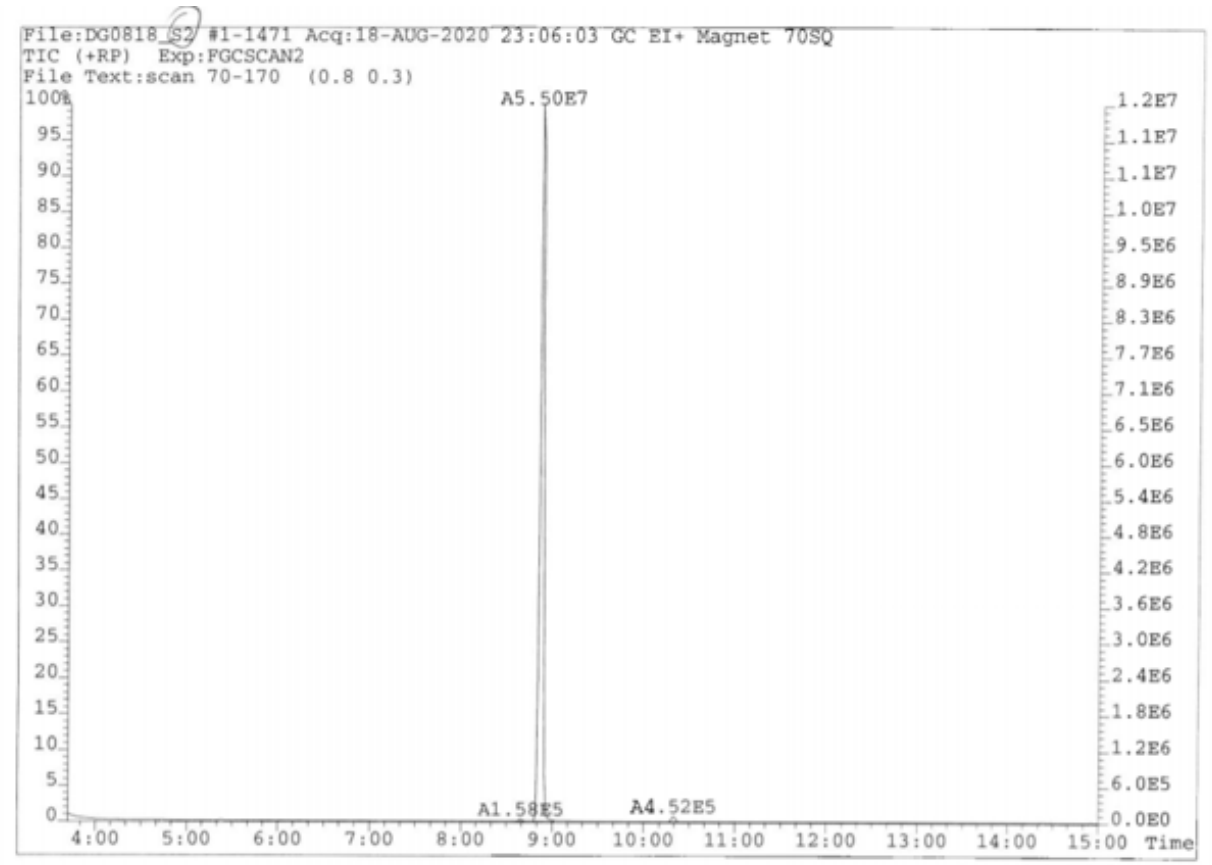

Figure S37. Gas chromatogram from GC/MS data taken on selective loading from a 1 to $99 o$-xylene $/ m$-xylene mixture (4 mL) using $5 \mathrm{mg}$ of crystalline $\mathbf{1}$ (trial 2).

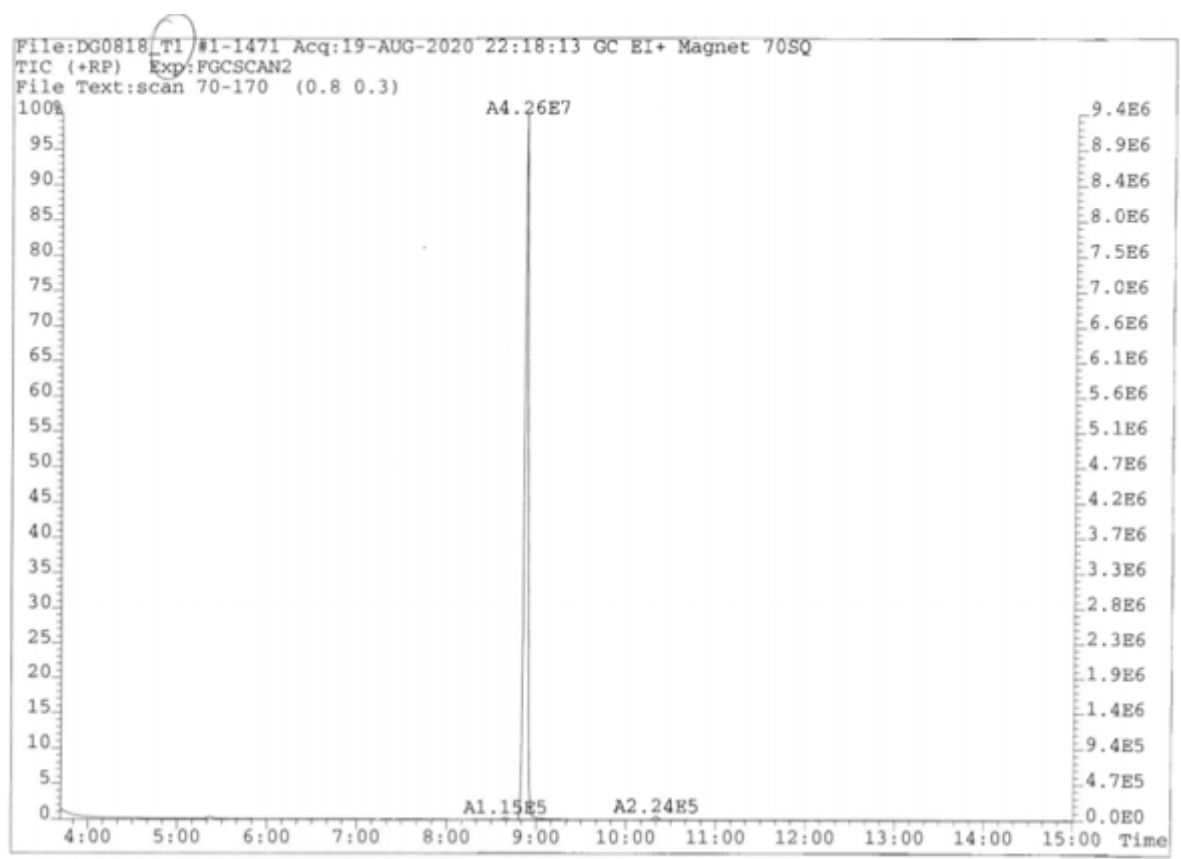

Figure S38. Gas chromatogram from GC/MS data taken on selective loading from a 1 to $99 o$-xylene $/ m$-xylene mixture ( $4 \mathrm{~mL}$ ) using $5 \mathrm{mg}$ of crystalline $\mathbf{1}$ (trial 3). 


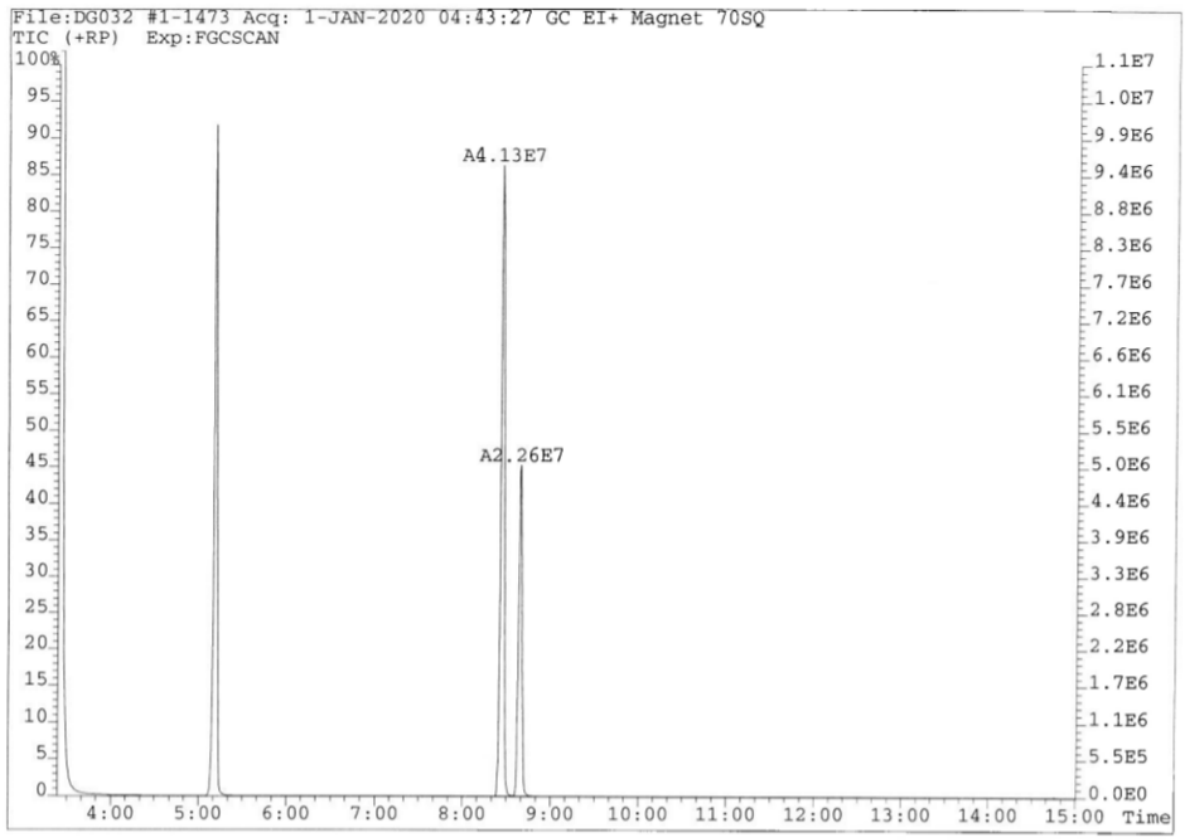

Figure S39. Gas chromatogram from GC/MS data taken on selective loading from a 99 to $1 \mathrm{~m}$-xylene/ $p$-xylene mixture (4 mL) using $5 \mathrm{mg}$ of crystalline $\mathbf{1}$ (trial 1).

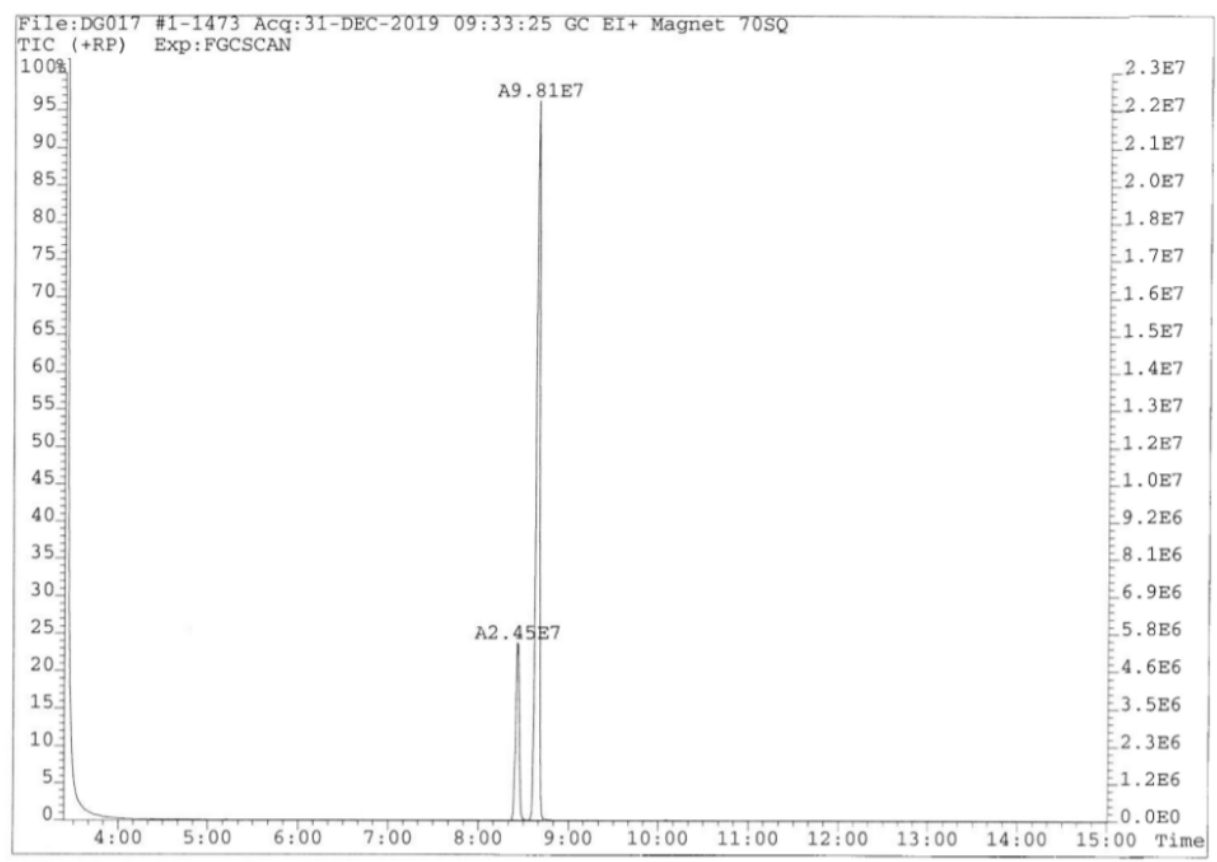

Figure S40. Gas chromatogram from GC/MS data taken on selective loading from a 99 to $1 \mathrm{~m}$-xylene/ $p$-xylene mixture (4 mL) using $5 \mathrm{mg}$ of crystalline $\mathbf{1}$ (trial 2). 


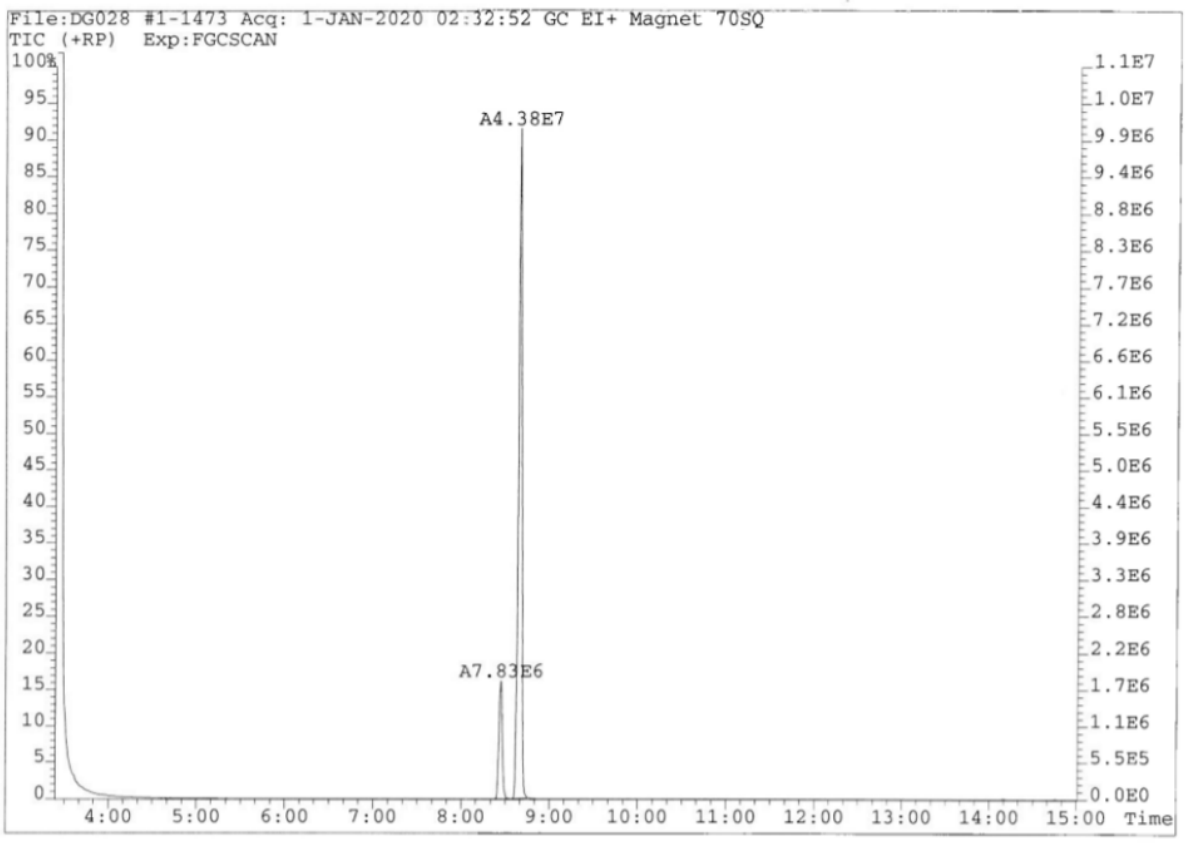

Figure S41. Gas chromatogram from GC/MS data taken on selective loading from a 99 to $1 \mathrm{~m}$-xylene/ $p$-xylene mixture (4 mL) using $5 \mathrm{mg}$ of crystalline $\mathbf{1}$ (trial 3 ).

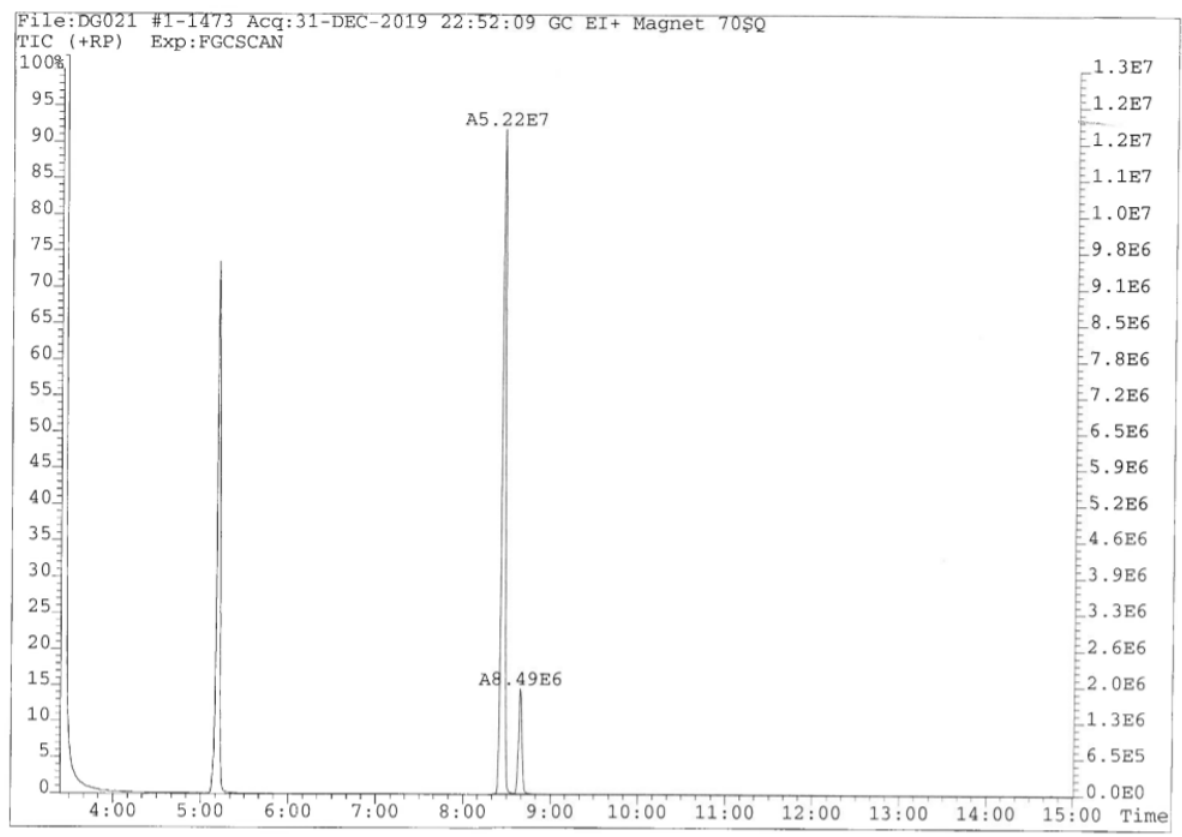

Figure S42. Gas chromatogram from GC/MS data taken on selective loading from a 4 to $1 \mathrm{~m}$-xylene $/ p$-xylene mixture (4 mL) using $5 \mathrm{mg}$ of crystalline $\mathbf{1}$ (trial 1 ). 


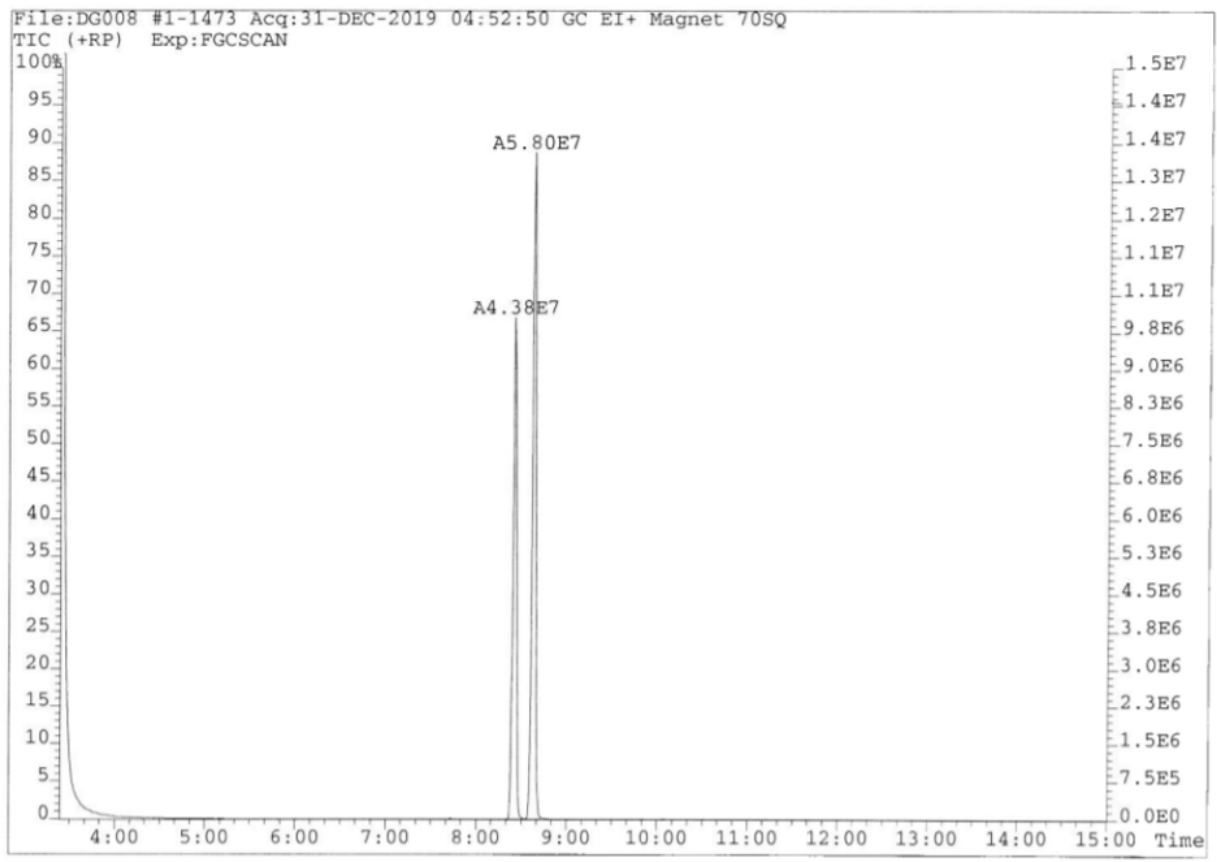

Figure S43. Gas chromatogram from GC/MS data taken on selective loading from a 4 to $1 \mathrm{~m}$-xylene/ $p$-xylene mixture (4 mL) using $5 \mathrm{mg}$ of crystalline $\mathbf{1}$ (trial 2).

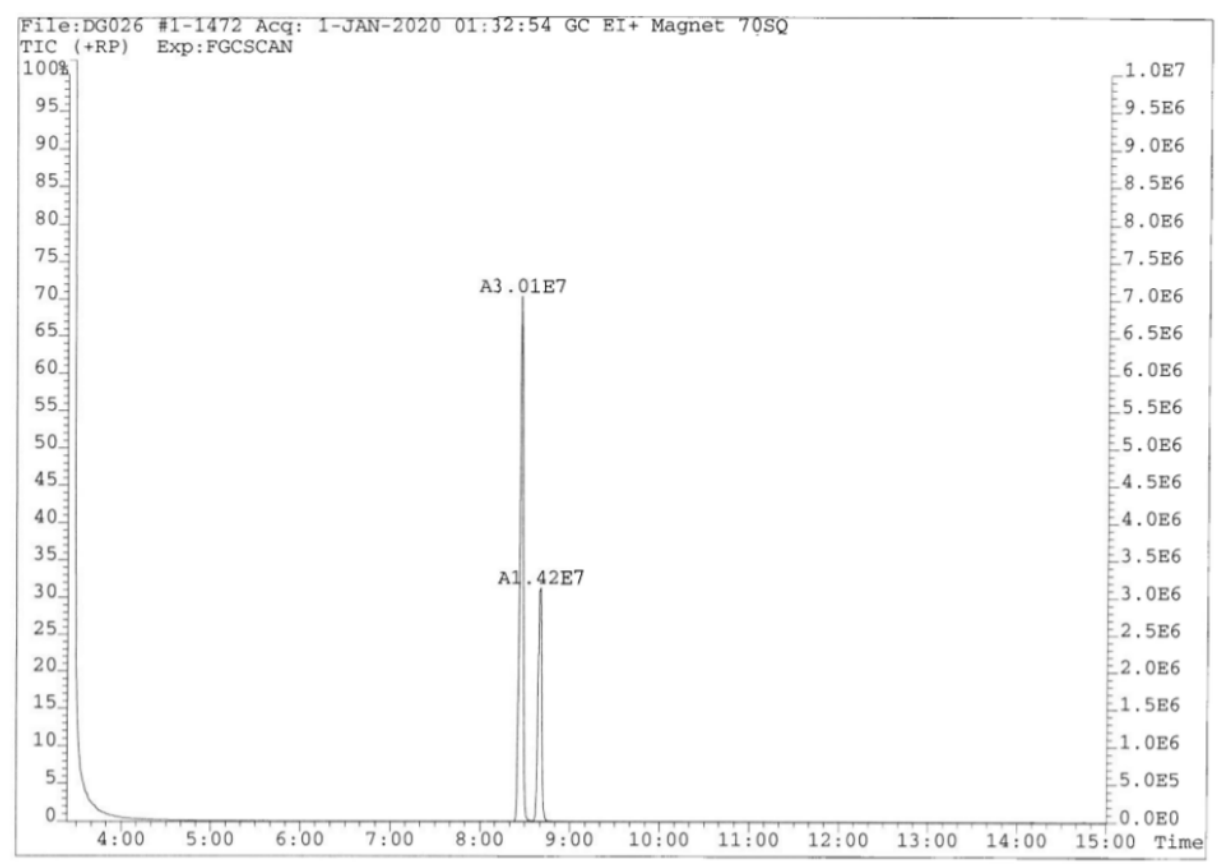

Figure S44. Gas chromatogram from GC/MS data taken on selective loading from a 4 to $1 \mathrm{~m}$-xylene $/ p$-xylene mixture ( $4 \mathrm{~mL}$ ) using $5 \mathrm{mg}$ of crystalline $\mathbf{1}$ (trial 3). 


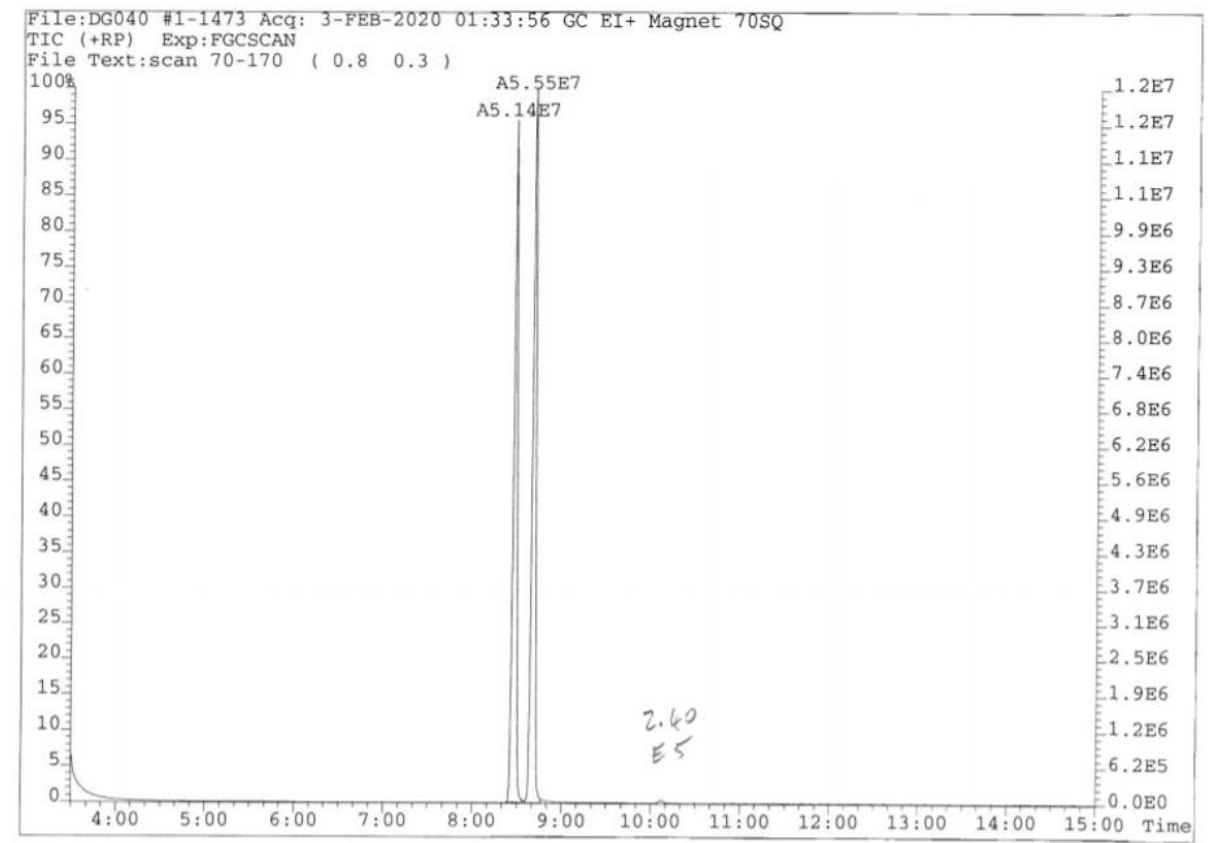

Figure S45. Gas chromatogram from GC/MS data taken on selective loading from a 3 to $1 \mathrm{~m}$-xylene $/ p$-xylene mixture (4 mL) using $5 \mathrm{mg}$ of crystalline $\mathbf{1}$ (trial 1 ).

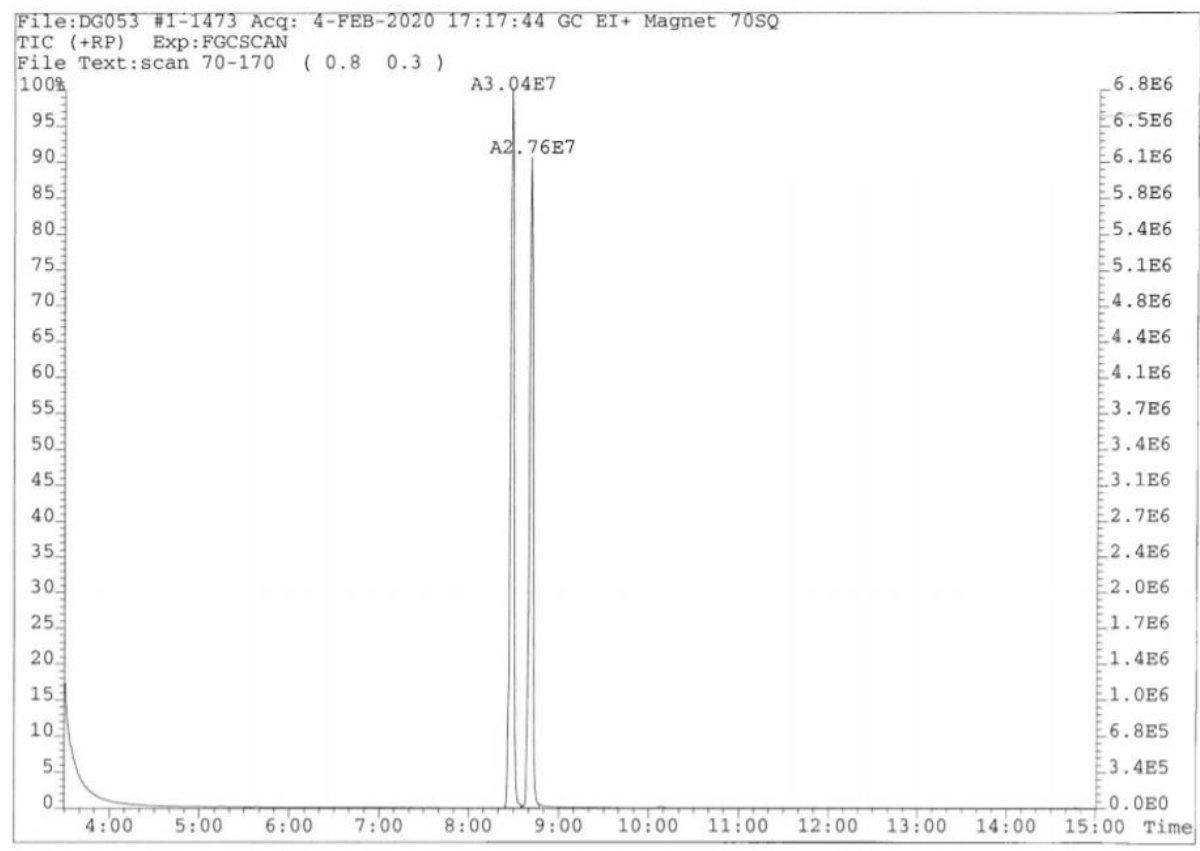

Figure S46. Gas chromatogram from GC/MS data taken on selective loading from a 3 to $1 \mathrm{~m}$-xylene/ $p$-xylene mixture (4 mL) using $5 \mathrm{mg}$ of crystalline $\mathbf{1}$ (trial 2). 


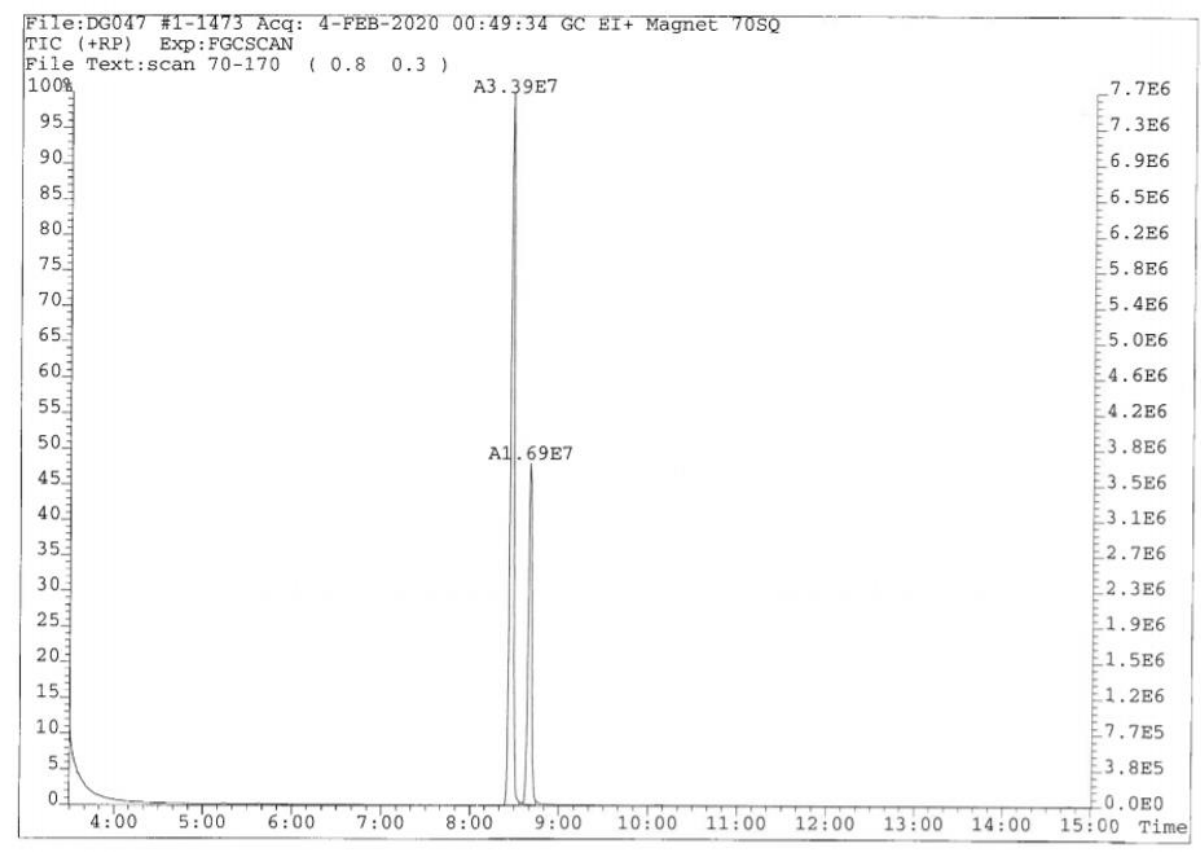

Figure S47. Gas chromatogram from GC/MS data taken on selective loading from a 3 to $1 \mathrm{~m}$-xylene/ $p$-xylene mixture (4 mL) using $5 \mathrm{mg}$ of crystalline $\mathbf{1}$ (trial 3 ).

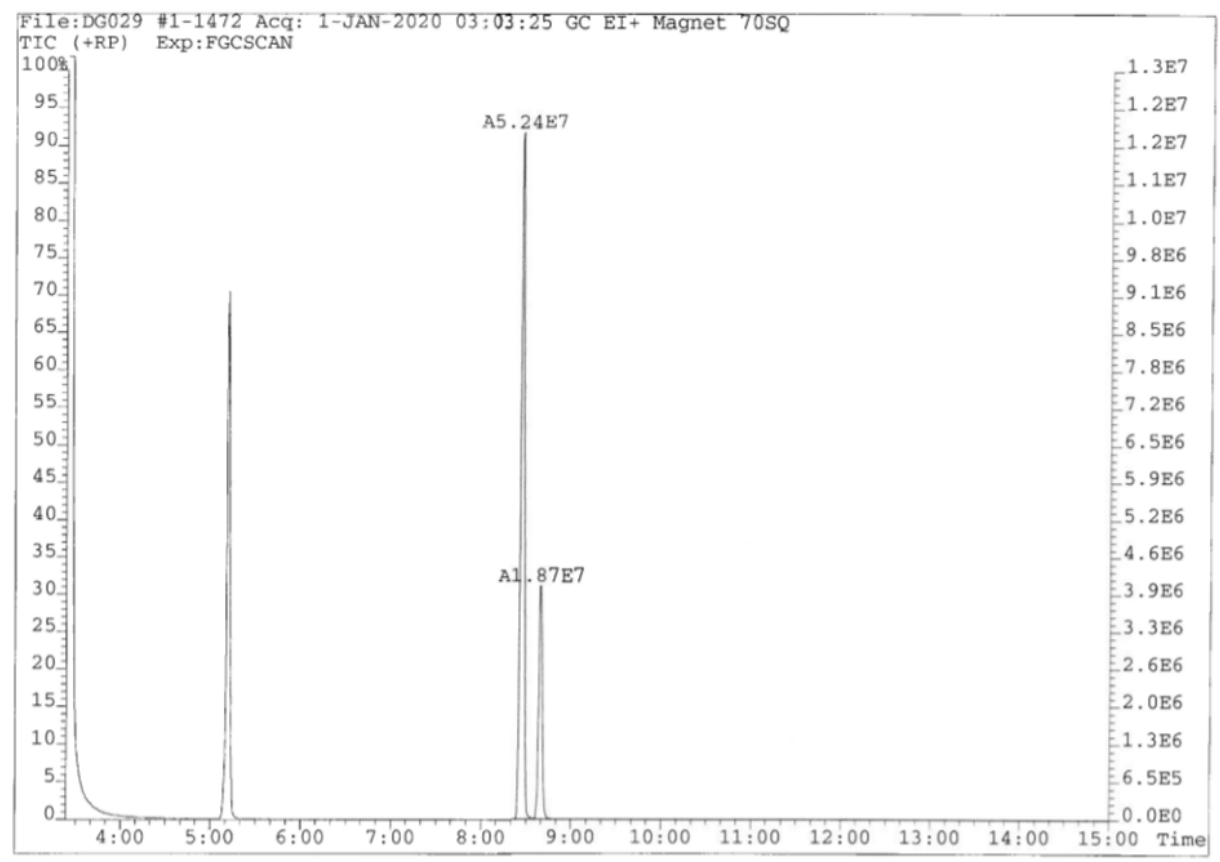

Figure S48. Gas chromatogram from GC/MS data taken on selective loading from a 2 to $1 \mathrm{~m}$-xylene $/ p$-xylene mixture (4 mL) using $5 \mathrm{mg}$ of crystalline 1 (trial 1 ). 


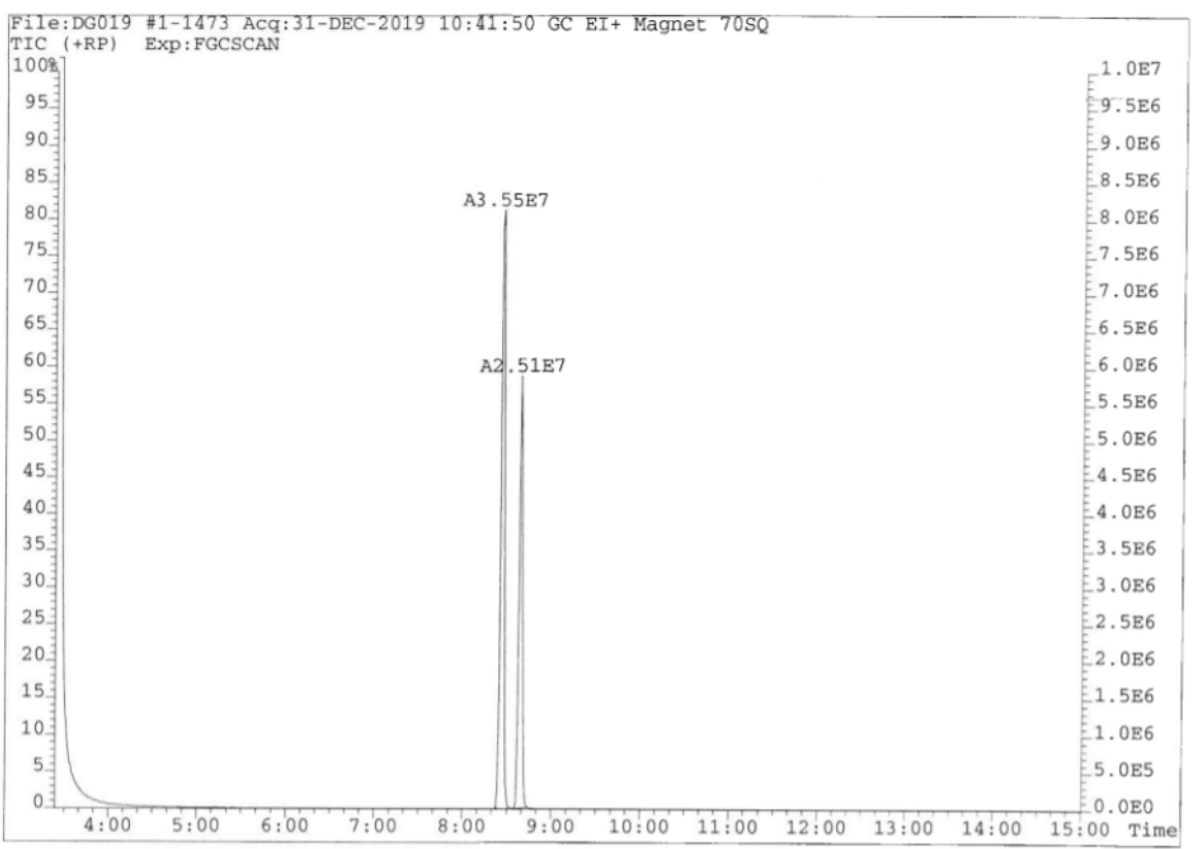

Figure S49. Gas chromatogram from GC/MS data taken on selective loading from a 2 to $1 \mathrm{~m}$-xylene $/ p$-xylene mixture (4 mL) using $5 \mathrm{mg}$ of crystalline $\mathbf{1}$ (trial 2).

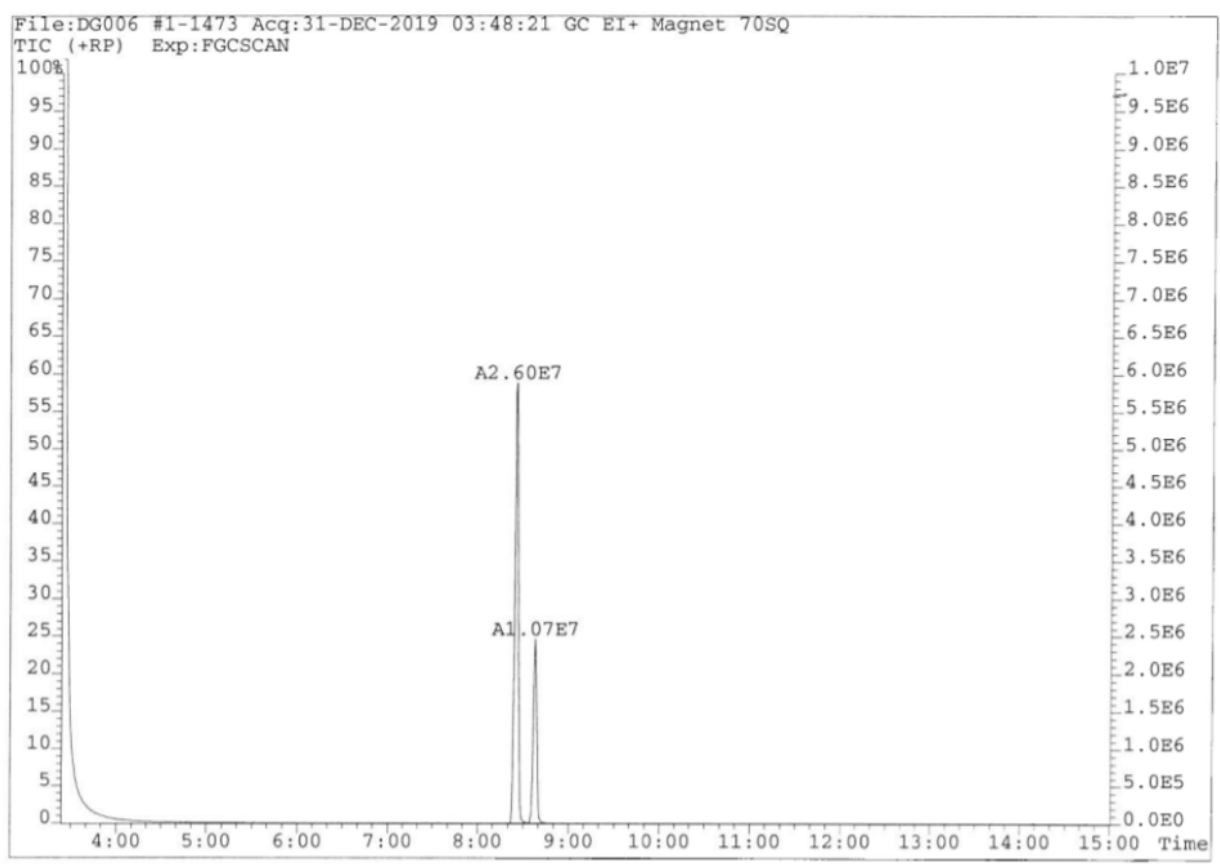

Figure S50. Gas chromatogram from GC/MS data taken on selective loading from a 2 to $1 \mathrm{~m}$-xylene $/ p$-xylene mixture ( $4 \mathrm{~mL}$ ) using $5 \mathrm{mg}$ of crystalline $\mathbf{1}$ (trial 3). 


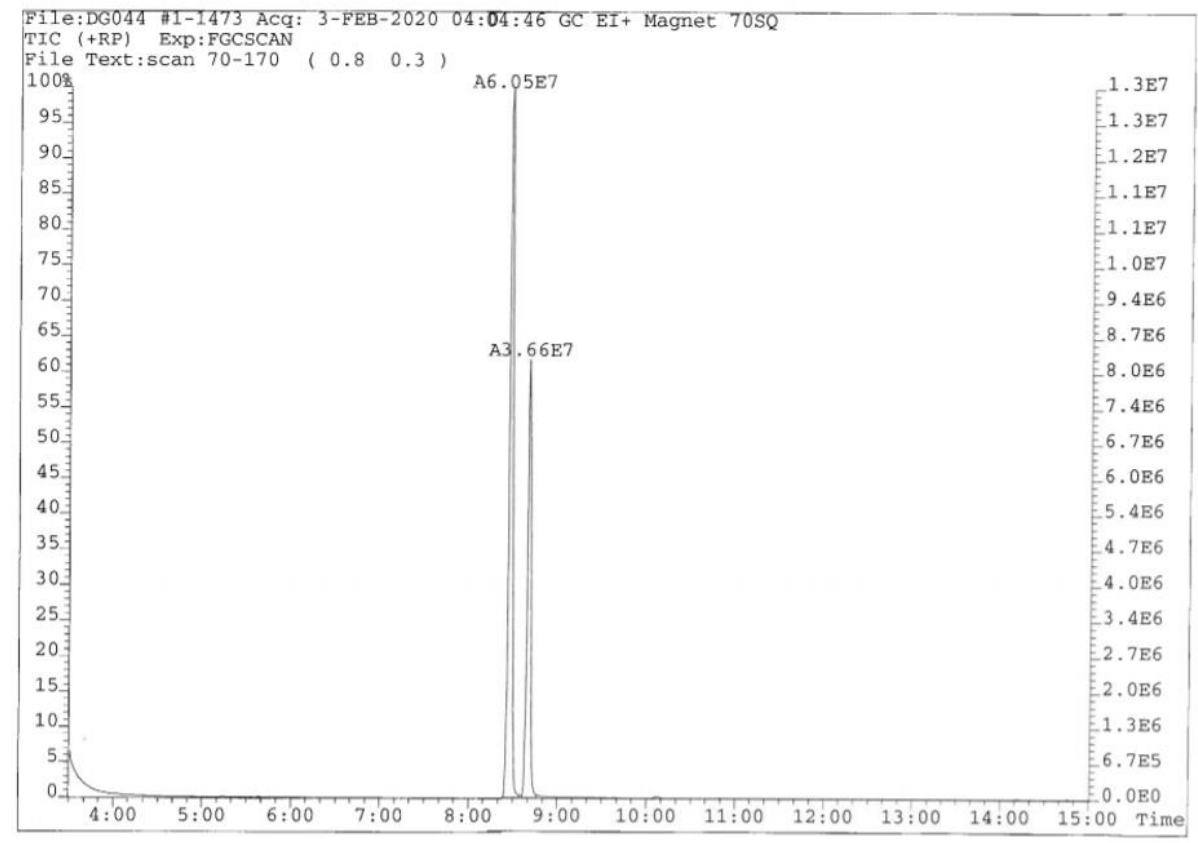

Figure S51. Gas chromatogram from GC/MS data taken on selective loading from a 1 to $1 \mathrm{~m}$-xylene $/ p$-xylene mixture (4 mL) using $5 \mathrm{mg}$ of crystalline $\mathbf{1}$ (trial 1).

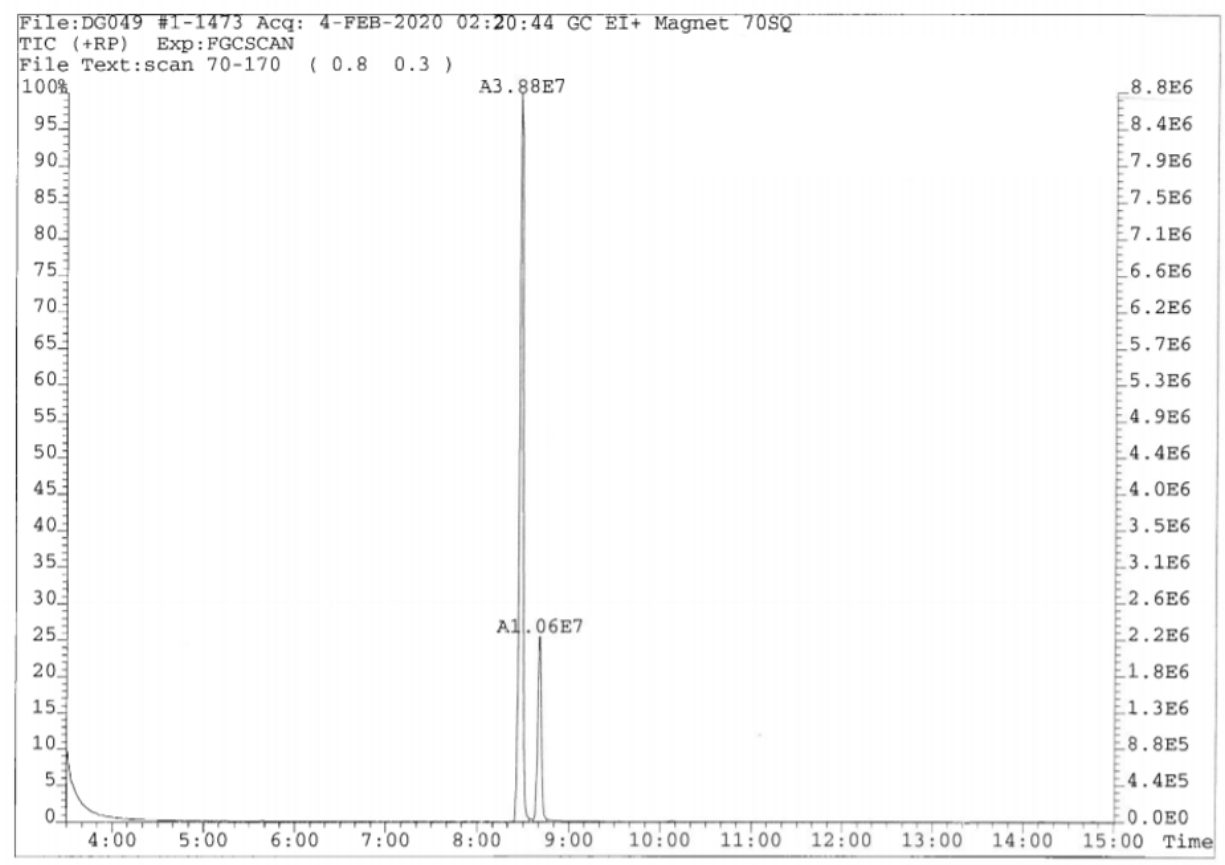

Figure S52. Gas chromatogram from GC/MS data taken on selective loading from a 1 to $1 \mathrm{~m}$-xylene/ $p$-xylene mixture (4 mL) using $5 \mathrm{mg}$ of crystalline $\mathbf{1}$ (trial 2). 


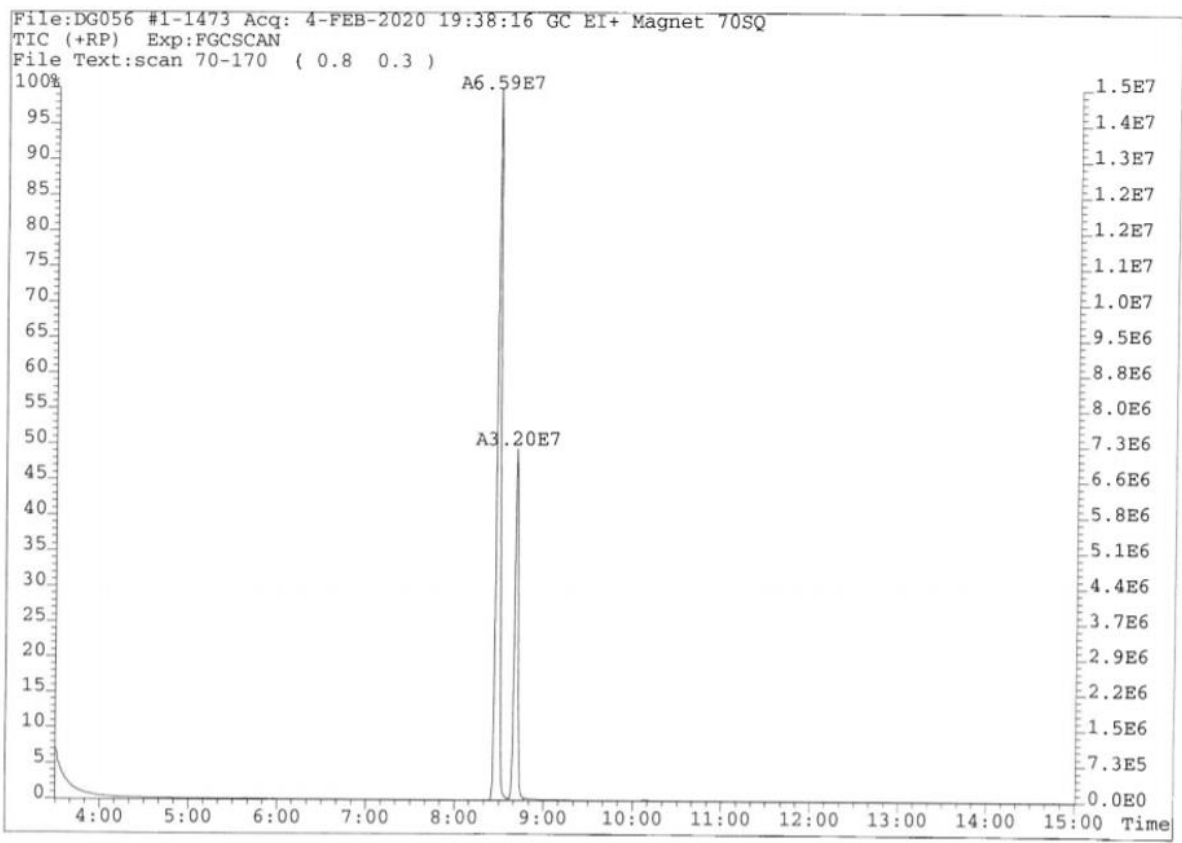

Figure S53. Gas chromatogram from GC/MS data taken on selective loading from a 1 to $1 \mathrm{~m}$-xylene $/ p$-xylene mixture (4 mL) using $5 \mathrm{mg}$ of crystalline $\mathbf{1}$ (trial 3 ).

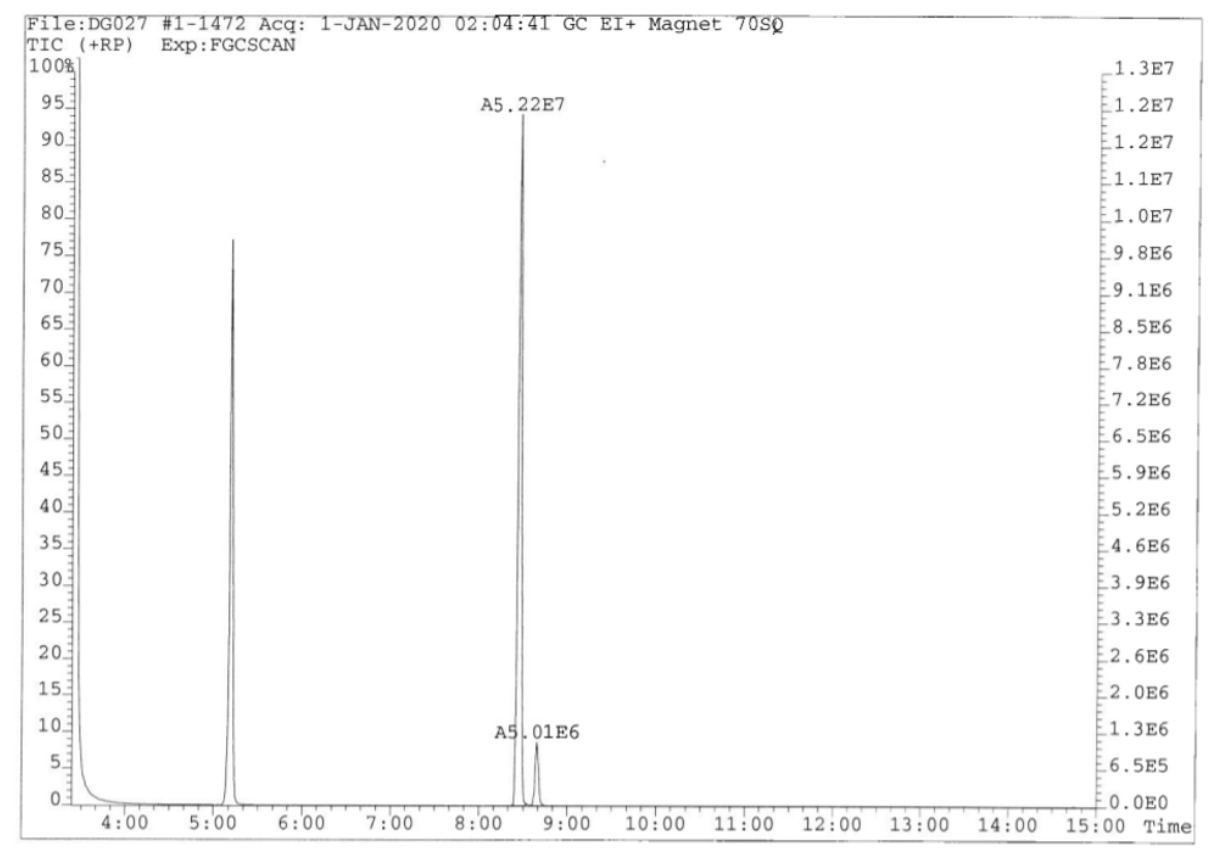

Figure S54. Gas chromatogram from GC/MS data taken on selective loading from a 1 to $3 m$-xylene/ $p$-xylene mixture (4 mL) using $5 \mathrm{mg}$ of crystalline $\mathbf{1}$ (trial 1). 


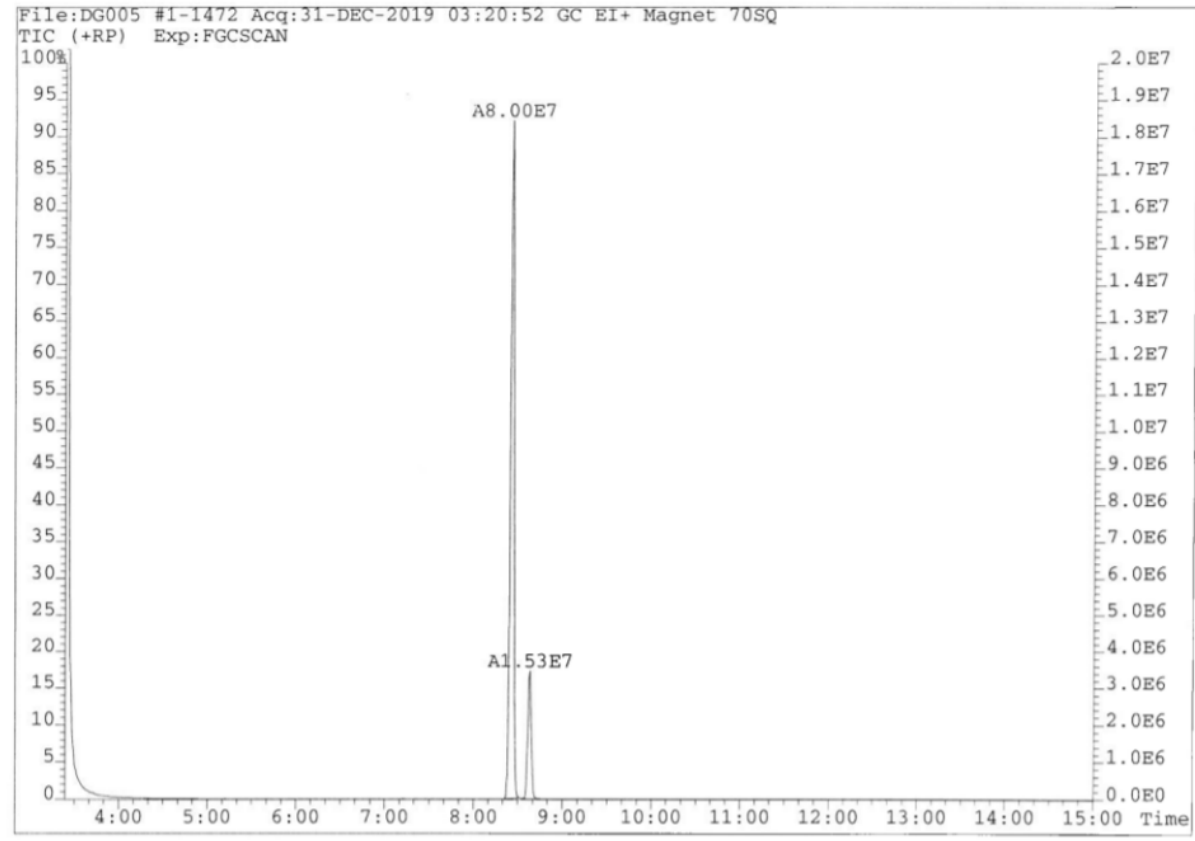

Figure S55. Gas chromatogram from GC/MS data taken on selective loading from a 1 to $3 \mathrm{~m}$-xylene $/ p$-xylene mixture (4 mL) using $5 \mathrm{mg}$ of crystalline $\mathbf{1}$ (trial 2).

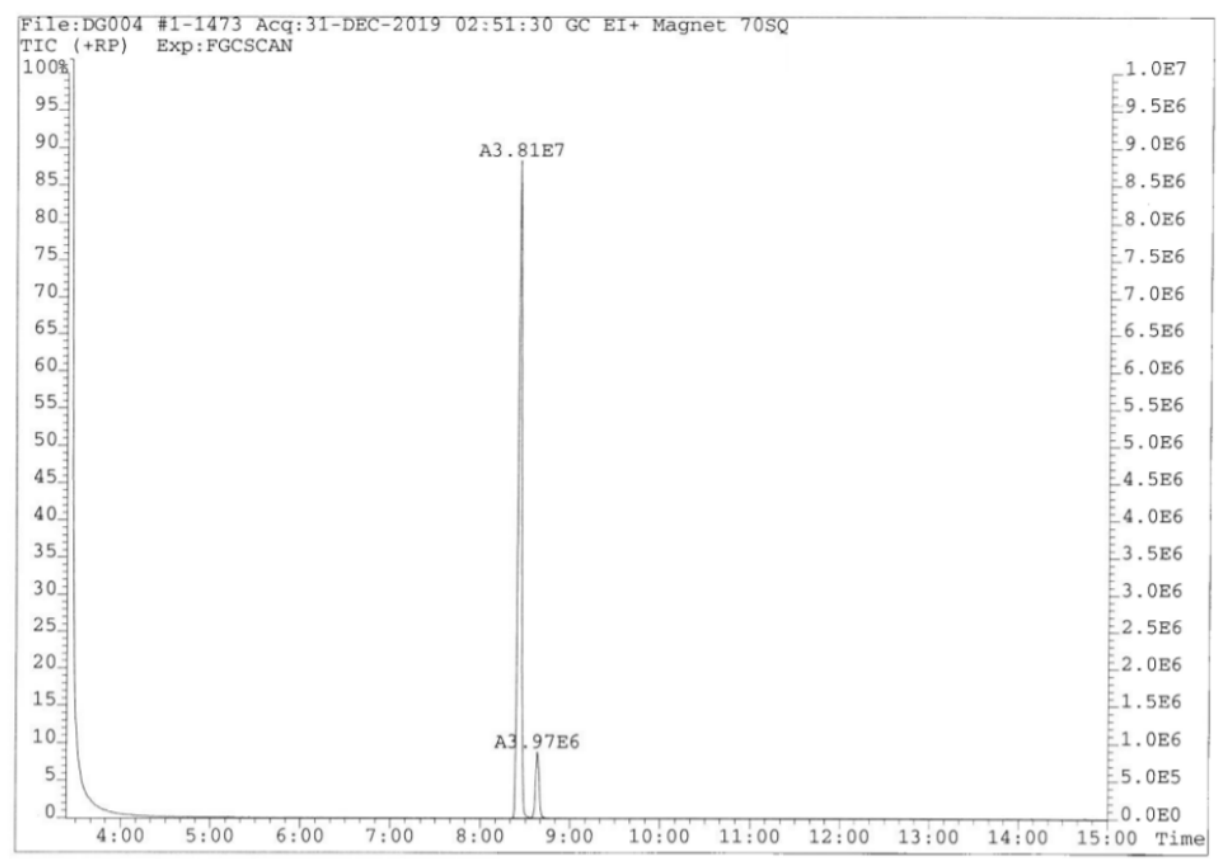

Figure S56. Gas chromatogram from GC/MS data taken on selective loading from a 1 to $3 \mathrm{~m}$-xylene/ $p$-xylene mixture (4 mL) using $5 \mathrm{mg}$ of crystalline $\mathbf{1}$ (trial 3). 


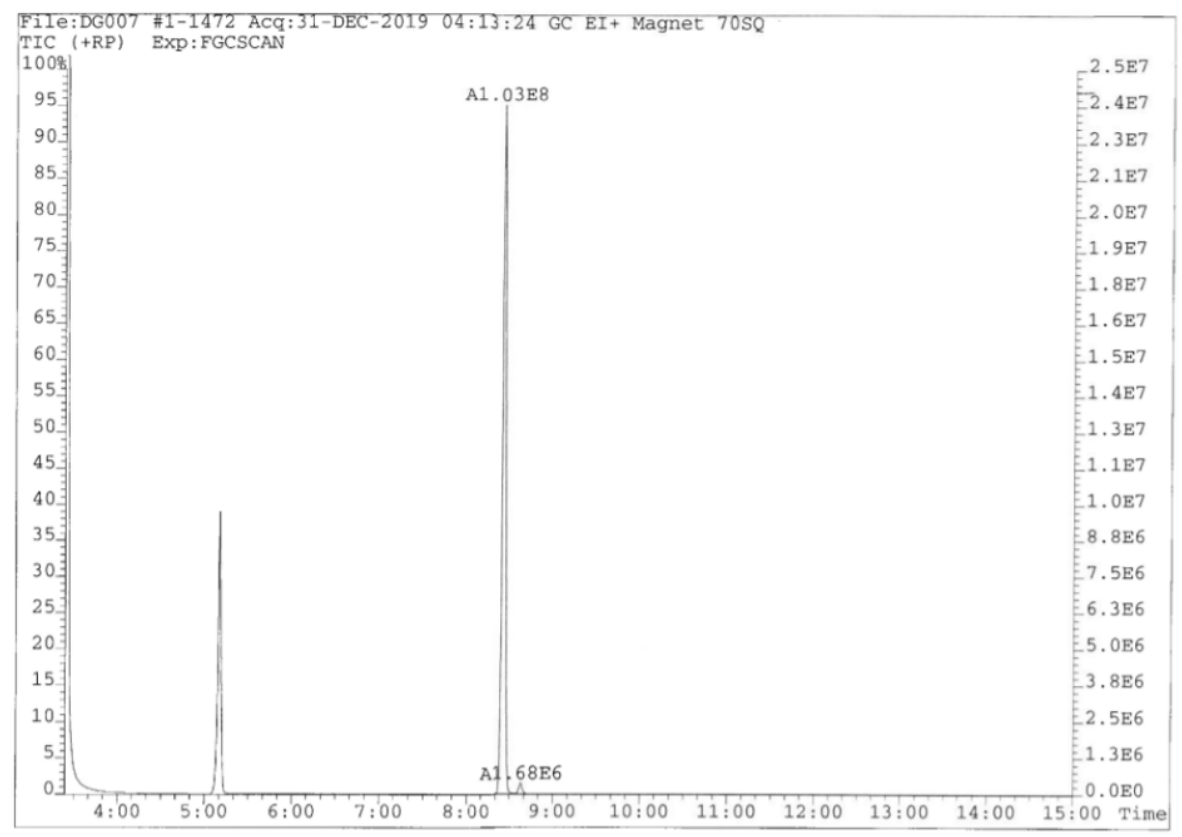

Figure S57. Gas chromatogram from GC/MS data taken on selective loading from a 1 to $99 \mathrm{~m}$-xylene/ $p$-xylene mixture (4 mL) using $5 \mathrm{mg}$ of crystalline $\mathbf{1}$ (trial 1).

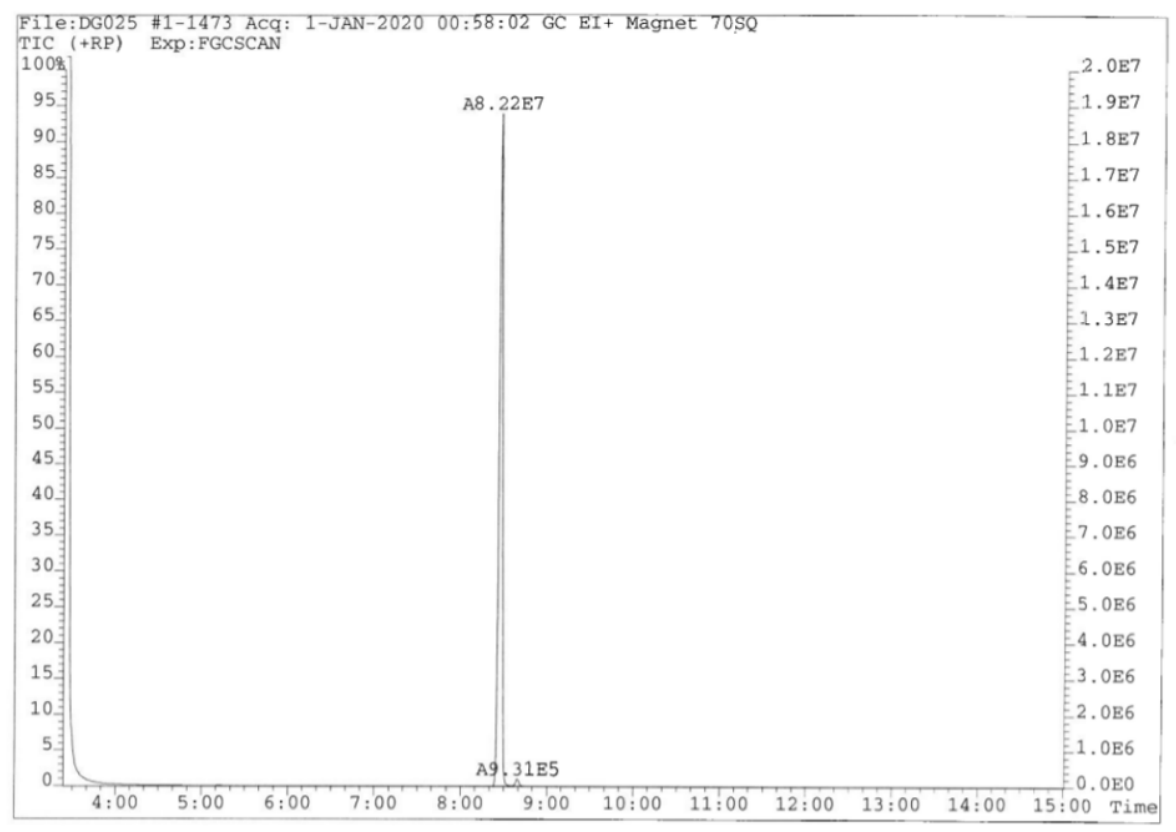

Figure S58. Gas chromatogram from GC/MS data taken on selective loading from a 1 to $99 \mathrm{~m}$-xylene/ $p$-xylene mixture (4 mL) using $5 \mathrm{mg}$ of crystalline $\mathbf{1}$ (trial 2). 


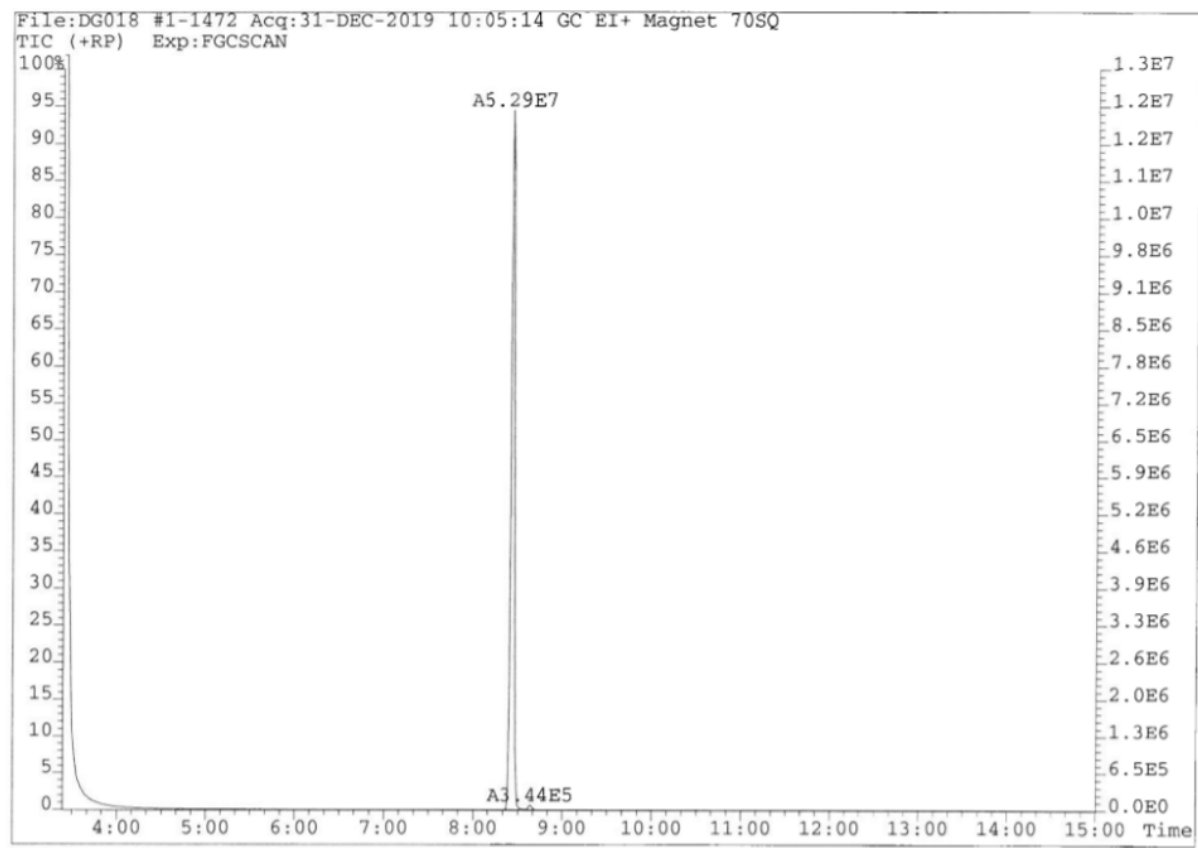

Figure S59. Gas chromatogram from GC/MS data taken on selective loading from a 1 to $99 m$-xylene/ $p$-xylene mixture (4 mL) using $5 \mathrm{mg}$ of crystalline 1 (trial 3).

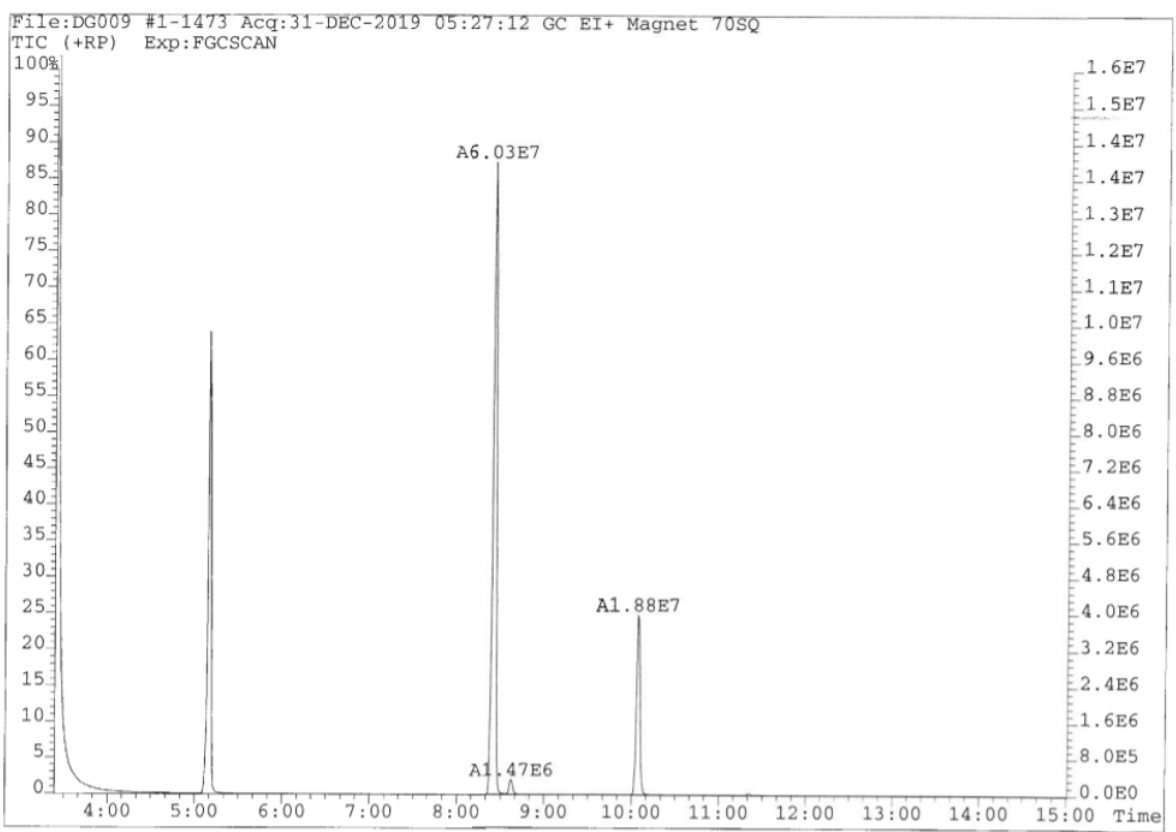

Figure S60. Gas chromatogram from GC/MS data taken on selective loading from a 99 to $1 o$-xylene/ $p$-xylene mixture (4 mL) using $5 \mathrm{mg}$ of crystalline $\mathbf{1}$ (trial 1). 


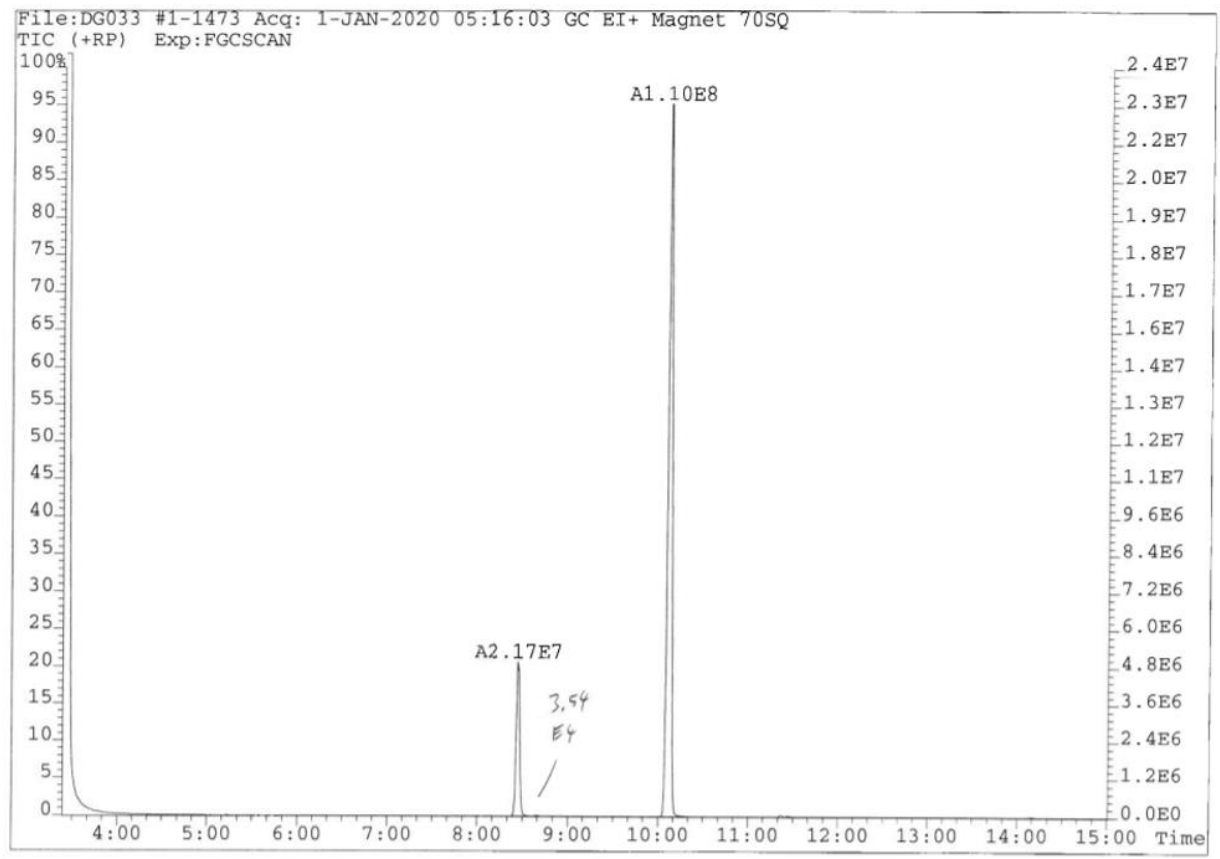

Figure S61. Gas chromatogram from GC/MS data taken on selective loading from a 99 to $1 o$-xylene/p-xylene mixture (4 mL) using $5 \mathrm{mg}$ of crystalline $\mathbf{1}$ (trial 2).

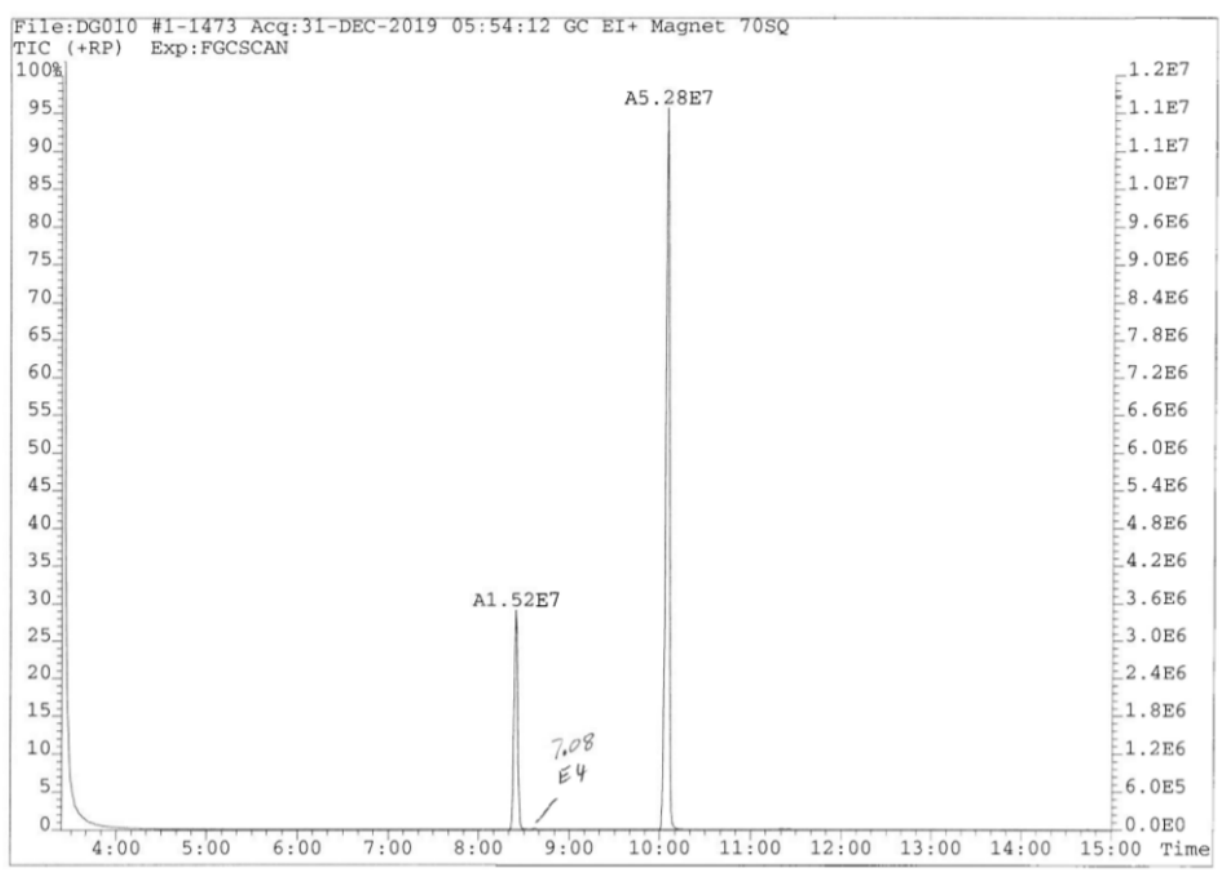

Figure S62. Gas chromatogram from GC/MS data taken on selective loading from a 99 to $1 o$-xylene/ $p$-xylene mixture (4 mL) using $5 \mathrm{mg}$ of crystalline $\mathbf{1}$ (trial 3). 


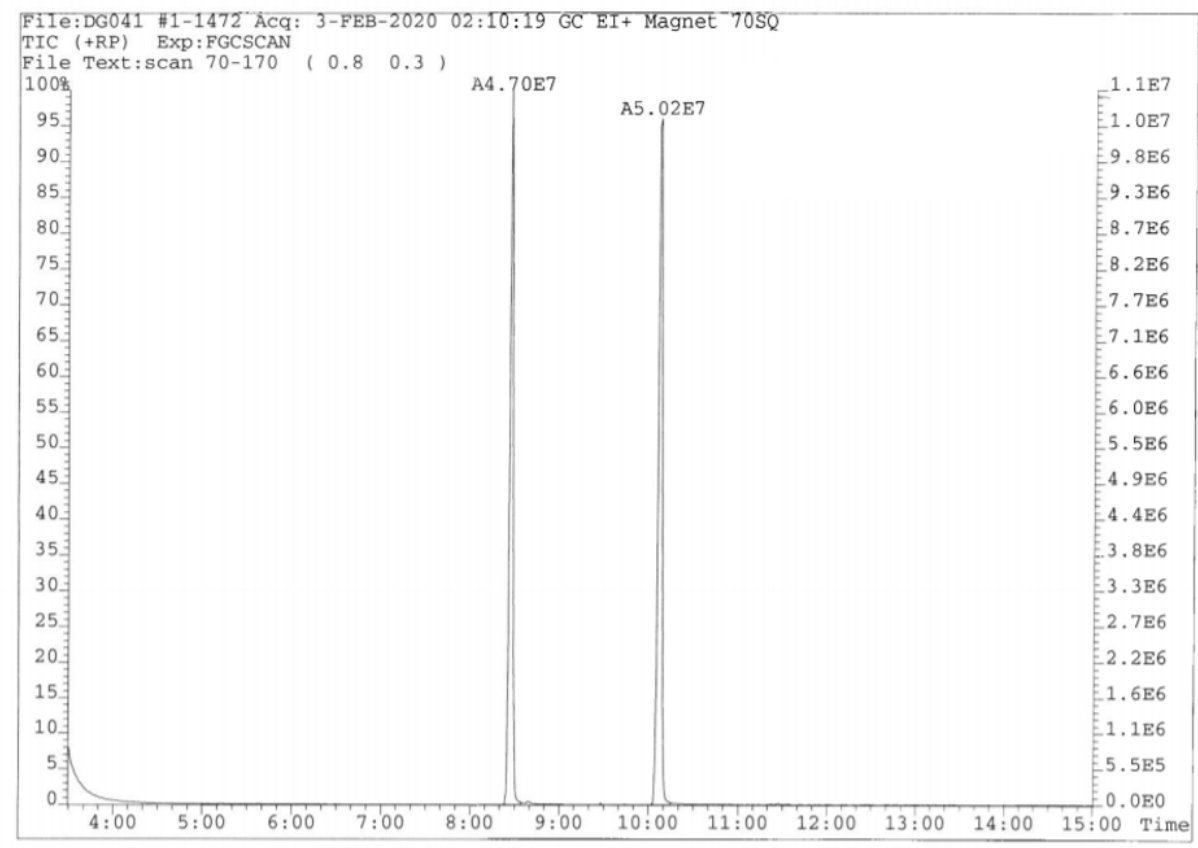

Figure S63. Gas chromatogram from GC/MS data taken on selective loading from a 4 to $1 o$-xylene/ $p$-xylene mixture (4 mL) using $5 \mathrm{mg}$ of crystalline $\mathbf{1}$ (trial 1).

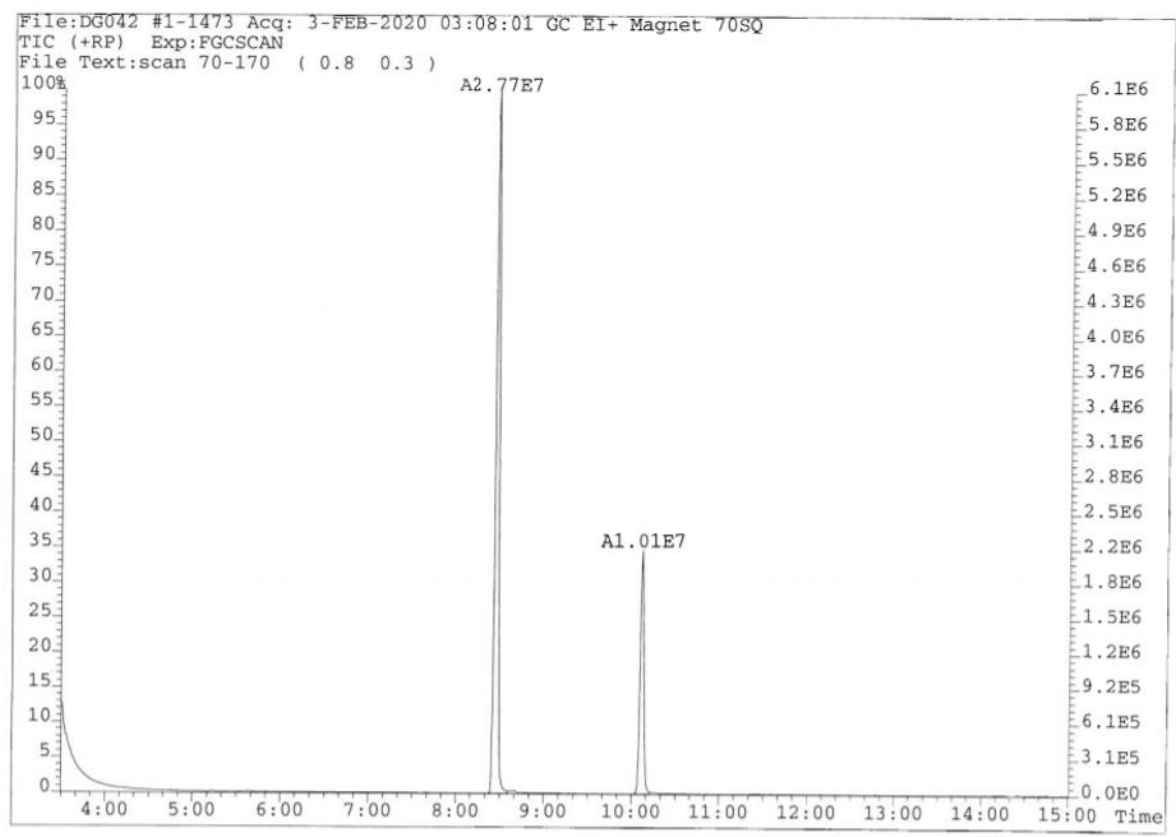

Figure S64. Gas chromatogram from GC/MS data taken on selective loading from a 4 to $1 o$-xylene/ $p$-xylene mixture ( $4 \mathrm{~mL}$ ) using $5 \mathrm{mg}$ of crystalline $\mathbf{1}$ (trial 2). 


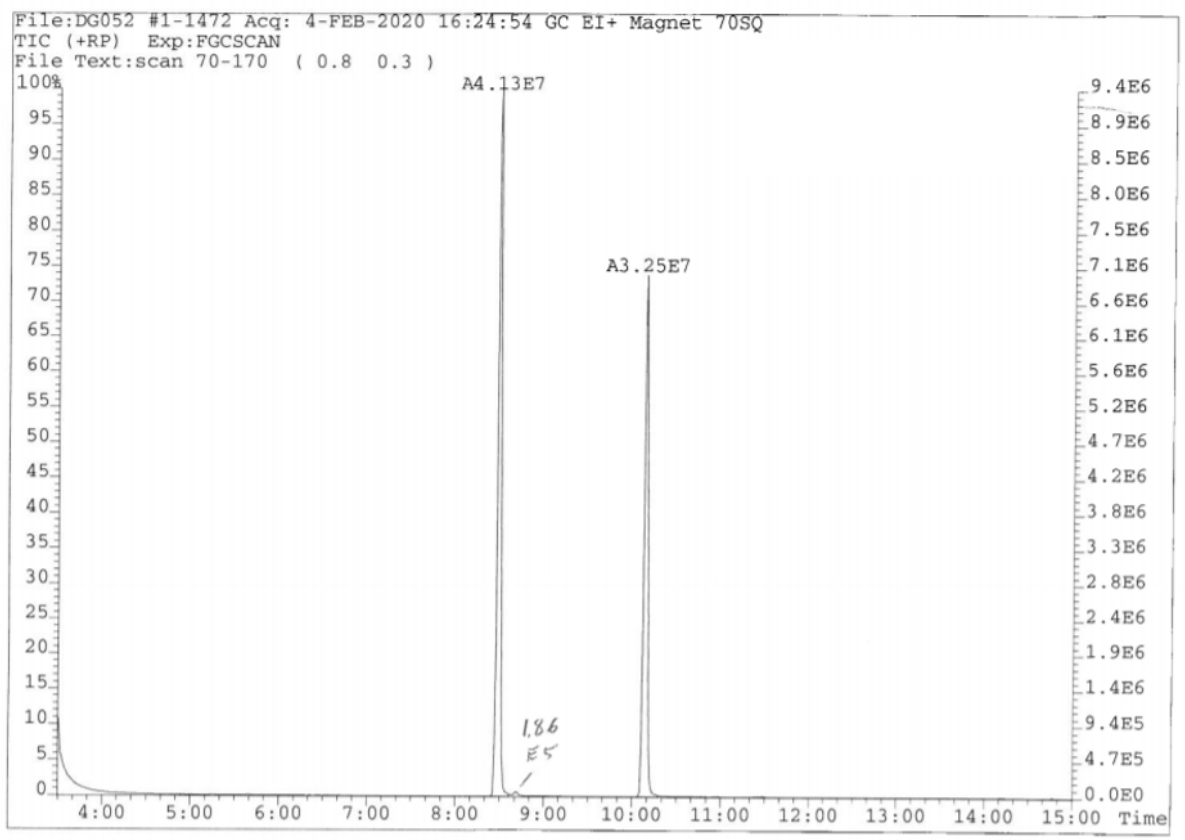

Figure S65. Gas chromatogram from GC/MS data taken on selective loading from a 4 to $1 o$-xylene/ $p$-xylene mixture ( $4 \mathrm{~mL}$ ) using $5 \mathrm{mg}$ of crystalline $\mathbf{1}$ (trial 3).

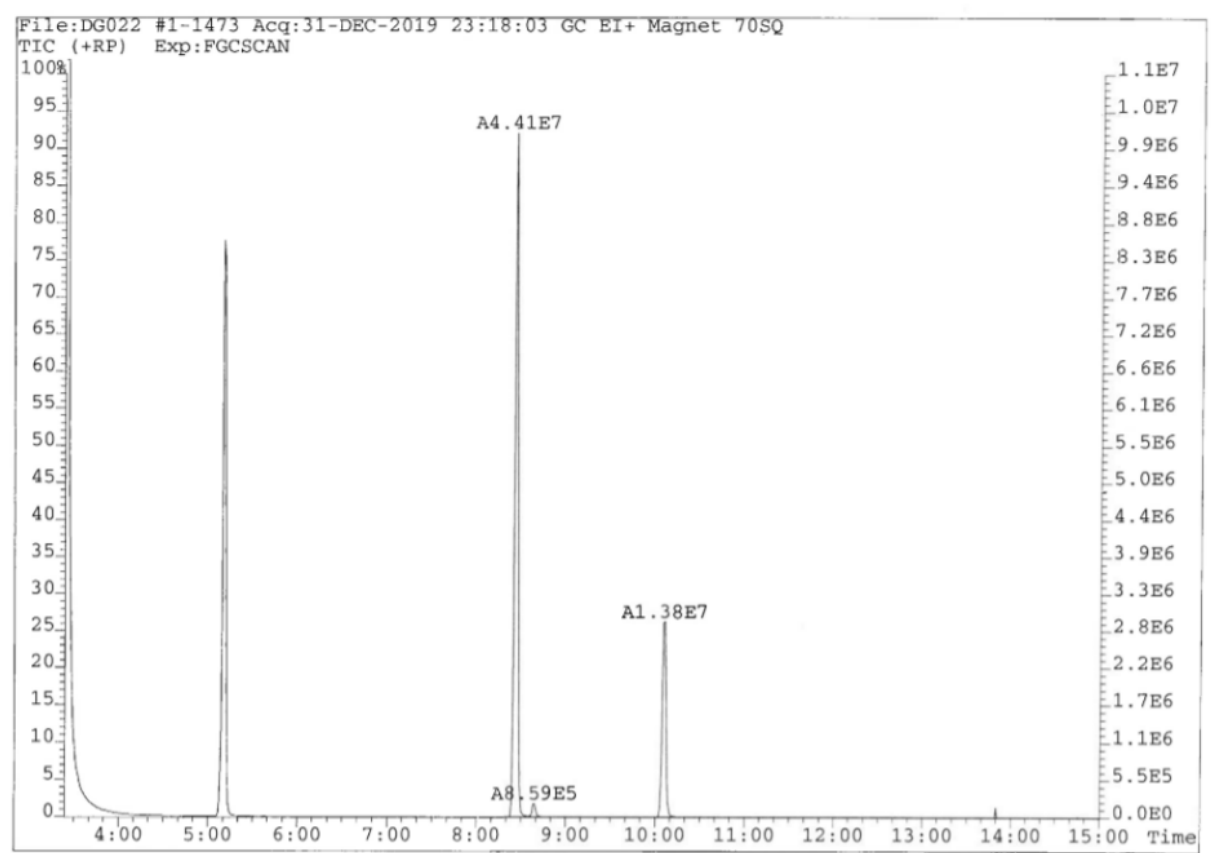

Figure S66. Gas chromatogram from GC/MS data taken on selective loading from a 3 to $1 o$-xylene/ $p$-xylene mixture (4 mL) using $5 \mathrm{mg}$ of crystalline $\mathbf{1}$ (trial 1). 


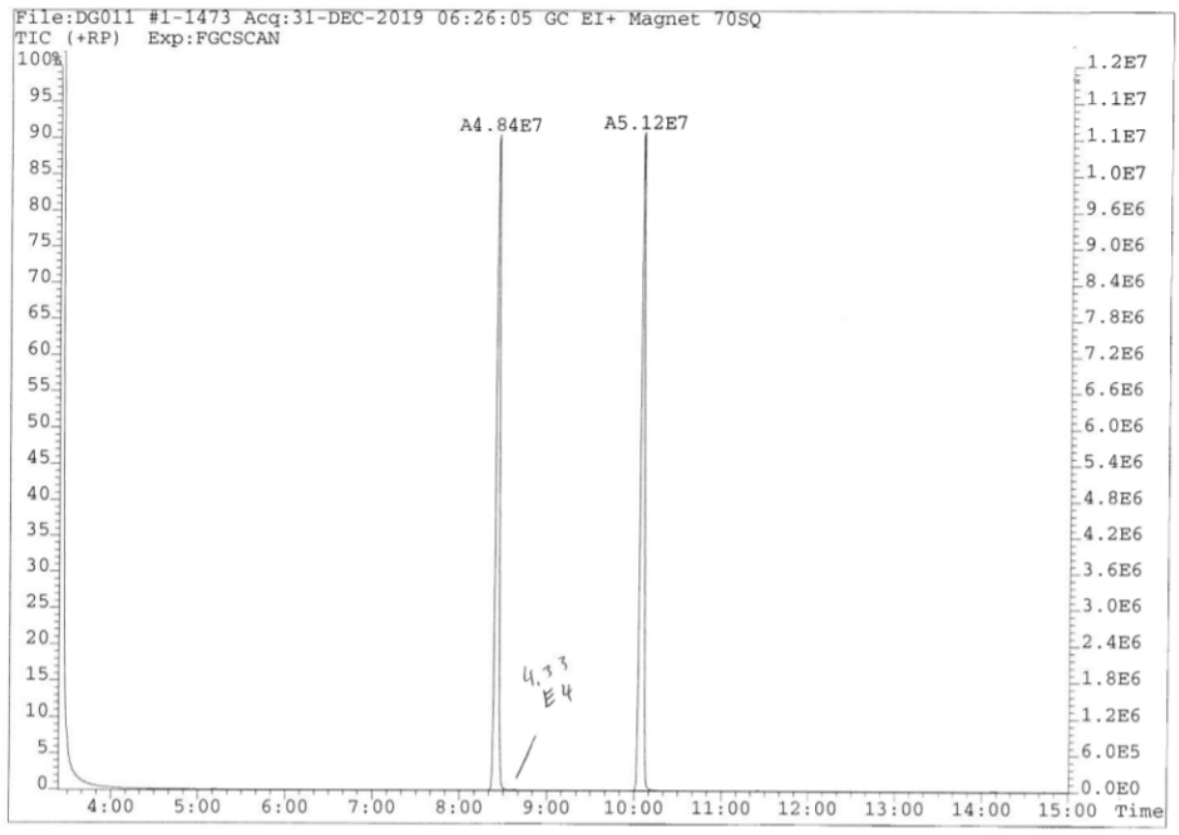

Figure S67. Gas chromatogram from GC/MS data taken on selective loading from a 3 to $1 o$-xylene/ $p$-xylene mixture (4 mL) using $5 \mathrm{mg}$ of crystalline $\mathbf{1}$ (trial 2).

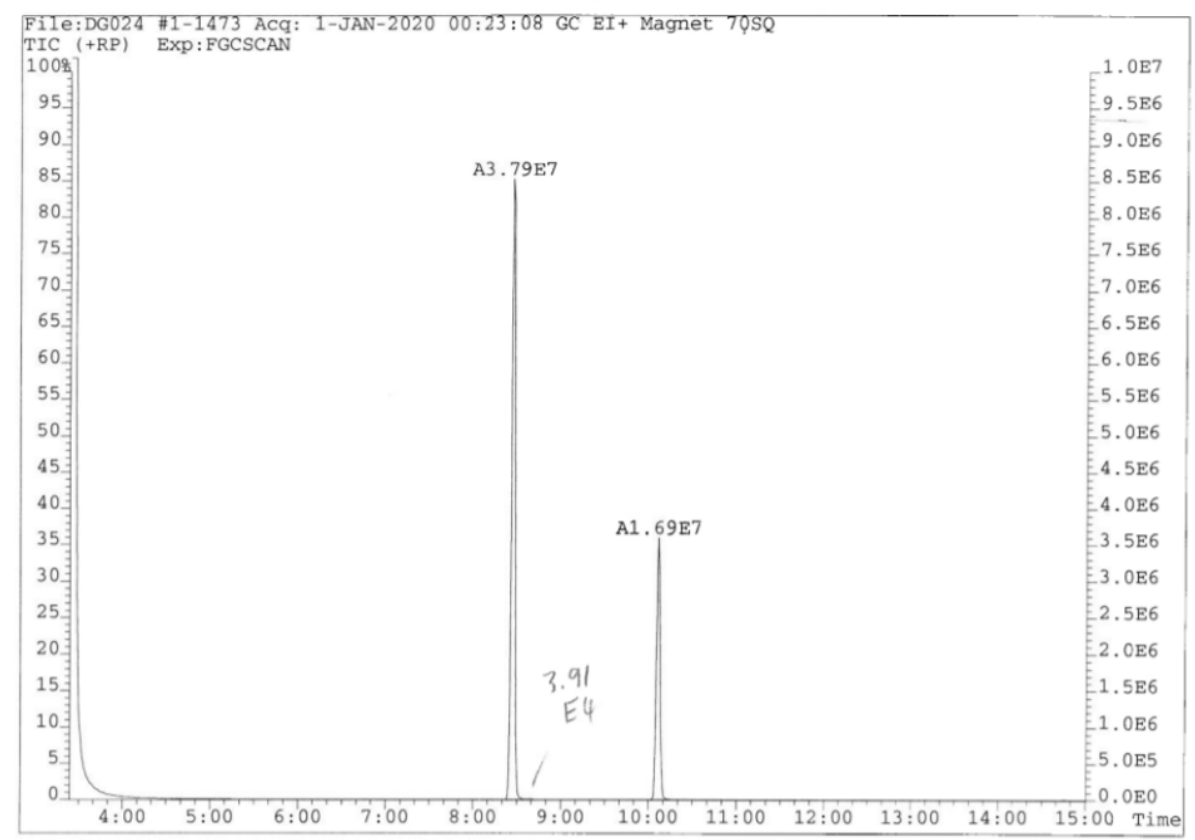

Figure S68. Gas chromatogram from GC/MS data taken on selective loading from a 3 to $1 o$-xylene $/ p$-xylene mixture ( $4 \mathrm{~mL}$ ) using $5 \mathrm{mg}$ of crystalline $\mathbf{1}$ (trial 3). 


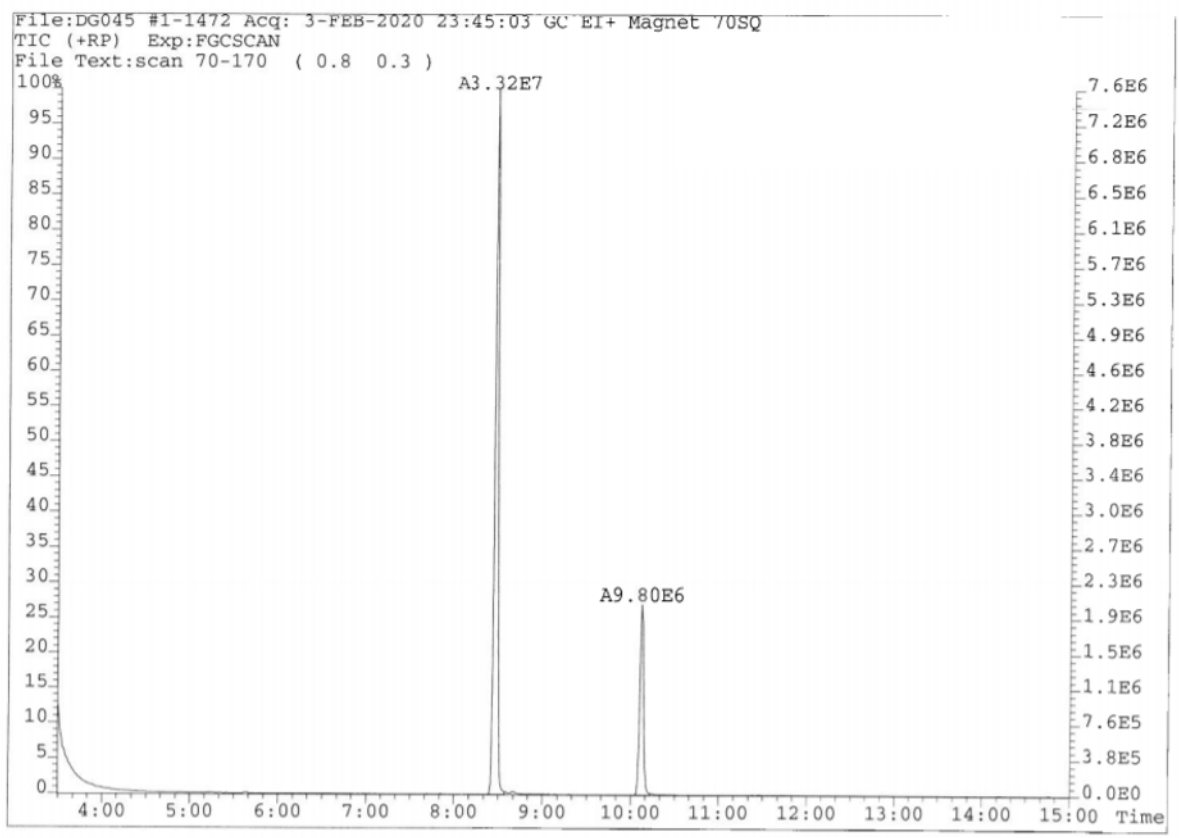

Figure S69. Gas chromatogram from GC/MS data taken on selective loading from a 2 to $1 o$-xylene/ $p$-xylene mixture (4 mL) using $5 \mathrm{mg}$ of crystalline $\mathbf{1}$ (trial 1).

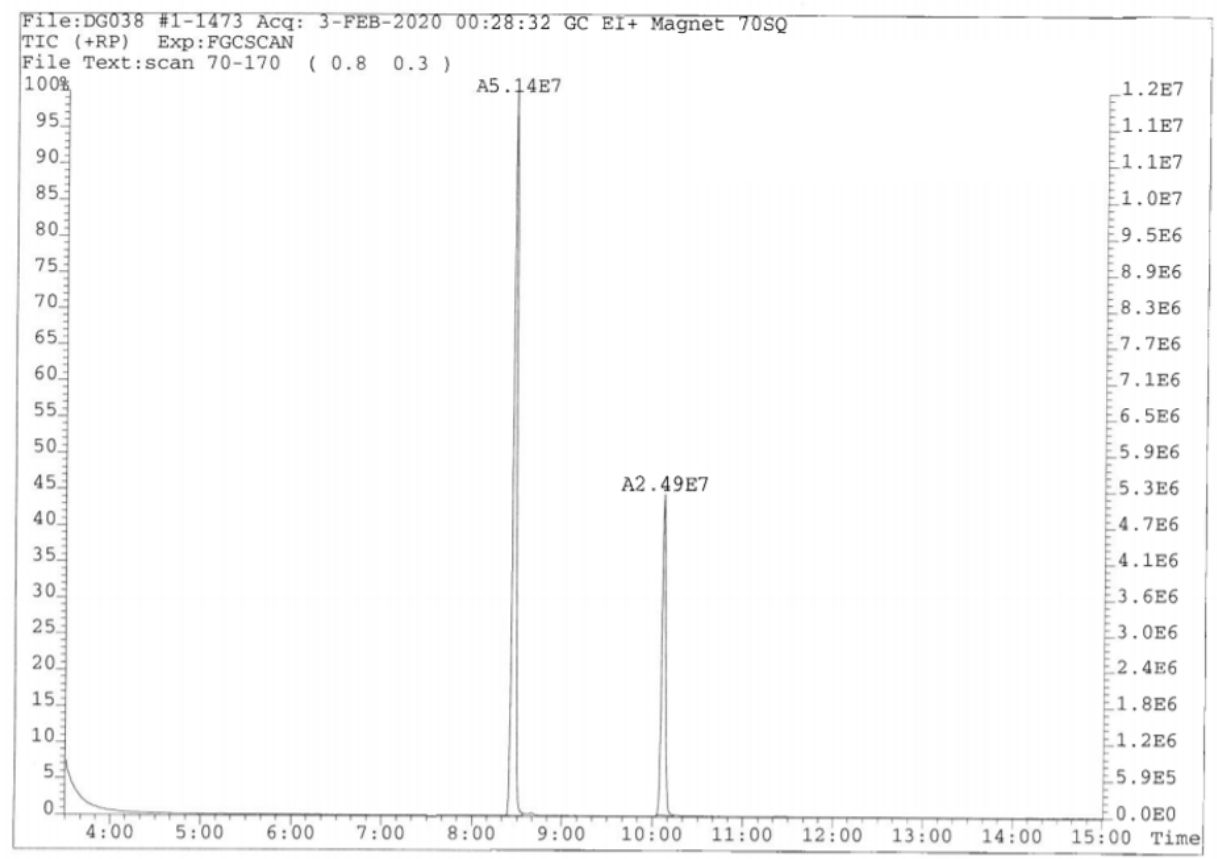

Figure S70. Gas chromatogram from GC/MS data taken on selective loading from a 2 to $1 o$-xylene/ $p$-xylene mixture (4 mL) using $5 \mathrm{mg}$ of crystalline $\mathbf{1}$ (trial 2). 


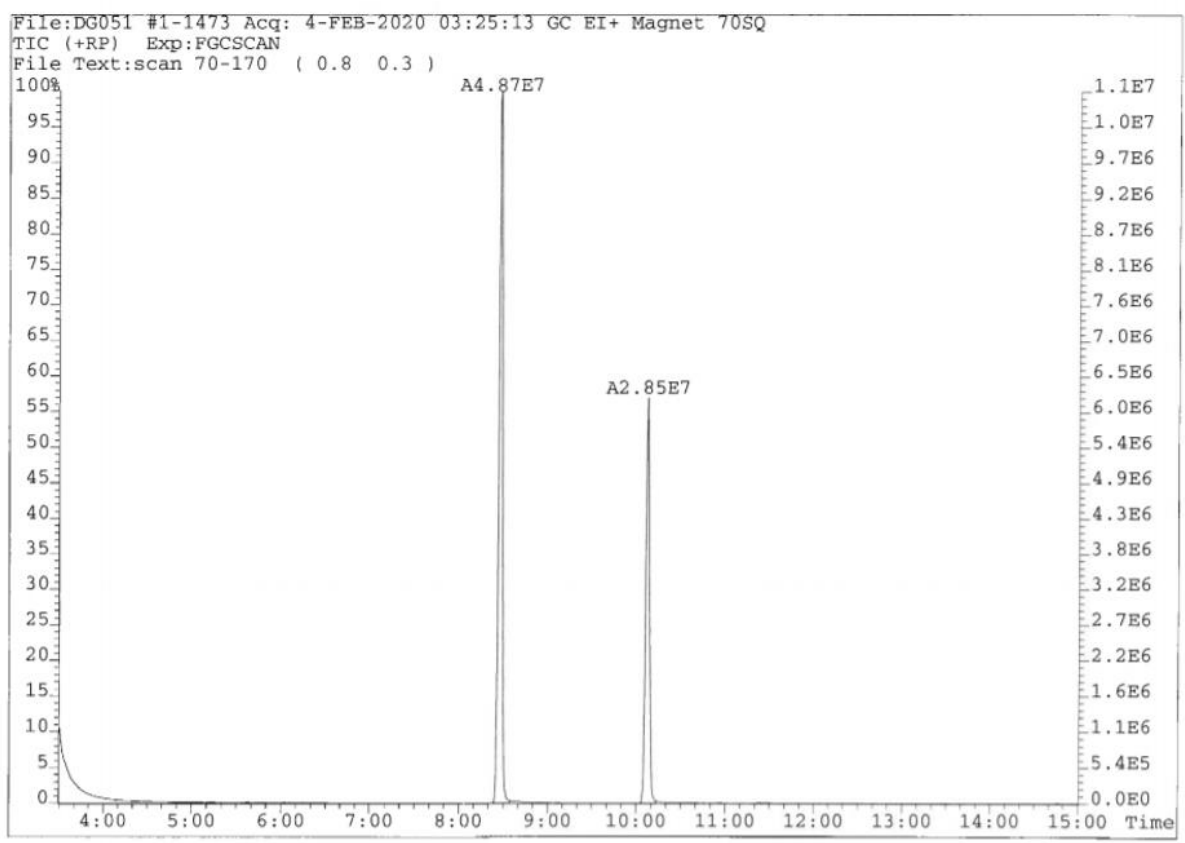

Figure S10. Gas chromatogram from GC/MS data taken on selective loading from a 2 to $1 o$-xylene/ $p$-xylene mixture (4 mL) using $5 \mathrm{mg}$ of crystalline $\mathbf{1}$ (trial 3).

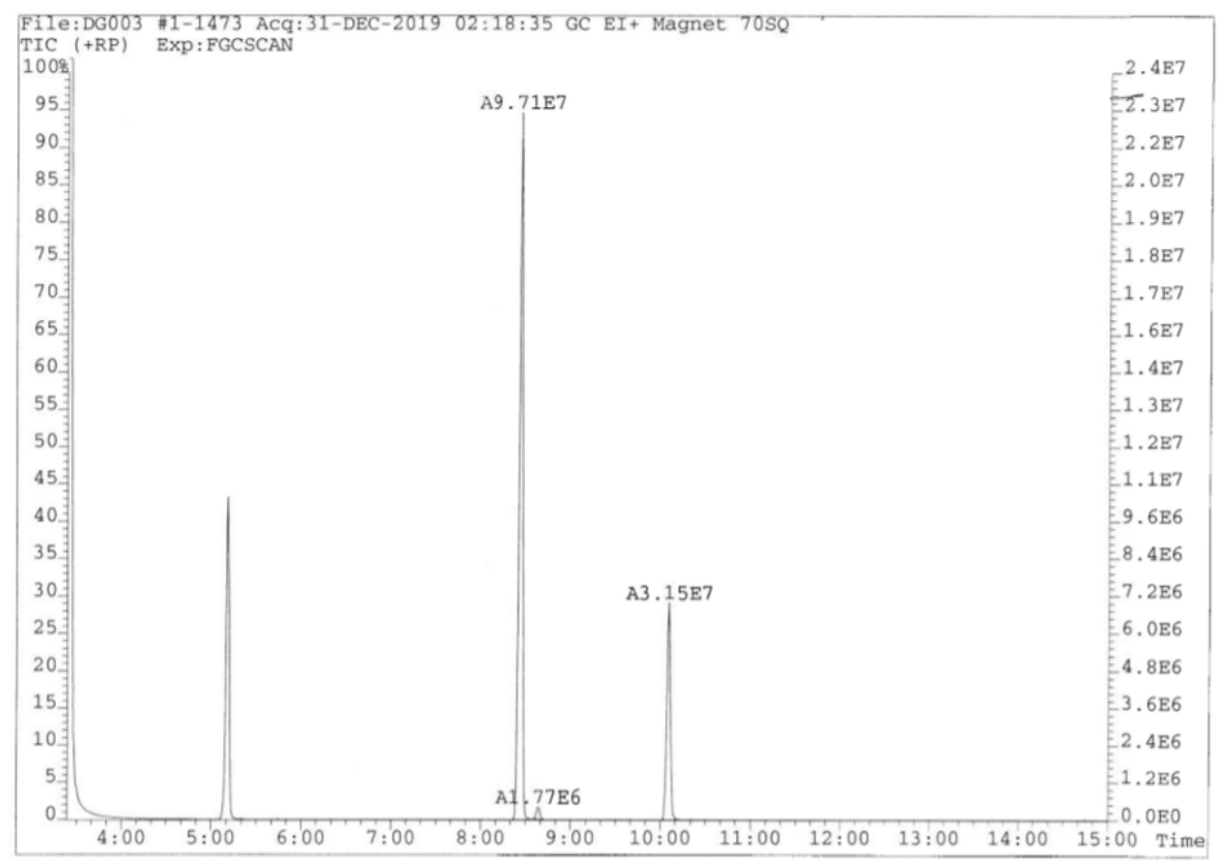

Figure S72. Gas chromatogram from GC/MS data taken on selective loading from a 1 to $1 o$-xylene/ $p$-xylene mixture (4 mL) using $5 \mathrm{mg}$ of crystalline $\mathbf{1}$ (trial 1). 


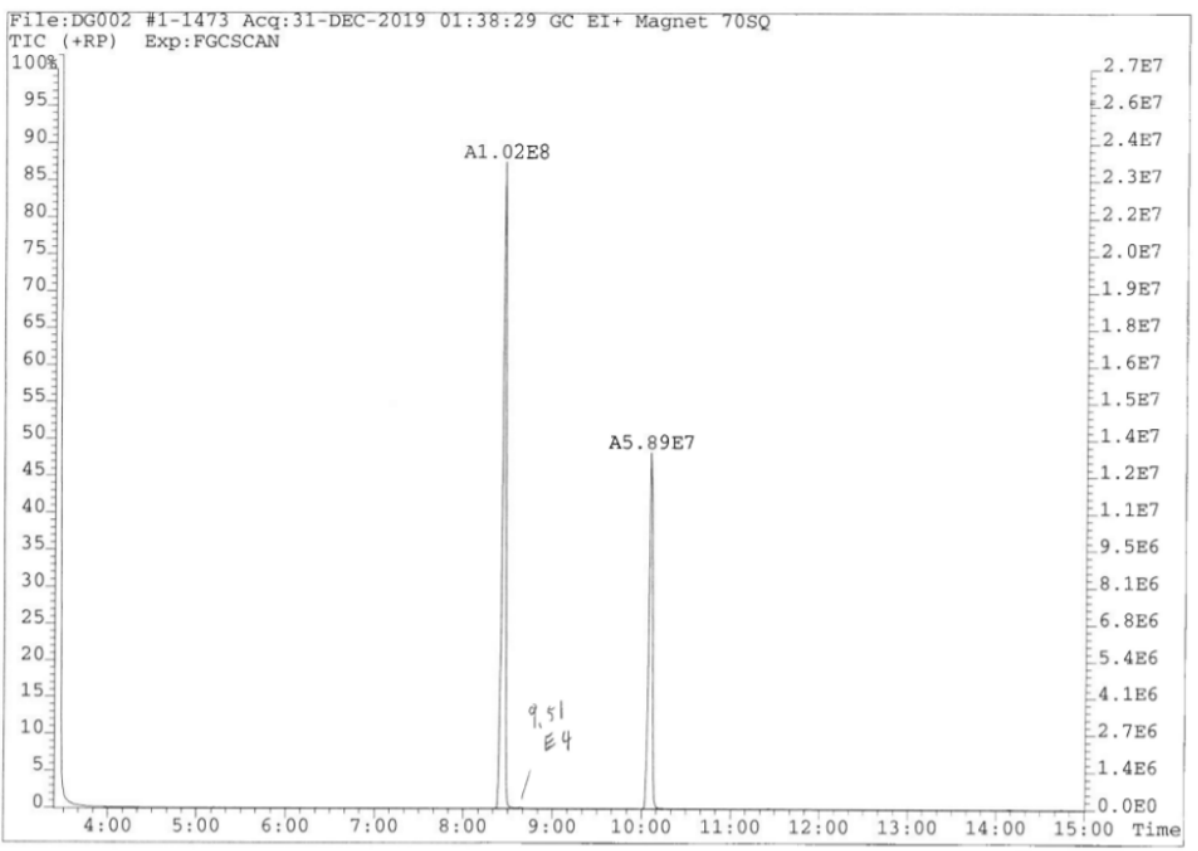

Figure S73. Gas chromatogram from GC/MS data taken on selective loading from a 1 to $1 o$-xylene/ $p$-xylene mixture (4 mL) using $5 \mathrm{mg}$ of crystalline $\mathbf{1}$ (trial 2).

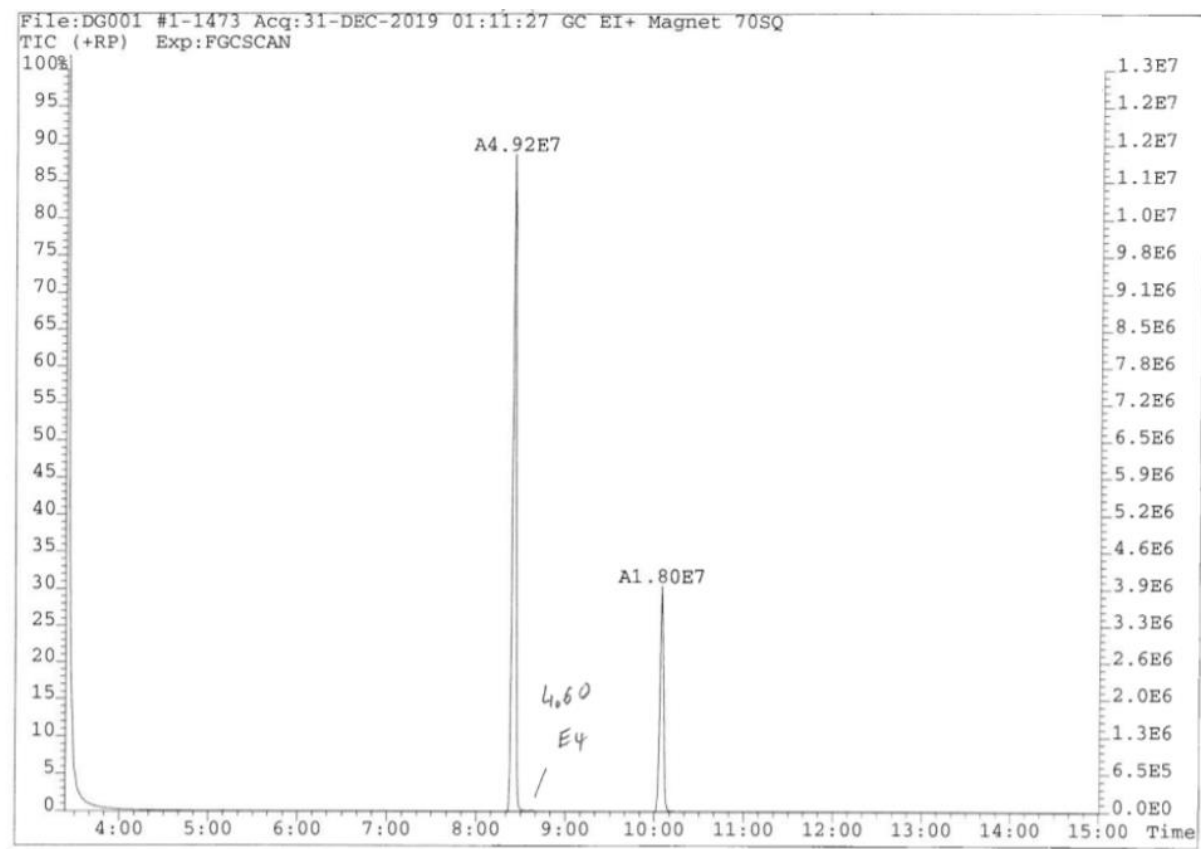

Figure S74. Gas chromatogram from GC/MS data taken on selective loading from a 1 to $1 o$-xylene $/ p$-xylene mixture (4 mL) using $5 \mathrm{mg}$ of crystalline $\mathbf{1}$ (trial 3). 


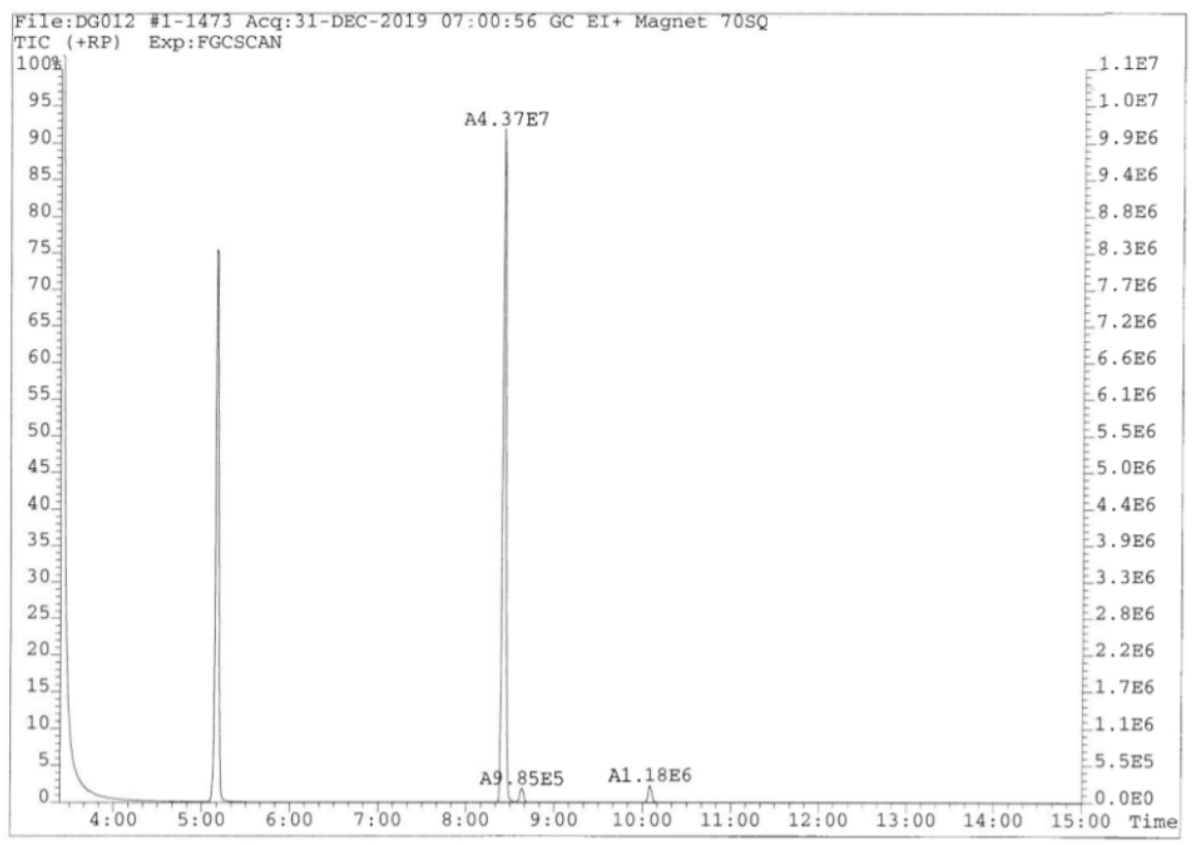

Figure S75. Gas chromatogram from GC/MS data taken on selective loading from a 1 to $3 o$-xylene/ $p$-xylene mixture ( $4 \mathrm{~mL}$ ) using $5 \mathrm{mg}$ of crystalline $\mathbf{1}$ (trial 1 ).

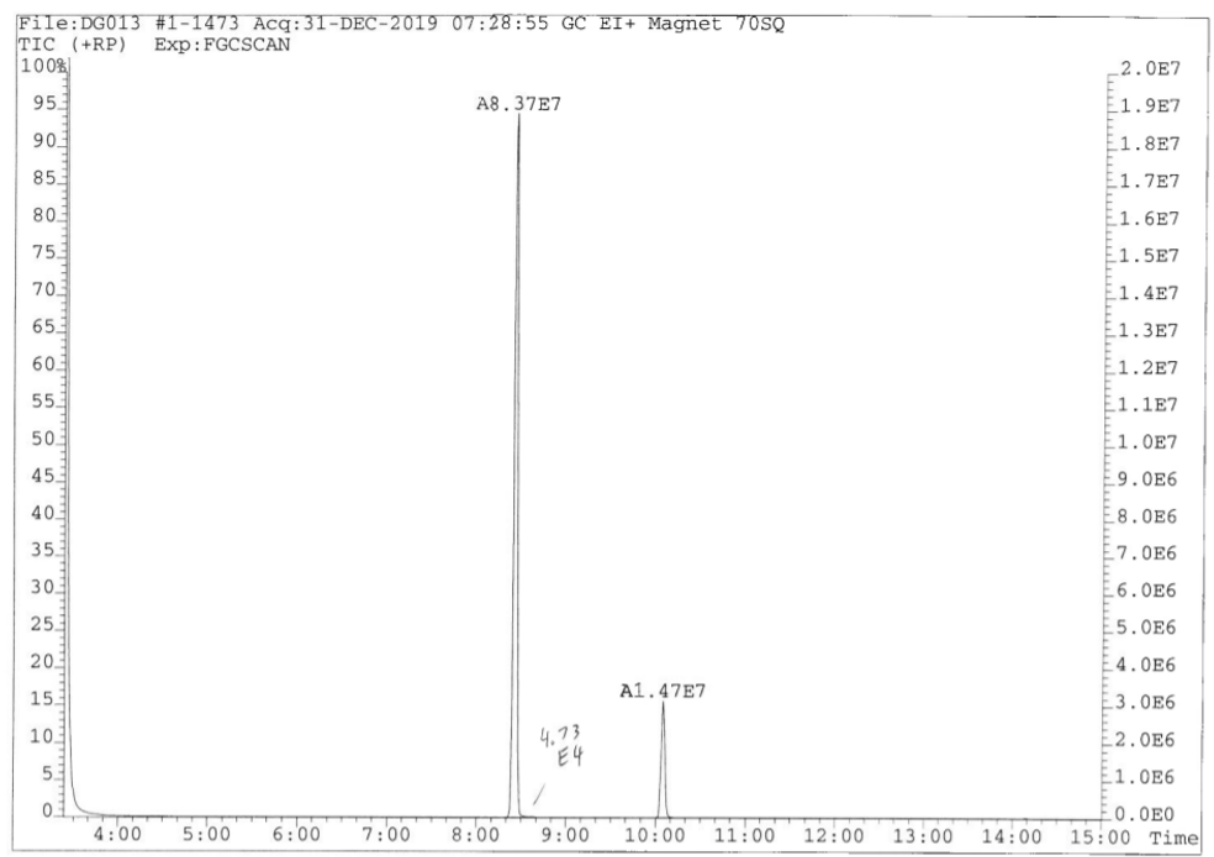

Figure S76. Gas chromatogram from GC/MS data taken on selective loading from a 1 to $3 o$-xylene/ $p$-xylene mixture (4 mL) using $5 \mathrm{mg}$ of crystalline $\mathbf{1}$ (trial 2). 


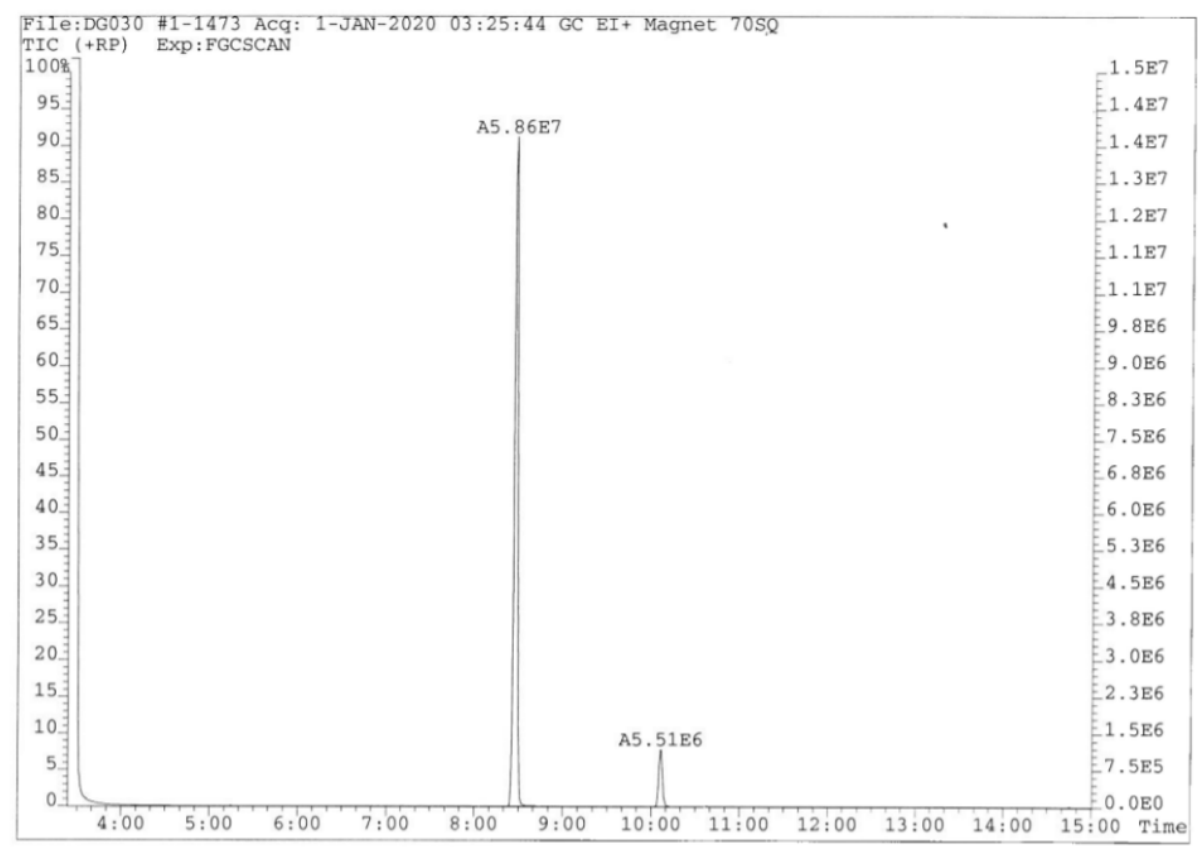

Figure S77. Gas chromatogram from GC/MS data taken on selective loading from a 1 to $3 o$-xylene/ $p$-xylene mixture (4 mL) using $5 \mathrm{mg}$ of crystalline $\mathbf{1}$ (trial 3).

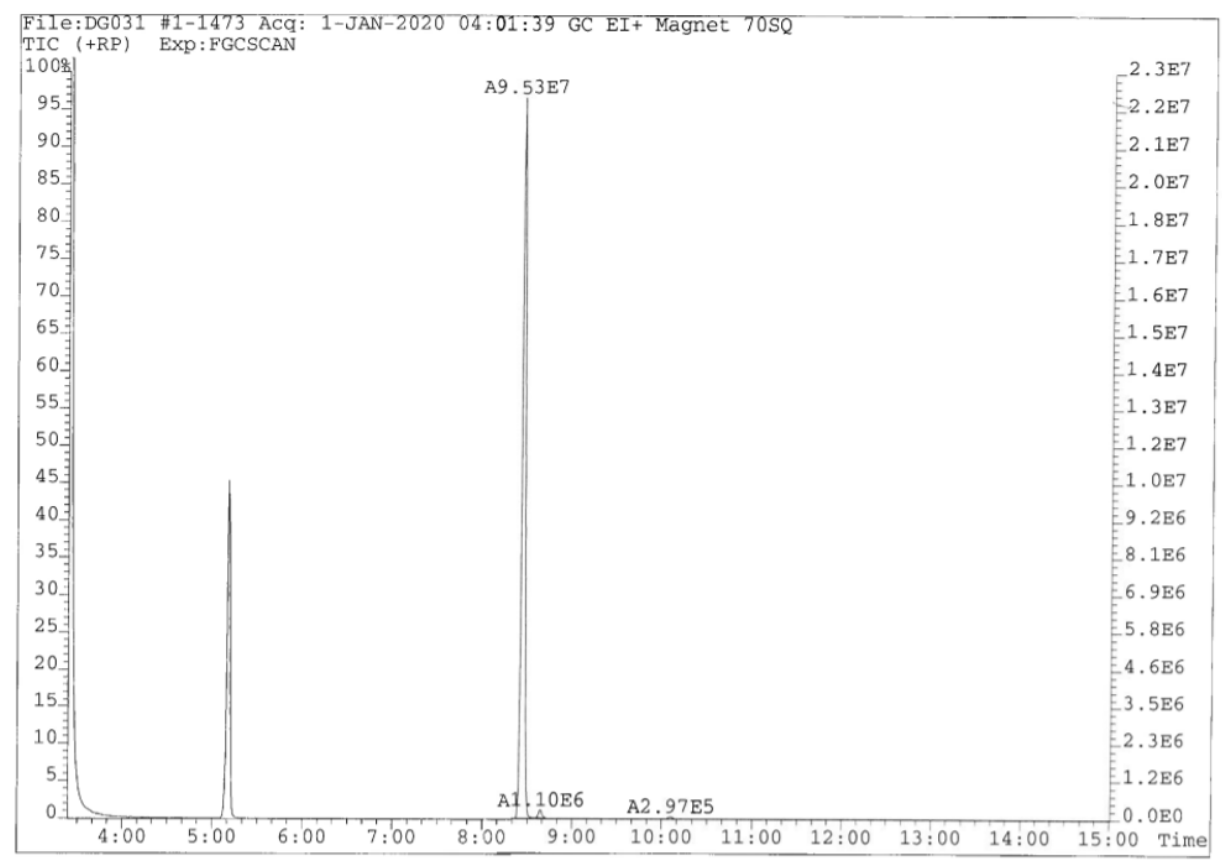

Figure S78. Gas chromatogram from GC/MS data taken on selective loading from a 1 to $99 o$-xylene/ $p$-xylene mixture (4 mL) using $5 \mathrm{mg}$ of crystalline $\mathbf{1}$ (trial 1). 


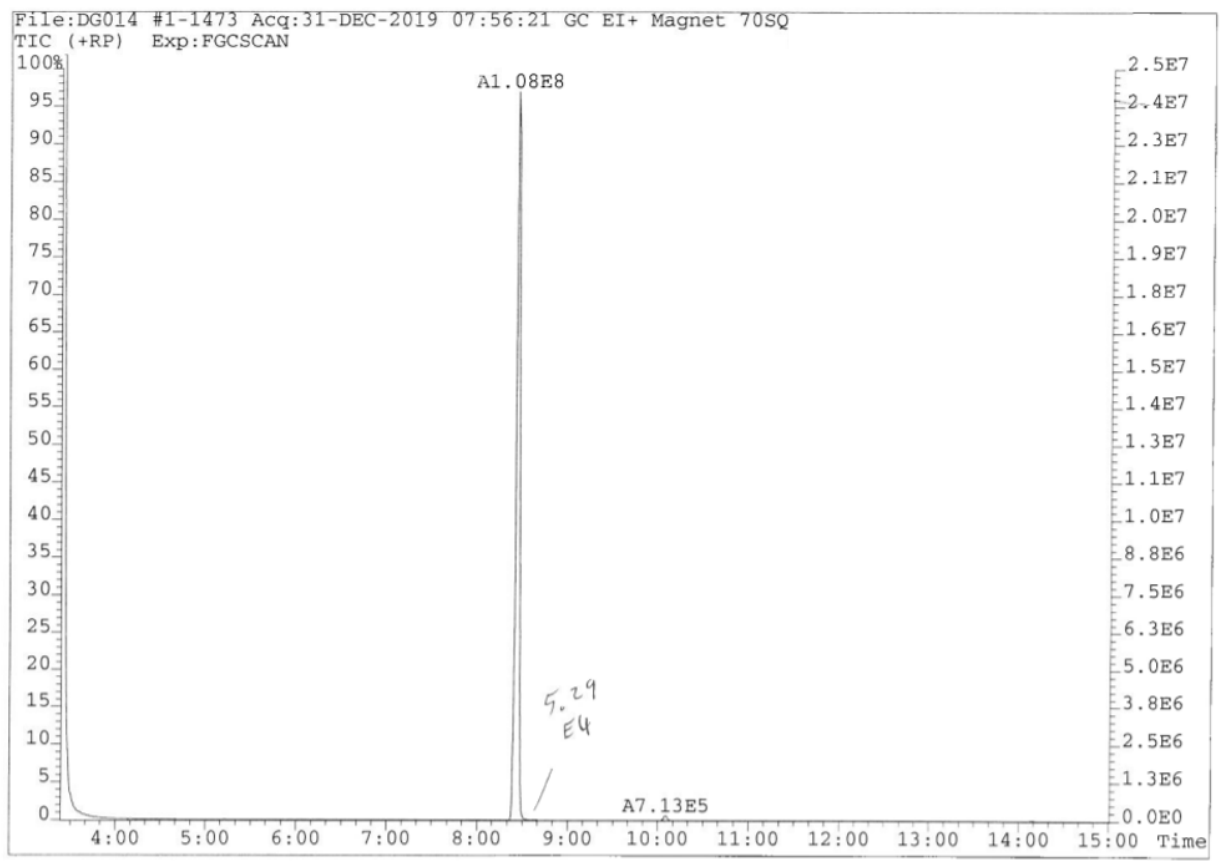

Figure S79. Gas chromatogram from GC/MS data taken on selective loading from a 1 to $99 o$-xylene/ $p$-xylene mixture (4 mL) using $5 \mathrm{mg}$ of crystalline $\mathbf{1}$ (trial 2).

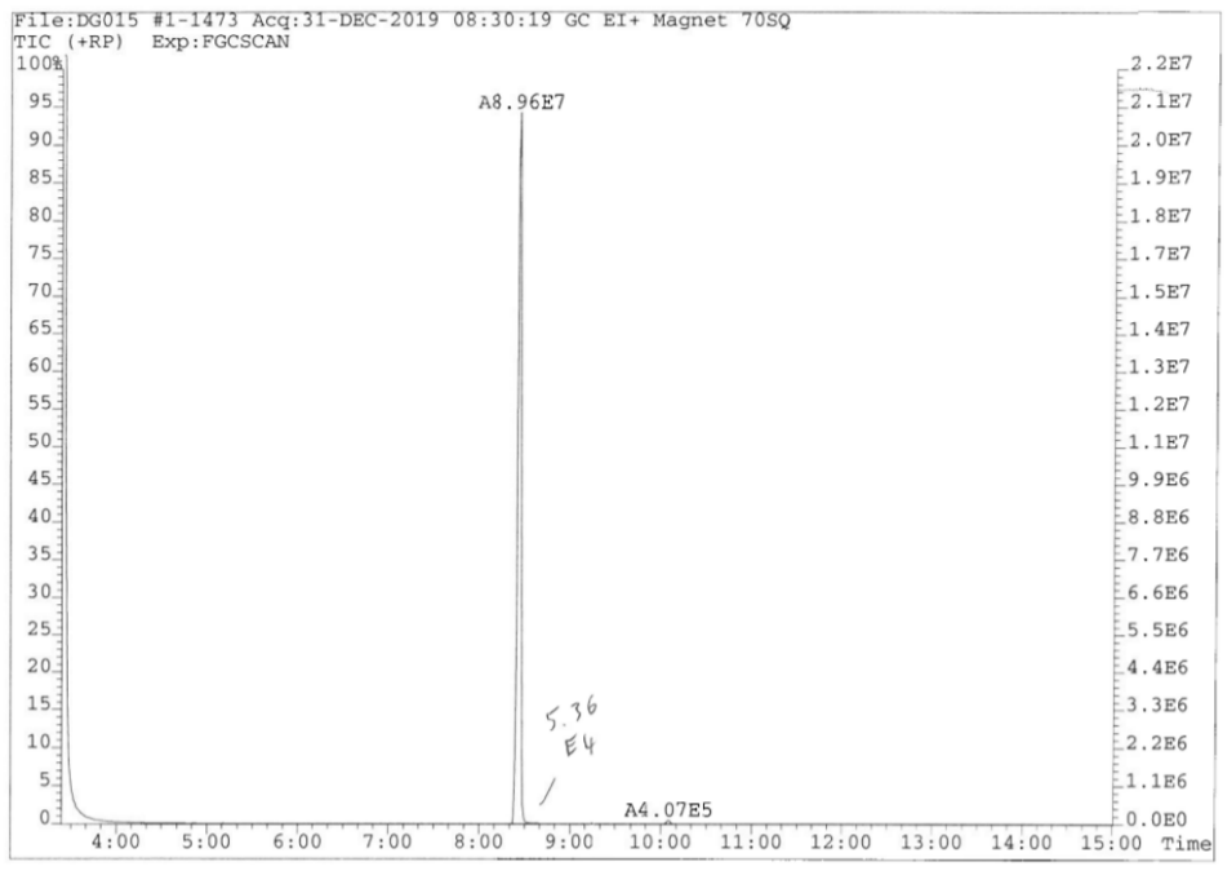

Figure S80. Gas chromatogram from GC/MS data taken on selective loading from a 1 to $99 o$-xylene/ $p$-xylene mixture ( $4 \mathrm{~mL}$ ) using $5 \mathrm{mg}$ of crystalline $\mathbf{1}$ (trial 3). 


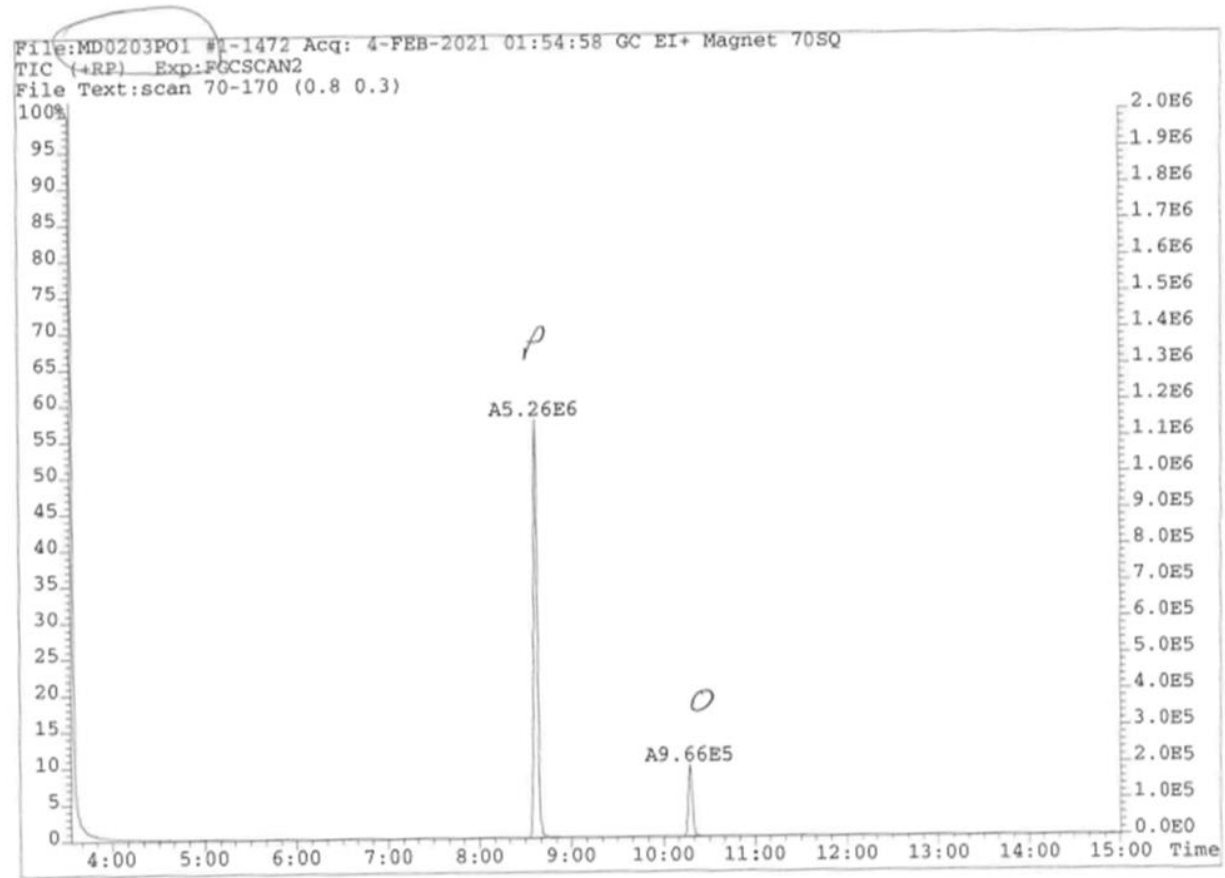

Figure S81. Gas chromatogram from GC/MS data taken on selective loading from a 1:1 $o$-xylene/ $p$-xylene mixture (4 mL) using $5 \mathrm{mg}$ of crystalline $\mathbf{1}$ (Different batch).

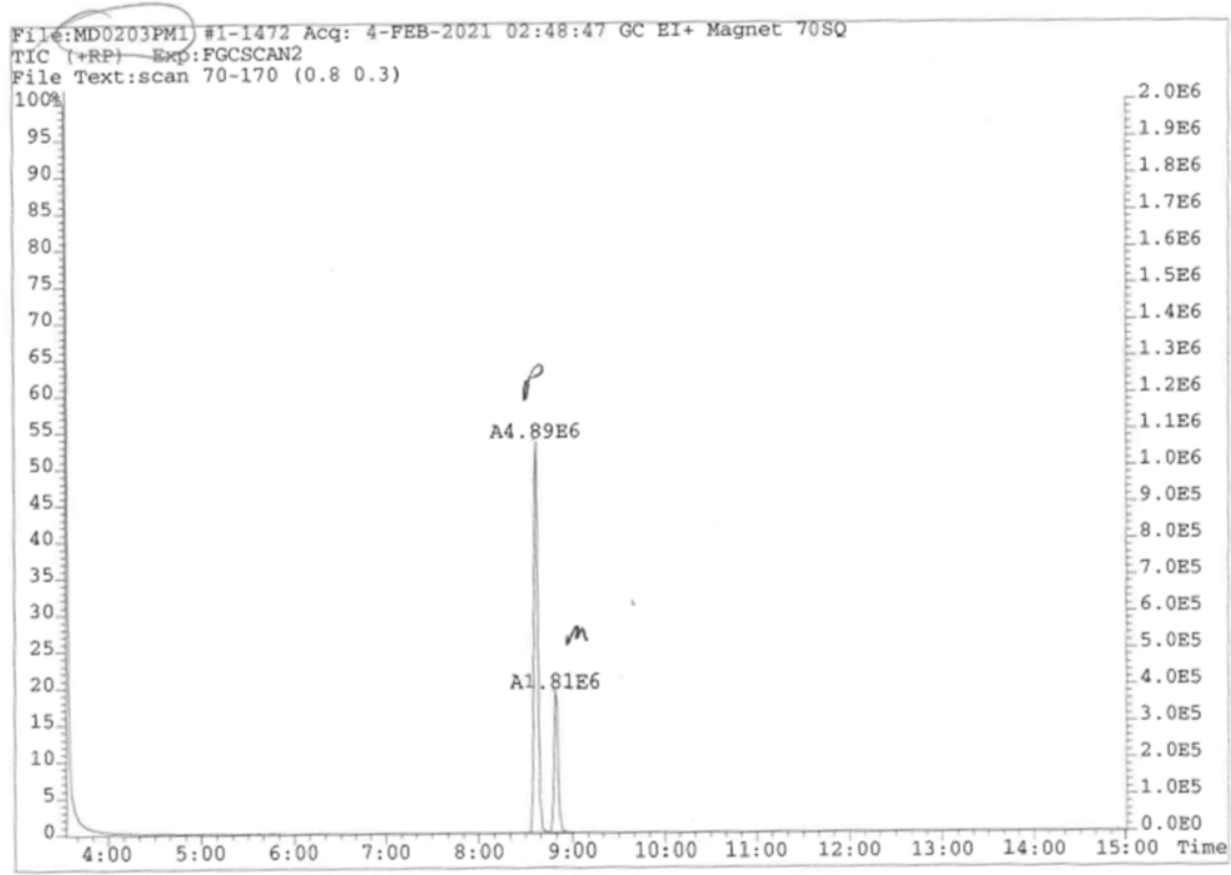

Figure S82. Gas chromatogram from GC/MS data taken on selective loading from a 1:1 m-xylene $/ p$-xylene mixture (4 mL) using $5 \mathrm{mg}$ of crystalline 1 (Different batch). 


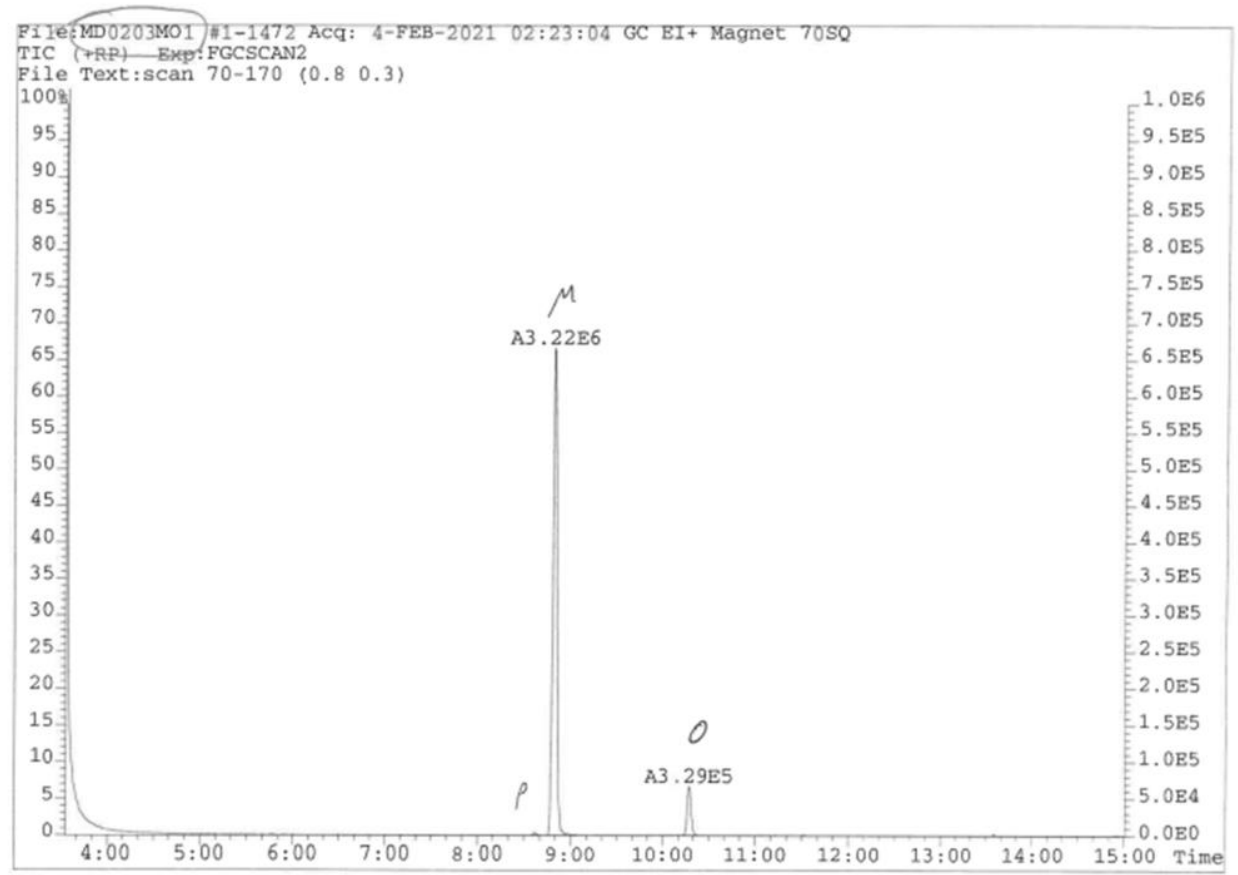

Figure S83. Gas chromatogram from GC/MS data taken on selective loading from a 1:1 $o$-xylene $/ \mathrm{m}$-xylene mixture ( $4 \mathrm{~mL}$ ) using $5 \mathrm{mg}$ of crystalline $\mathbf{1}$ (Different batch).

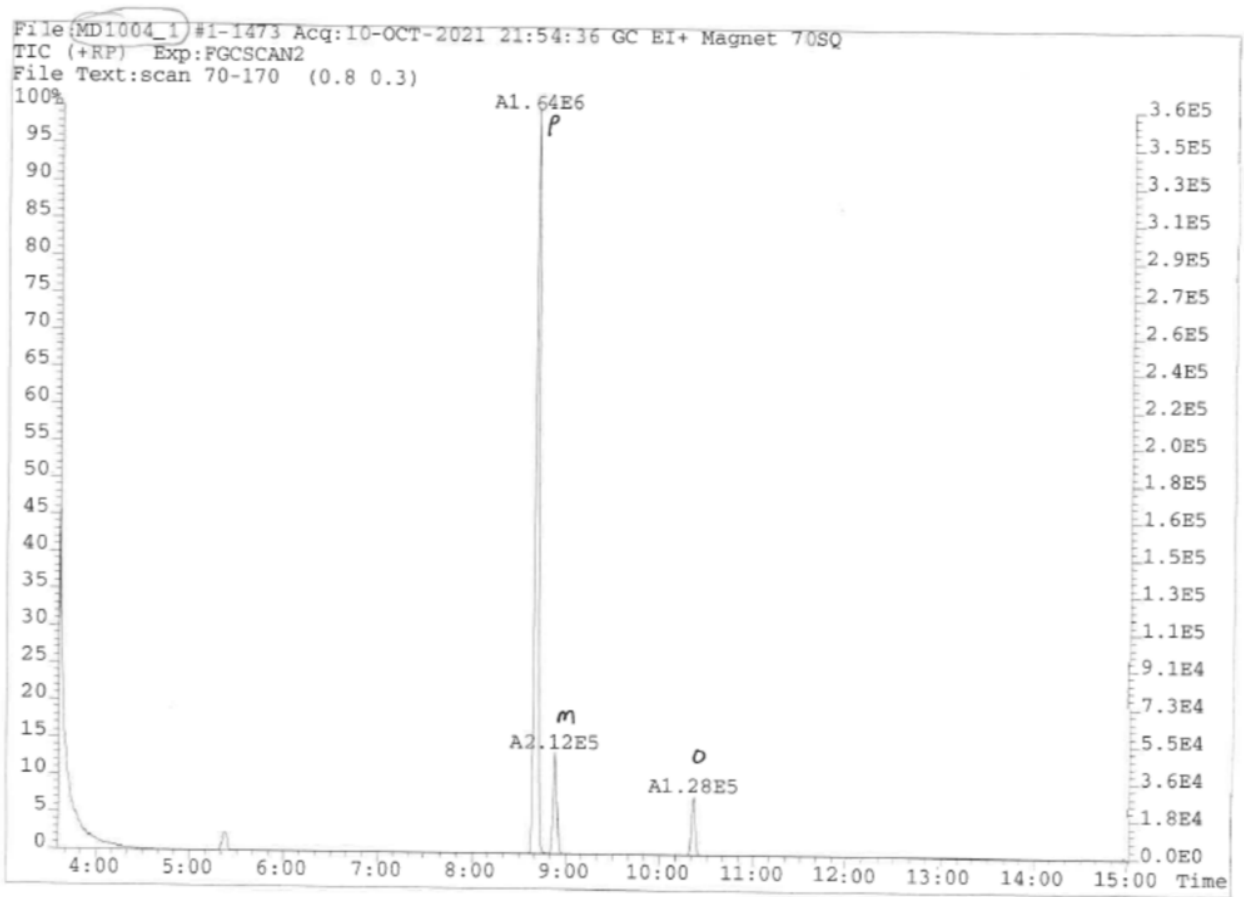

Figure S84. Gas chromatogram from GC/MS data taken on selective loading from a 1:1:1 mixture of $p$-xylene/oxylene $/ \mathrm{m}$-xylene mixture $(3 \mathrm{~mL}$ ) using $5 \mathrm{mg}$ of crystalline $\mathbf{1}$ (trial 1 ). 


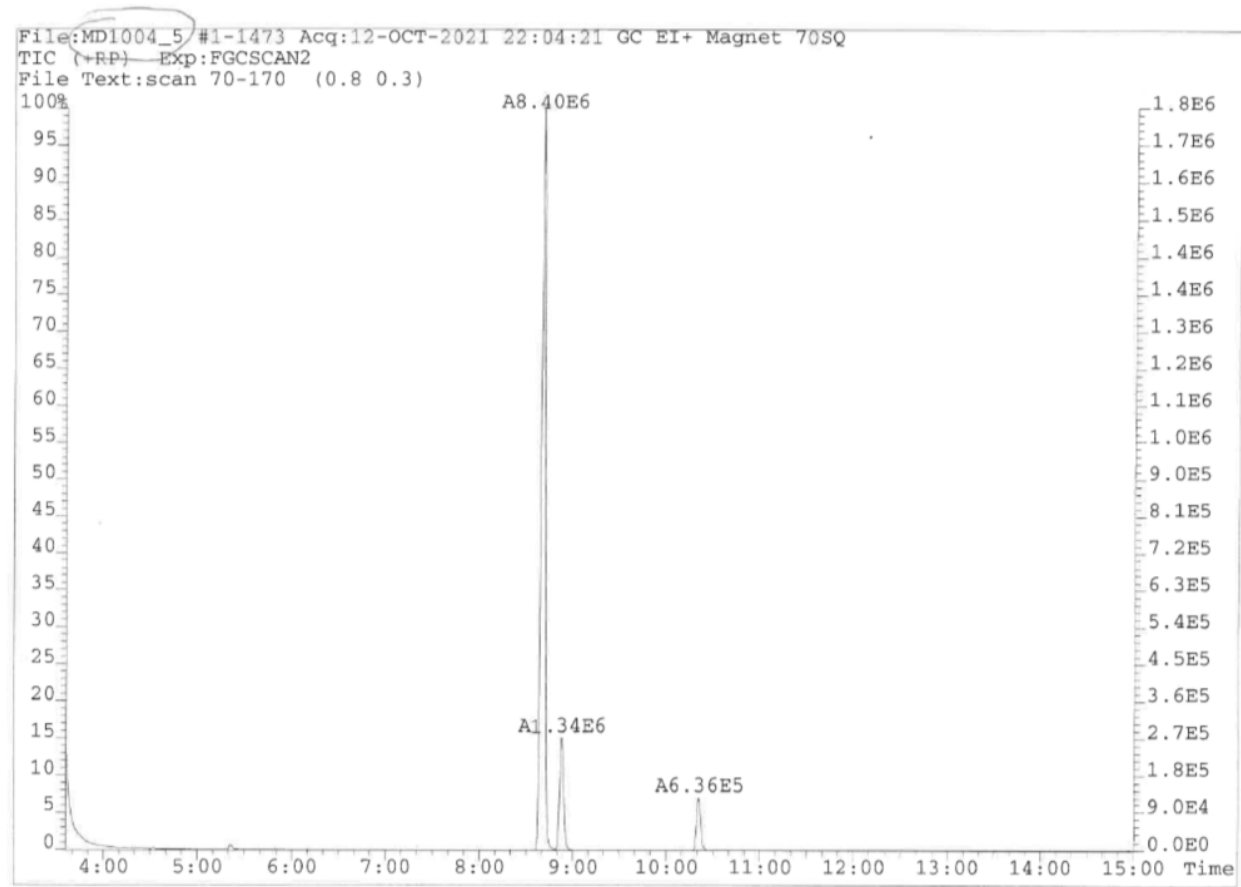

Figure S85. Gas chromatogram from GC/MS data taken on selective loading from a 1:1:1 mixture of $p$-xylene/oxylene $/ \mathrm{m}$-xylene mixture ( $3 \mathrm{~mL}$ ) using $5 \mathrm{mg}$ of crystalline $\mathbf{1}$ (trial 2 ).

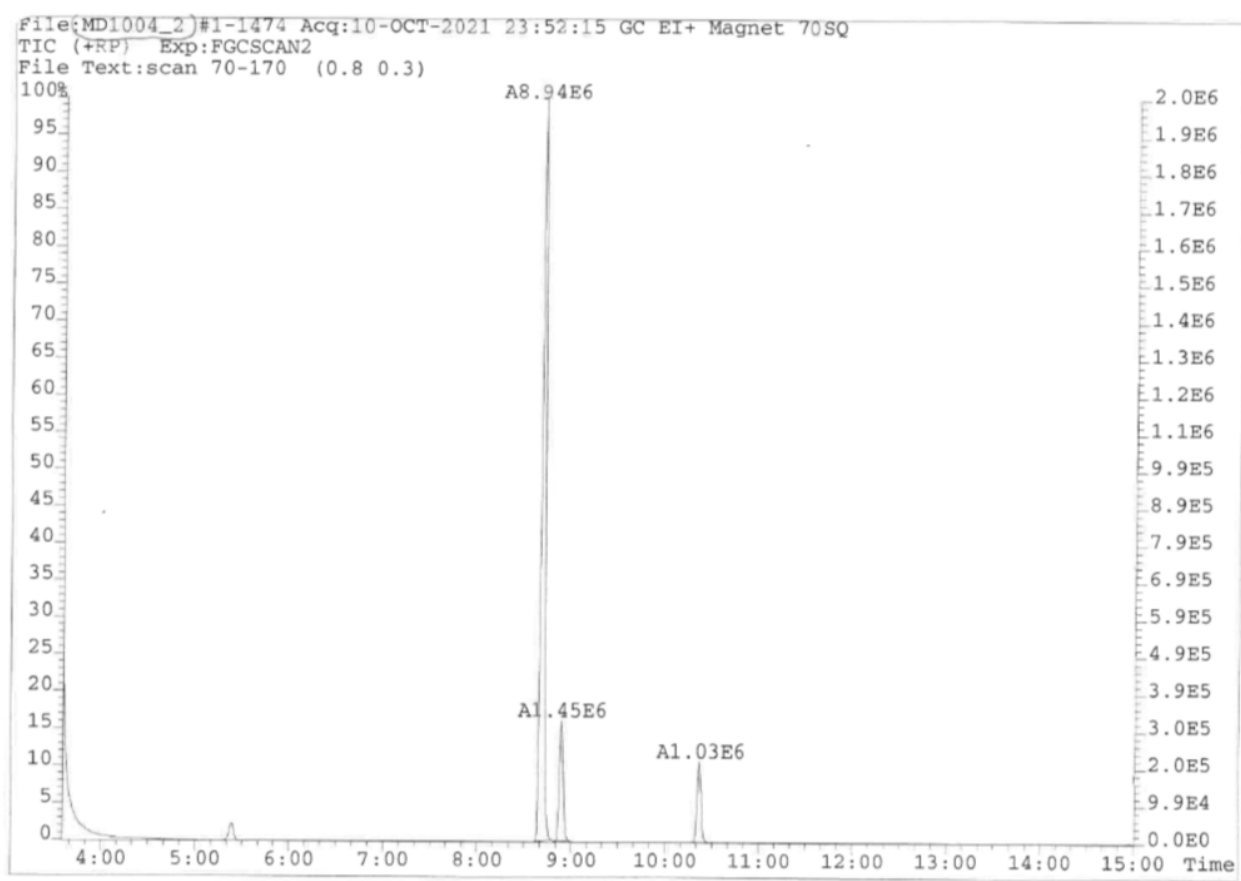

Figure S86. Gas chromatogram from GC/MS data taken on selective loading from a 1:1:1 mixture of $p$-xylene/oxylene $/ \mathrm{m}$-xylene mixture ( $3 \mathrm{~mL}$ ) using $5 \mathrm{mg}$ of crystalline $\mathbf{1}$ (trial 3 ). 


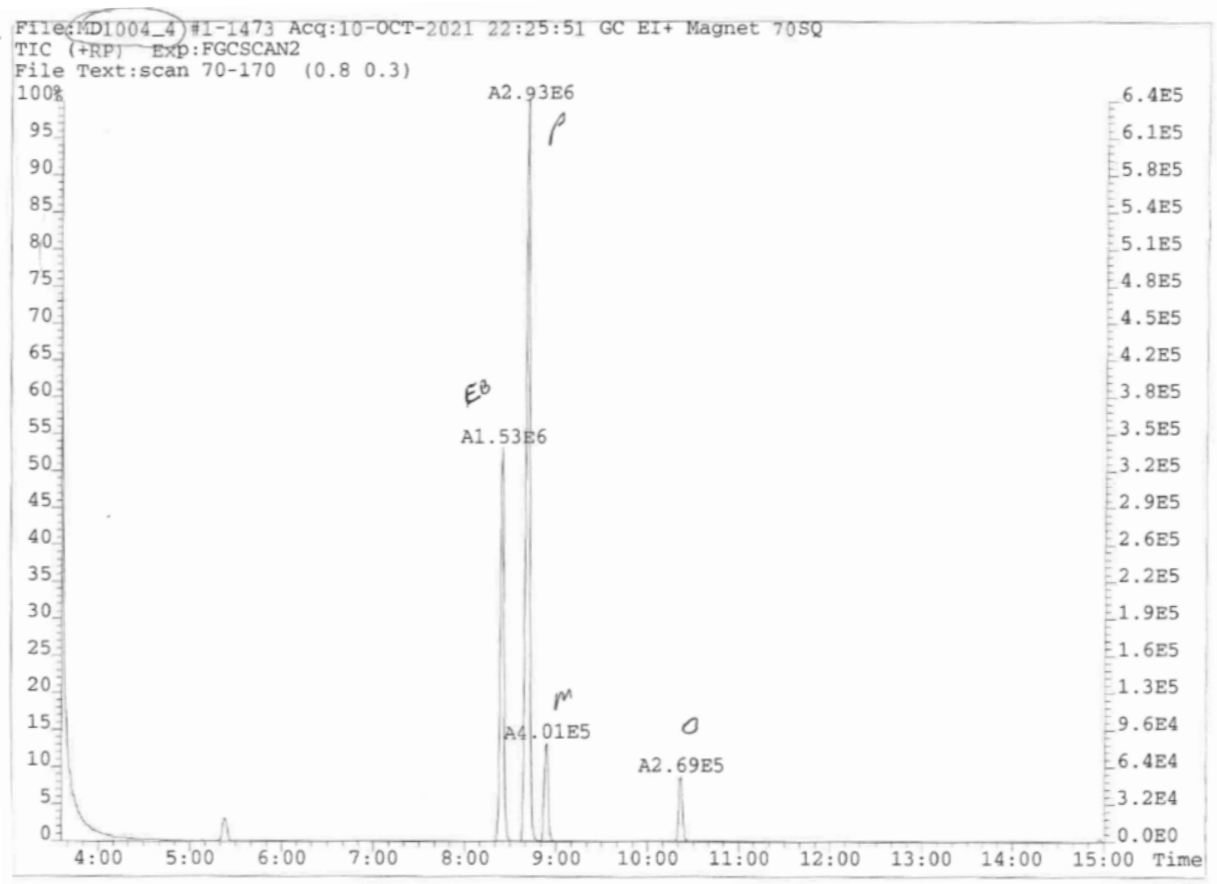

Figure S87. Gas chromatogram from GC/MS data taken on selective loading from a 1:1:1:1 mixture of $p$-xylene/oxylene/ $m$-xylene/ethyl benzene mixture ( $4 \mathrm{~mL}$ ) using $5 \mathrm{mg}$ of crystalline $\mathbf{1}$.

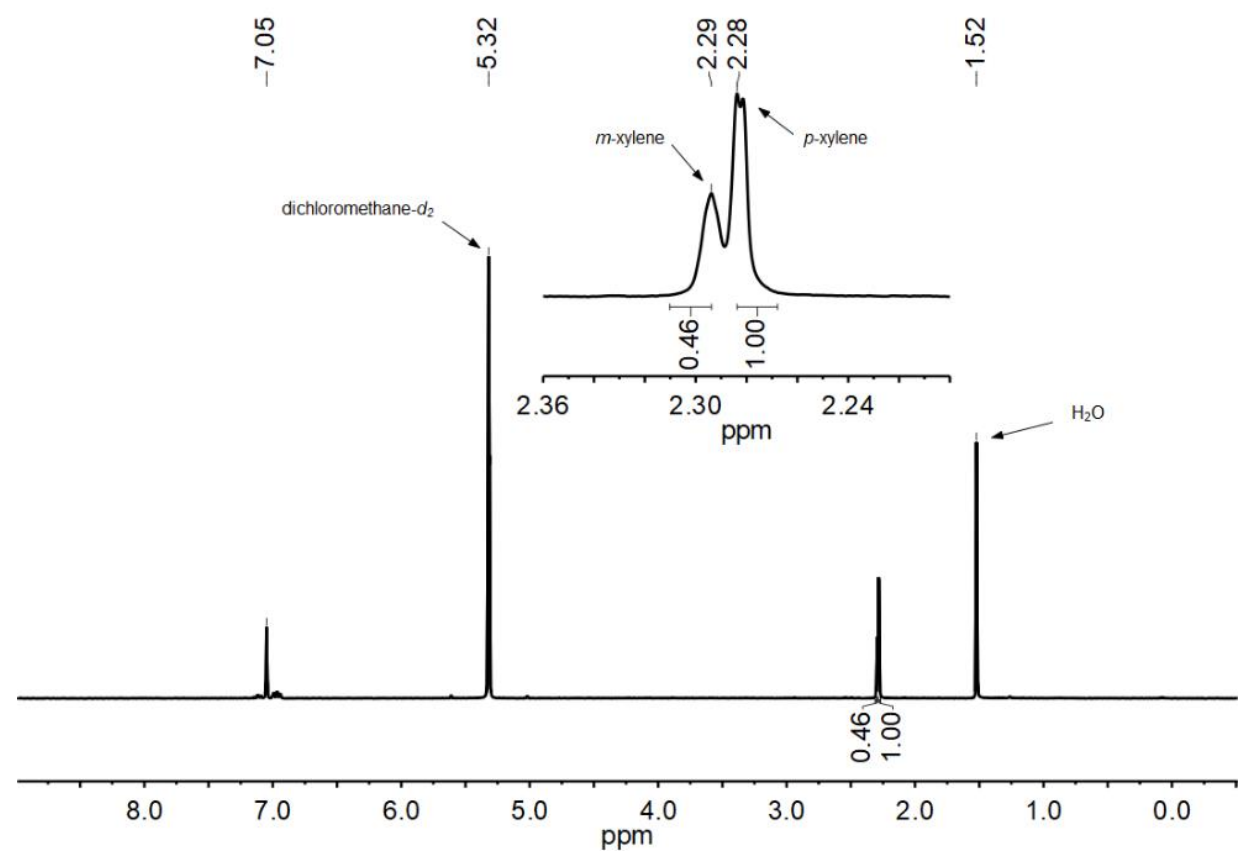

Figure S88. ${ }^{1} \mathrm{H}$ NMR taken on selective loading from a 99 to $1 \mathrm{~m}$-xylene/ $p$-xylene mixture (4 mL) using $5 \mathrm{mg}$ of crystalline 1 suggesting $\sim 32 \% m$-xylene loading. 


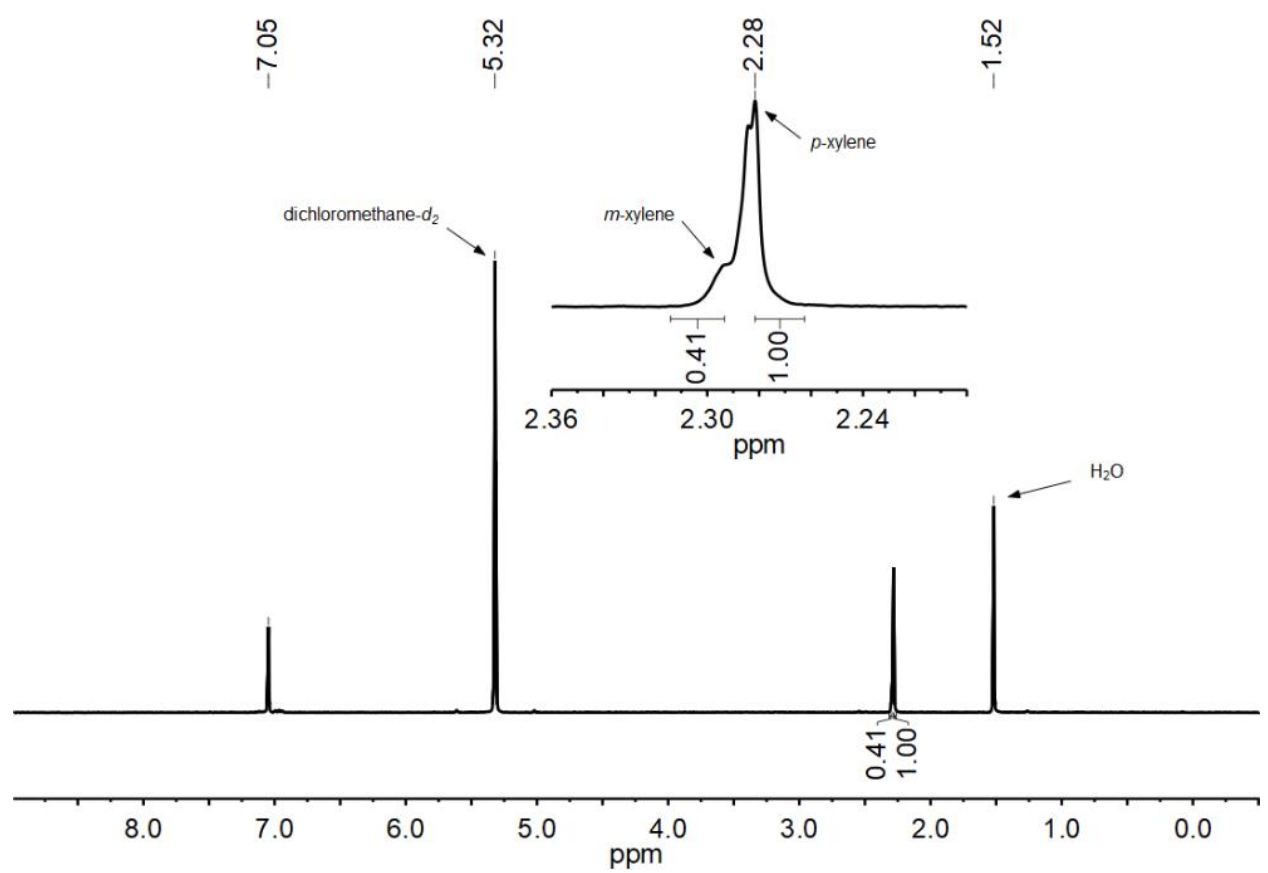

Figure S89. ${ }^{1} \mathrm{H}$ NMR taken on selective loading from a 4 to $1 \mathrm{~m}$-xylene/p-xylene mixture (4 mL) using $5 \mathrm{mg}$ of crystalline 1 suggesting $\sim 29 \% m$-xylene loading.

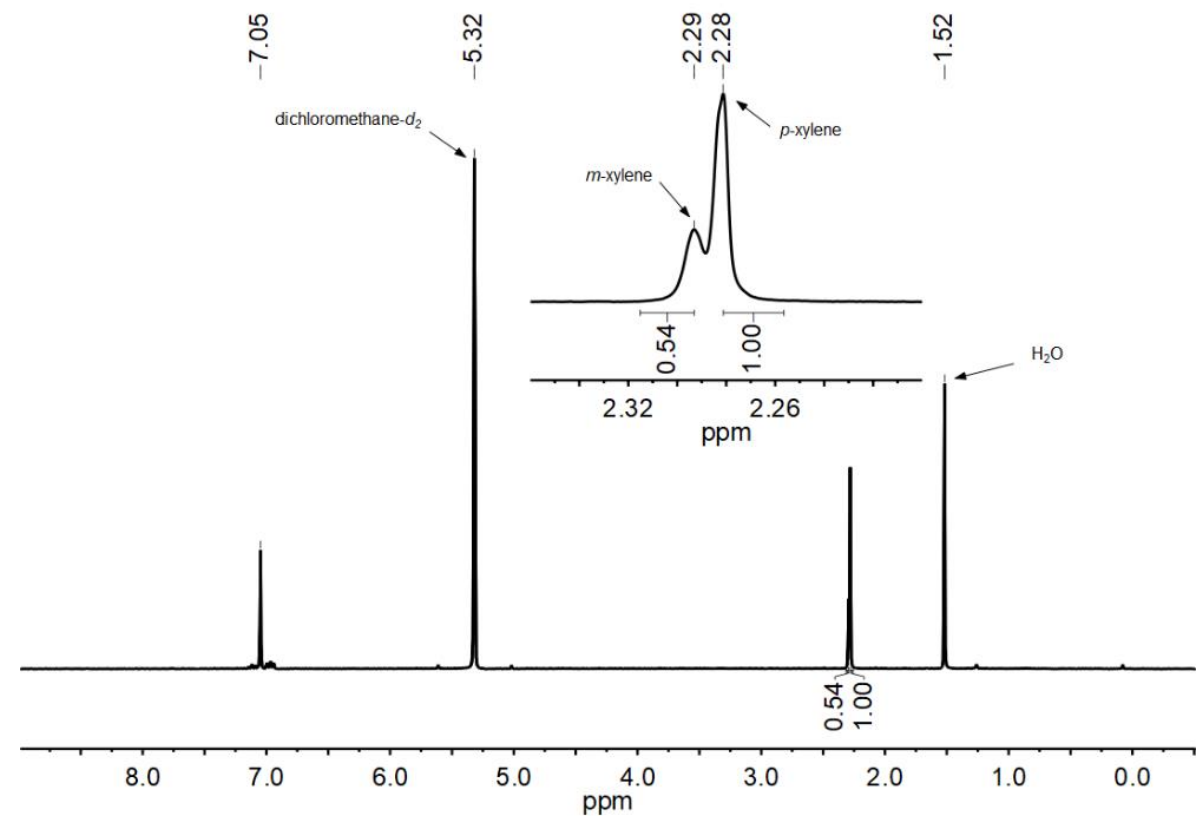

Figure S90. ${ }^{1} \mathrm{H}$ NMR taken on selective loading from a 2 to $1 \mathrm{~m}$-xylene $/ p$-xylene mixture (4 mL) using $5 \mathrm{mg}$ of crystalline 1 suggesting $\sim 35 \% m$-xylene loading. 


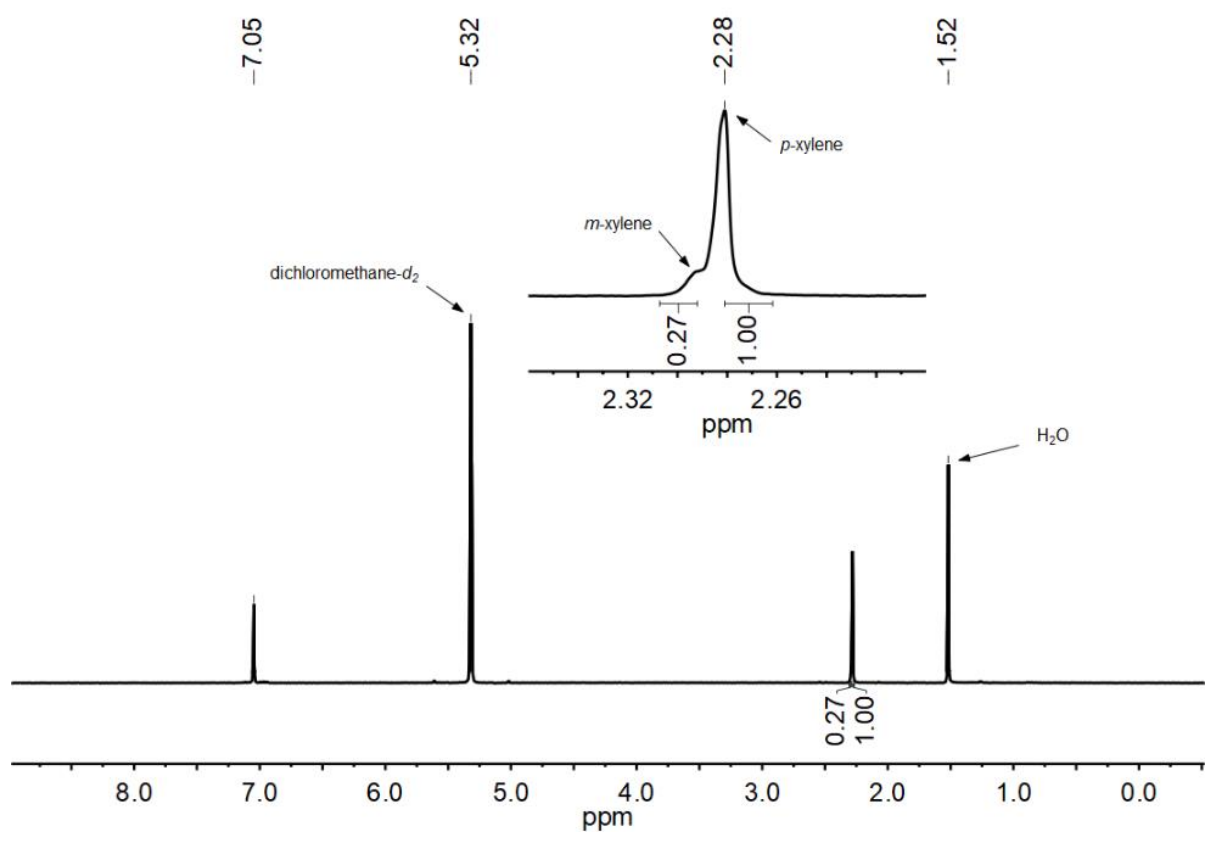

Figure S91. ${ }^{1} \mathrm{H}$ NMR taken on selective loading from a 1 to $3 \mathrm{~m}$-xylene/ $p$-xylene mixture (4 mL) using $5 \mathrm{mg}$ of crystalline 1 suggesting $\sim 21 \% \mathrm{~m}$-xylene loading.

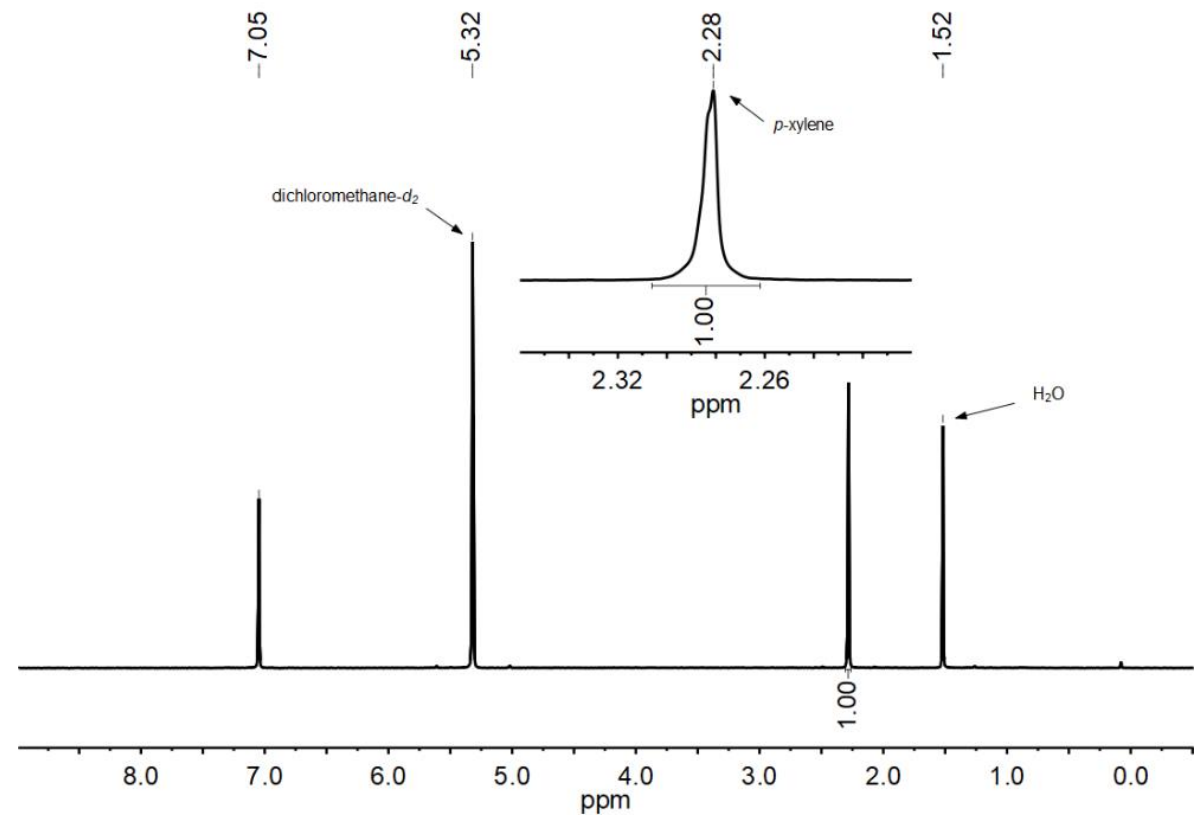

Figure S92. ${ }^{1} \mathrm{H}$ NMR taken on selective loading from a 1 to $99 \mathrm{~m}$-xylene/ $p$-xylene mixture (4 mL) using $5 \mathrm{mg}$ of crystalline 1 suggesting $100 \% p$-xylene loading. 


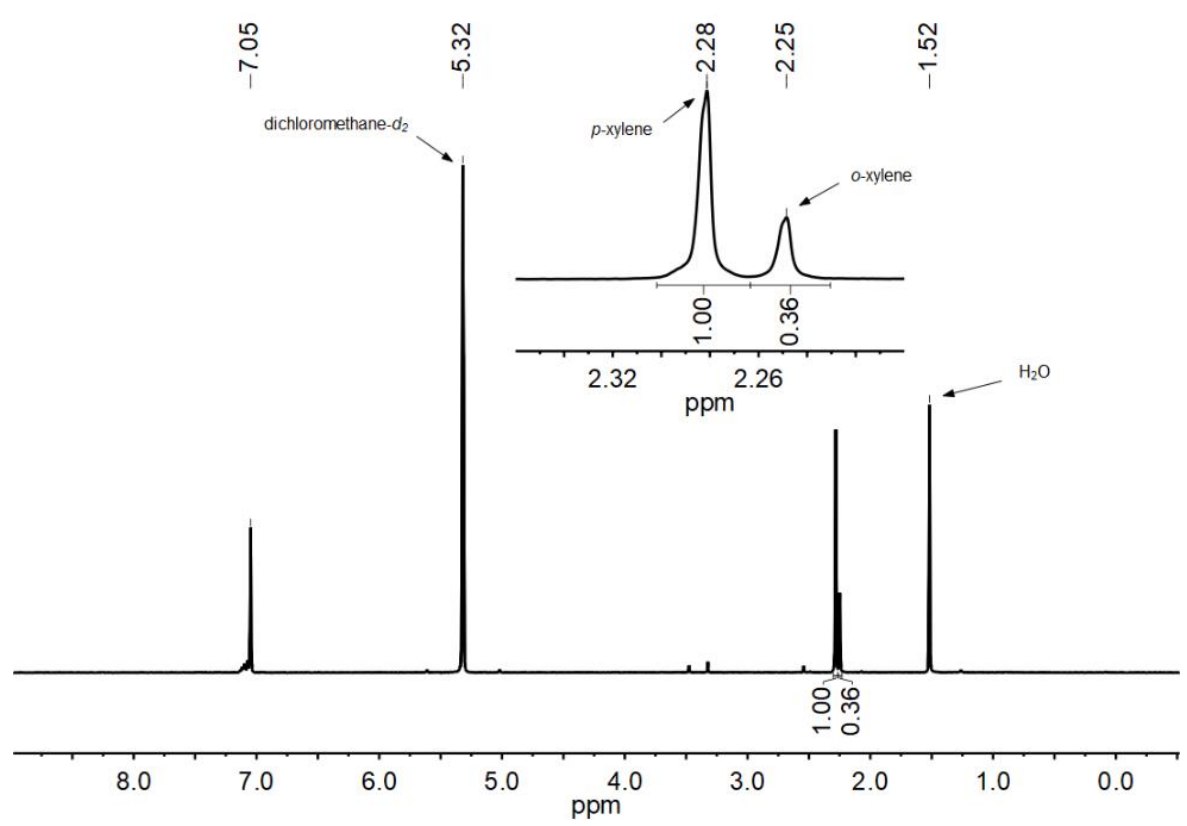

Figure S93. ${ }^{1} \mathrm{H}$ NMR taken on selective loading from a 99 to $1 o$-xylene/ $p$-xylene mixture (4 mL) using $5 \mathrm{mg}$ of crystalline 1 suggesting $\sim 26 \% o$-xylene loading.

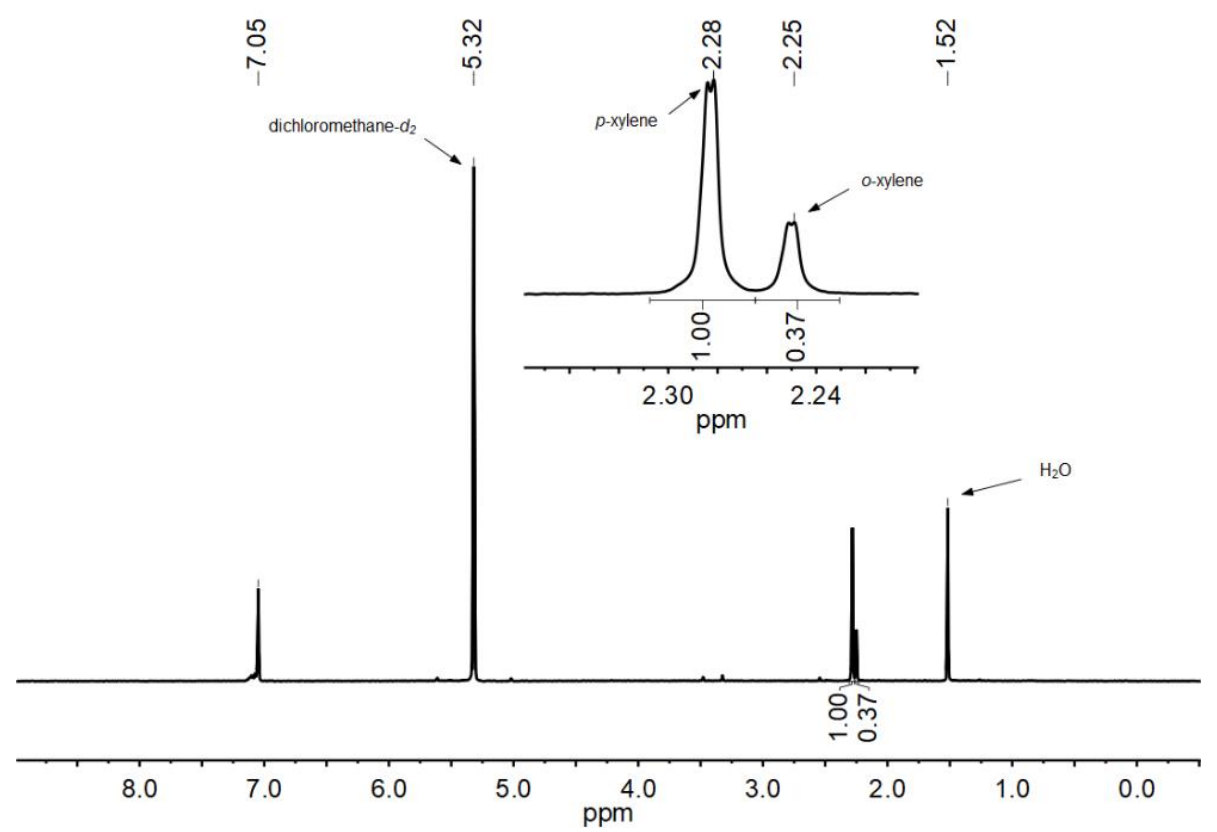

Figure S94. ${ }^{1} \mathrm{H}$ NMR taken on selective loading from a 3 to $1 o$-xylene/p-xylene mixture (4 mL) using $5 \mathrm{mg}$ of crystalline 1 suggesting $\sim 27 \% o$-xylene loading. 


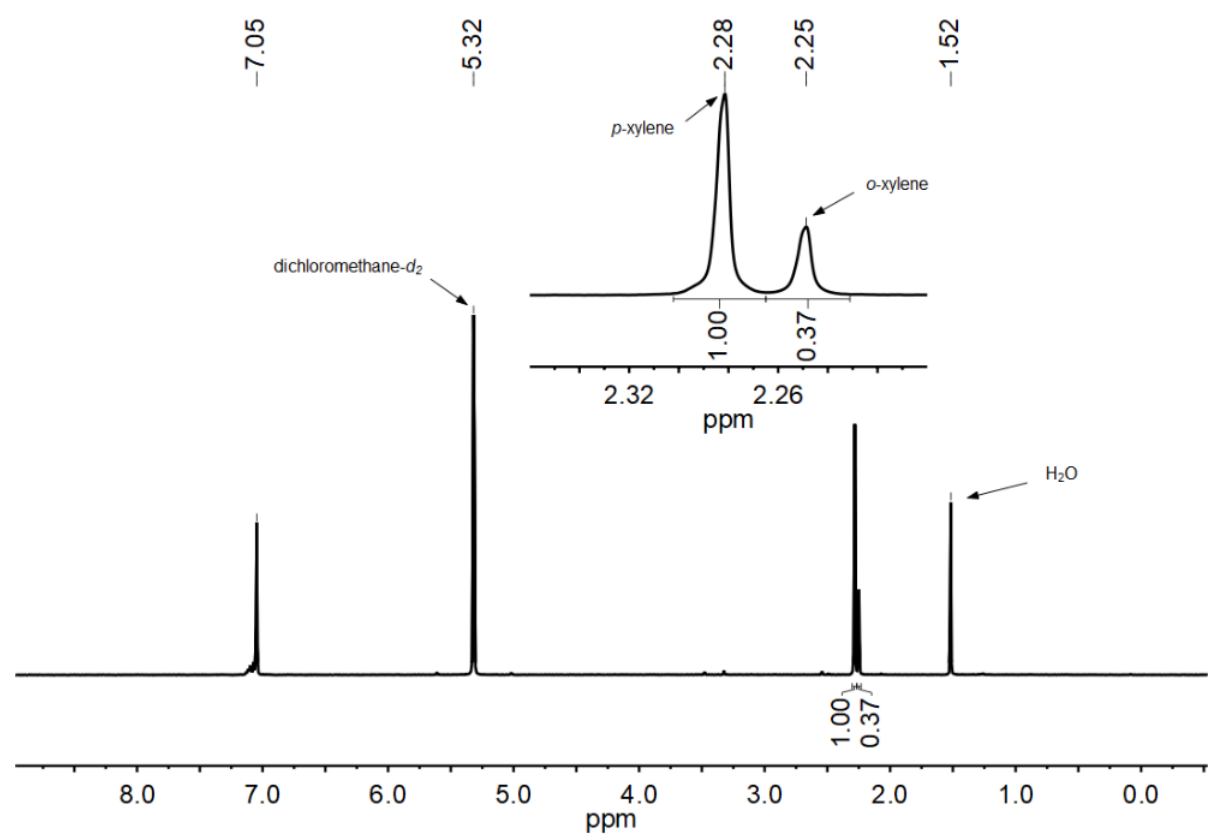

Figure S95. ${ }^{1} \mathrm{H}$ NMR taken on selective loading from a 1 to $1 o$-xylene/p-xylene mixture (4 mL) using $5 \mathrm{mg}$ of crystalline 1 suggesting $27 \% o$-xylene loading.

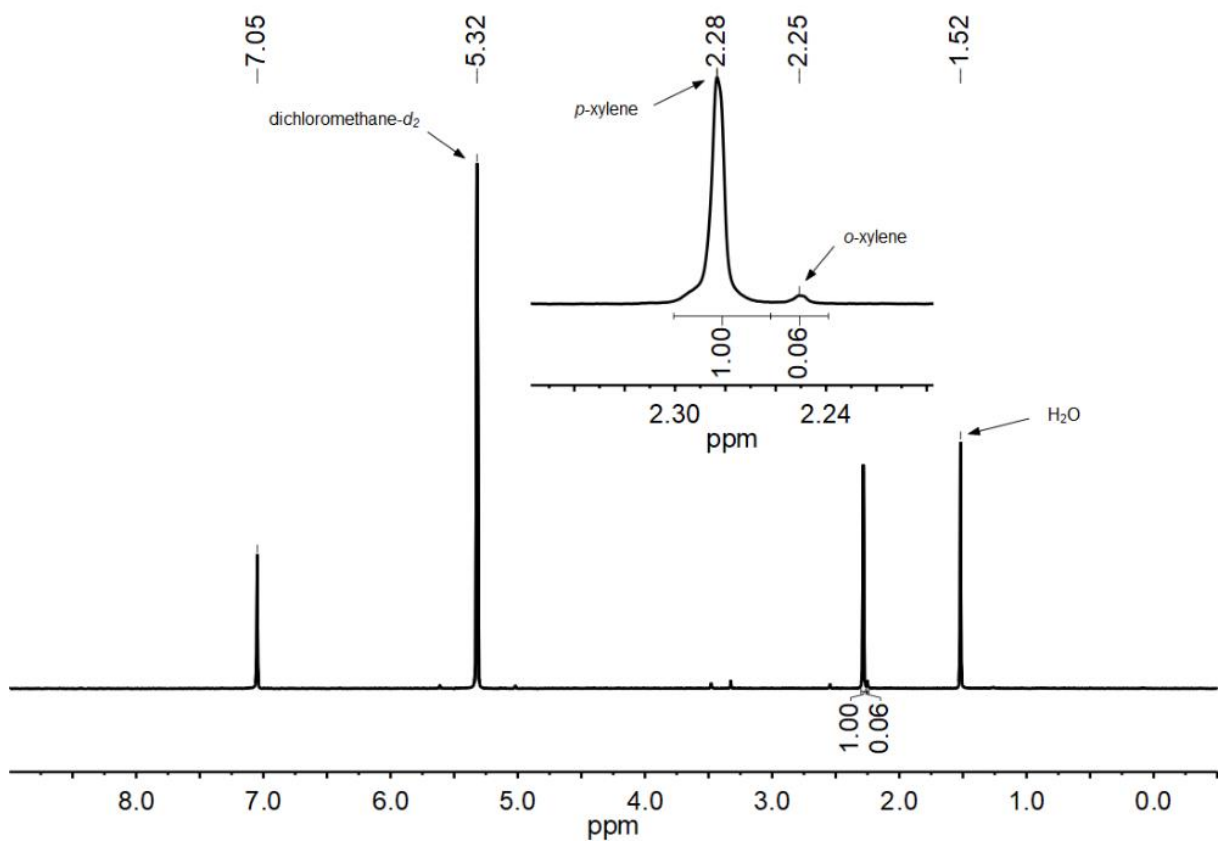

Figure S96. ${ }^{1} \mathrm{H}$ NMR taken on selective loading from a 1 to $3 o$-xylene/ $p$-xylene mixture (4 mL) using $5 \mathrm{mg}$ of crystalline 1 suggesting $\sim 6 \% o$-xylene loading. 


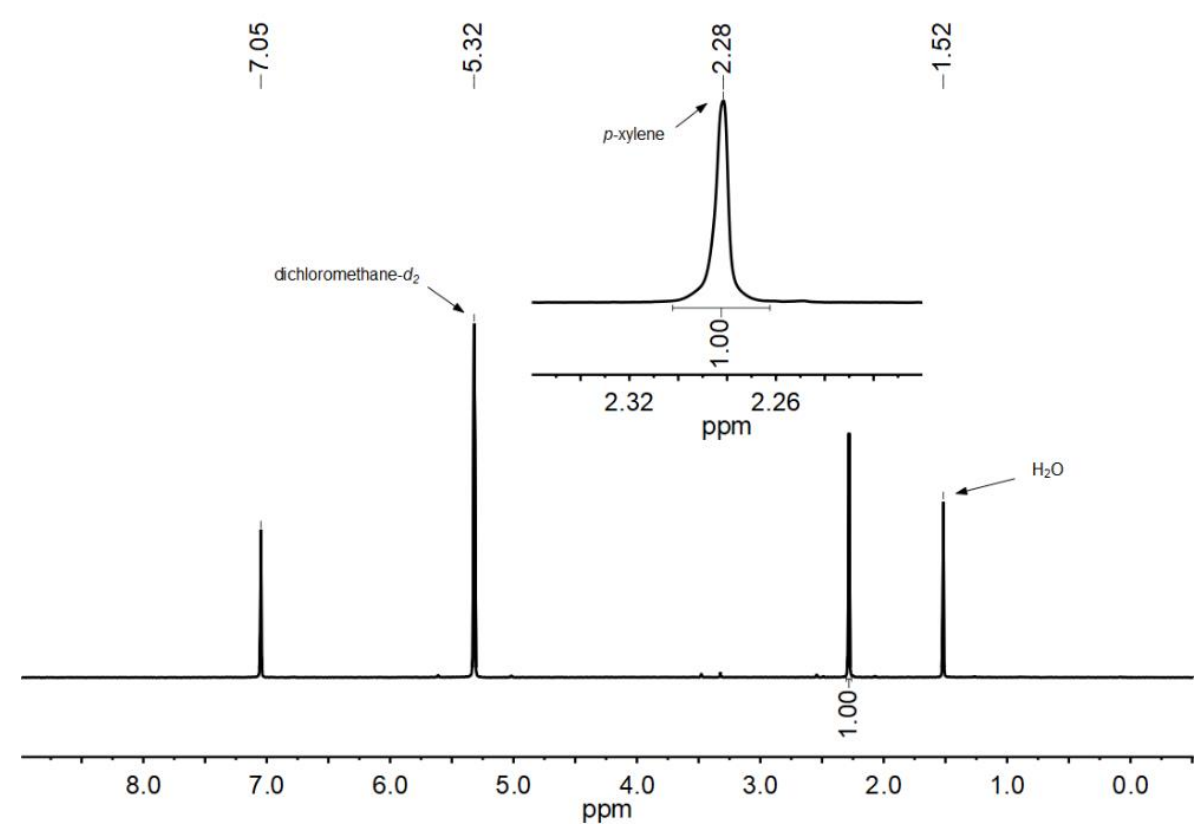

Figure S97. ${ }^{1} \mathrm{H}$ NMR taken on selective loading from a 1 to $99 o$-xylene/p-xylene mixture (4 mL) using $5 \mathrm{mg}$ of crystalline 1 suggesting $\sim 100 \% p$-xylene loading.

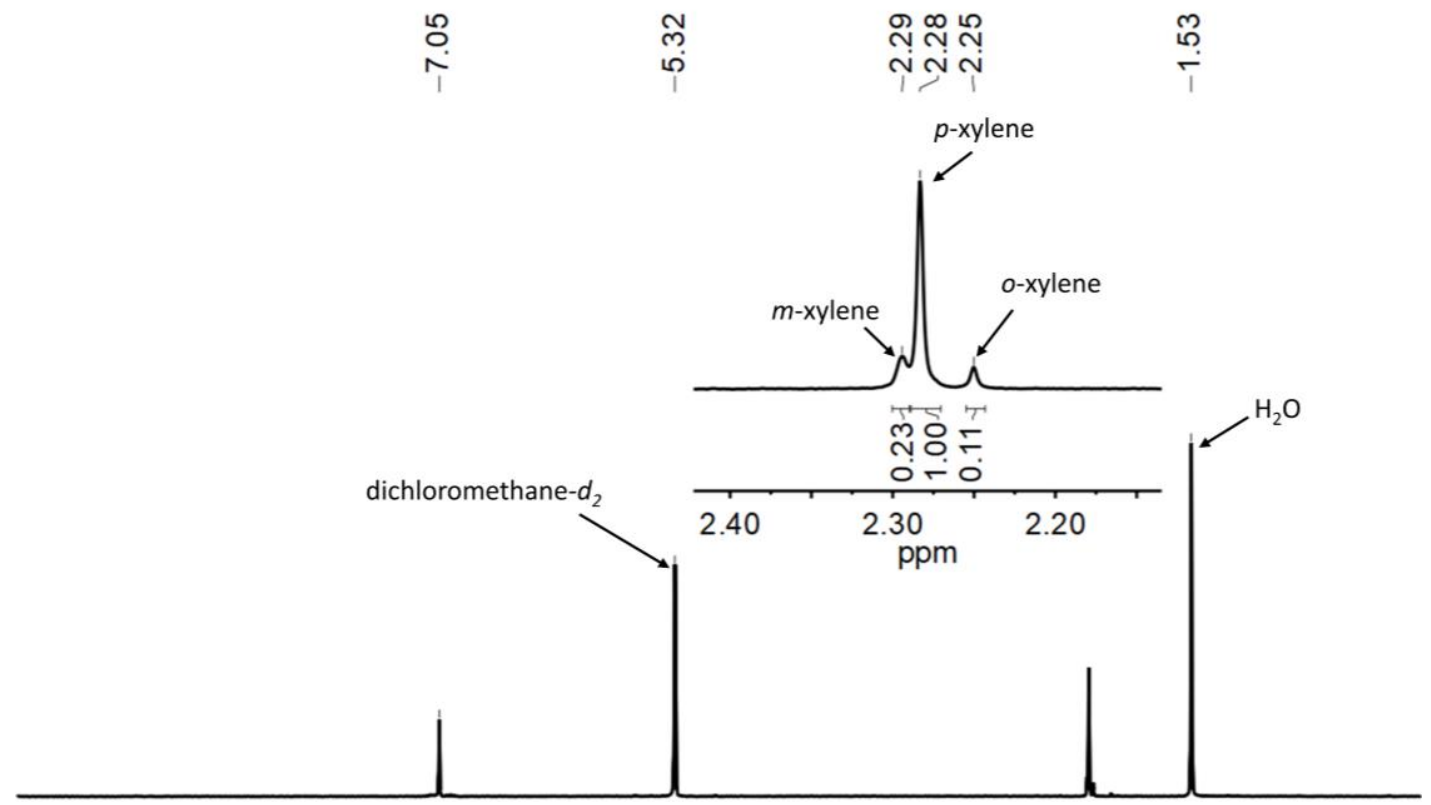

9.5

8.5

7.5

6.5

5.5

ppm

Figure S98. ${ }^{1} \mathrm{H}$ NMR taken on selective loading from a 1:1:1 $p$-xylene/o-xylene/ $m$-xylene mixture (3 mL) using 5 mg of crystalline $\mathbf{1}$ (trial 1 ) 


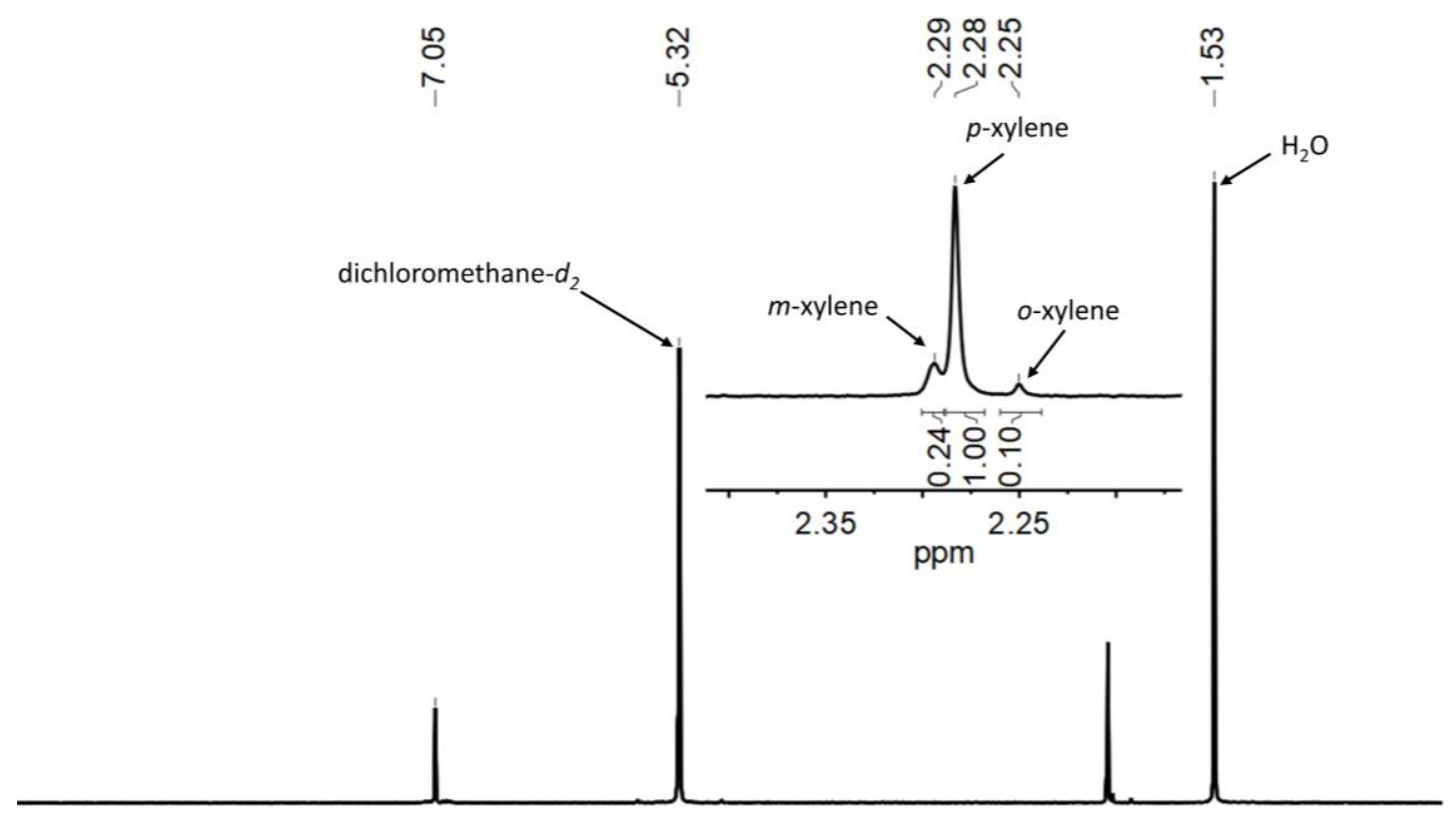

\begin{tabular}{|c|c|c|c|c|c|c|c|c|c|}
\hline 9.5 & 8.5 & 7.5 & 6.5 & 5.5 & 4.5 & 3.5 & 2.5 & 1.5 & 0.5 \\
\hline
\end{tabular}

Figure S99. ${ }^{1} \mathrm{H}$ NMR taken on selective loading from a 1:1:1 $p$-xylene/o-xylene/ $m$-xylene mixture (3 mL) using 5 mg of crystalline $\mathbf{1}$ (trial 2)

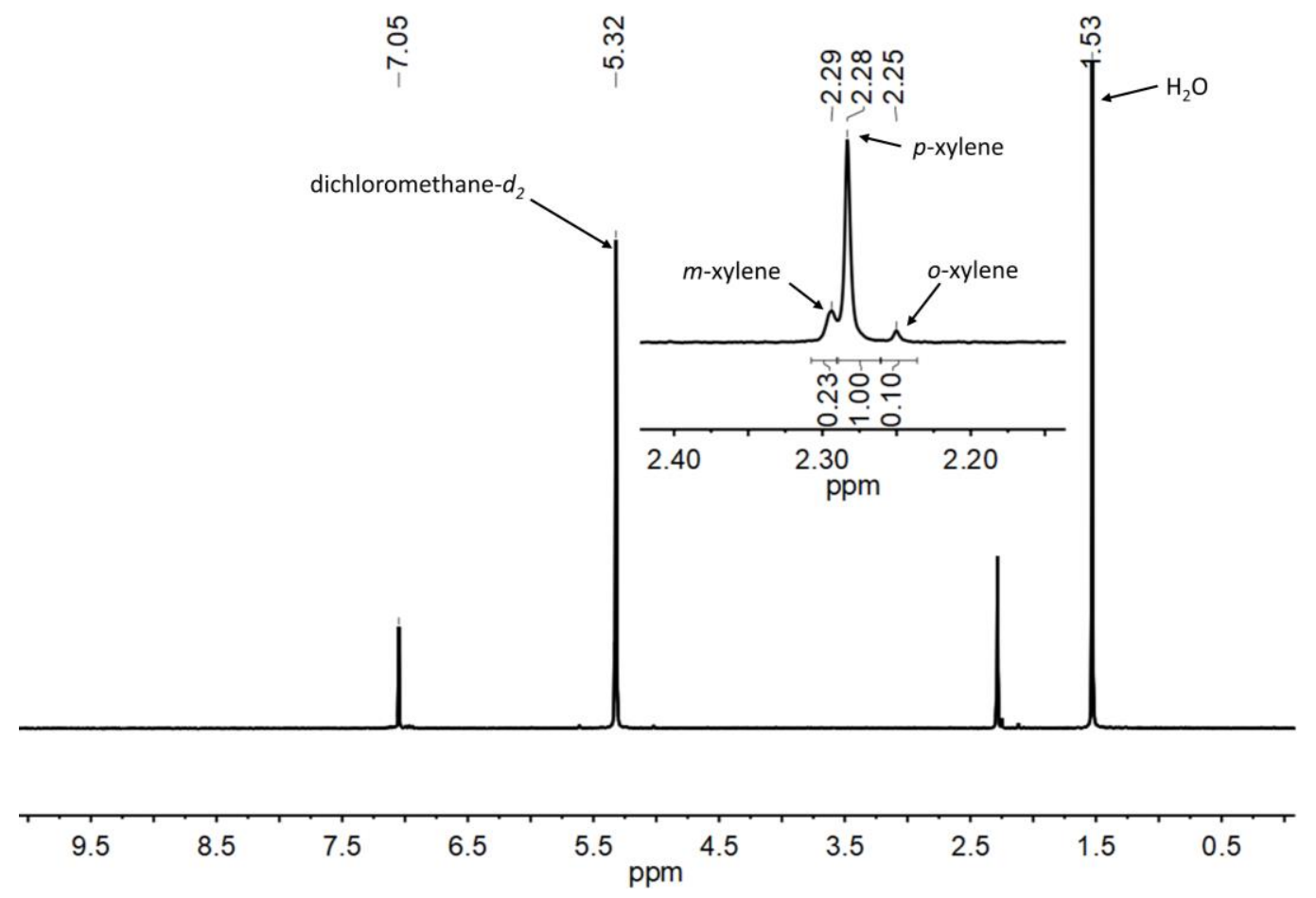

Figure S100. ${ }^{1} \mathrm{H}$ NMR taken on selective loading from a 1:1:1 $p$-xylene/o-xylene/m-xylene mixture (3 mL) using 5 mg of crystalline $\mathbf{1}$ (trial 3) 


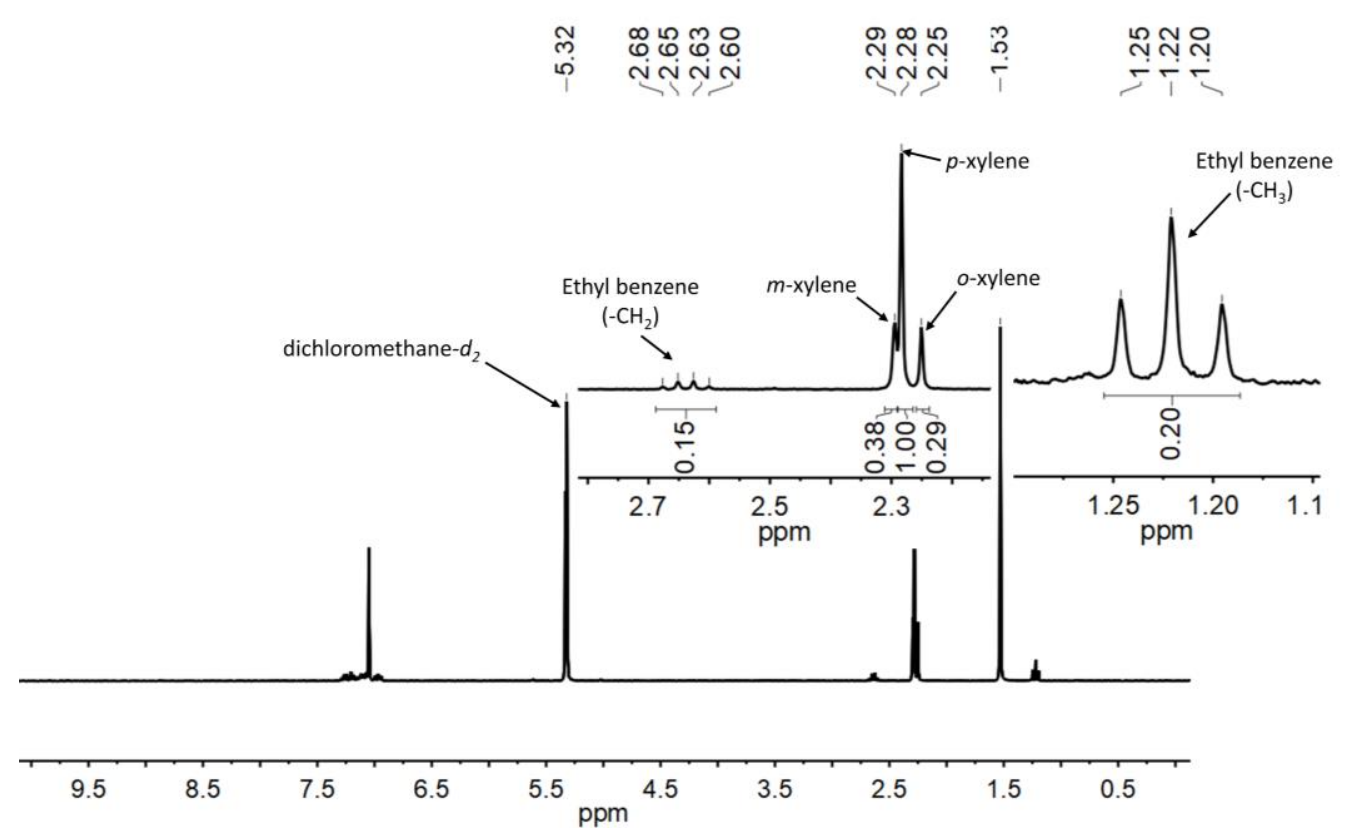

Figure S101. ${ }^{1} \mathrm{H}$ NMR taken on selective loading from a 1:1:1:1 $p$-xylene/o-xylene $/ m$-xylene/ethyl benzene mixture (4 mL) using $5 \mathrm{mg}$ of crystalline $\mathbf{1}$.

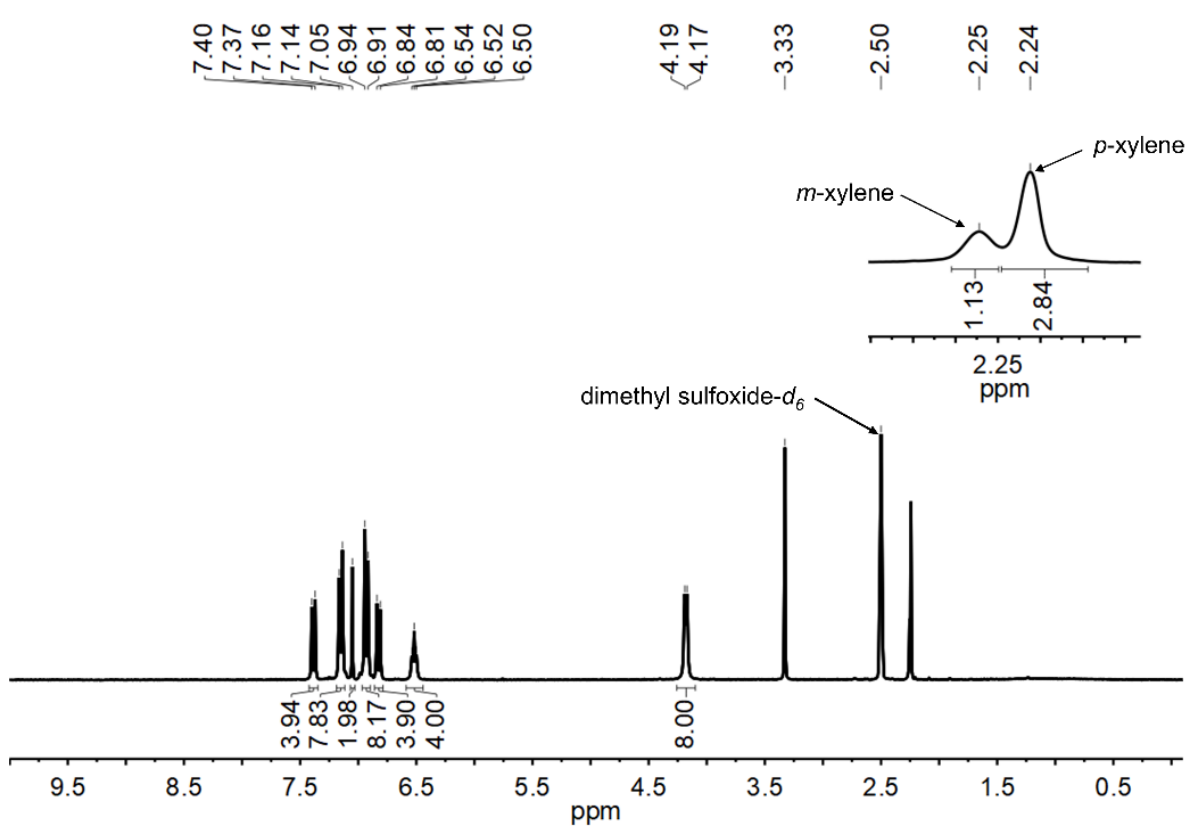

Figure S102. ${ }^{1} \mathrm{H}$ NMR taken on selective loading from a 1:1 $\mathrm{m}$-xylene/ $p$-xylene mixture (4 mL) using $5 \mathrm{mg}$ of crystalline 1. (300 MHz, DMSO) $\delta 7.39$ (d, $J=8.8 \mathrm{~Hz}, 4 \mathrm{H}), 7.15(\mathrm{~d}, J=8.4 \mathrm{~Hz}, 8 \mathrm{H}), 7.05(\mathrm{~s}, 2 \mathrm{H}), 6.93(\mathrm{~d}, J=8.4 \mathrm{~Hz}$, $8 \mathrm{H}), 6.82(\mathrm{~d}, J=8.8 \mathrm{~Hz}, 4 \mathrm{H}), 6.52(\mathrm{t}, J=6.2 \mathrm{~Hz}, 4 \mathrm{H}), 4.18(\mathrm{~d}, J=5.9 \mathrm{~Hz}, 8 \mathrm{H}), 2.25(\mathrm{~s}, 1 \mathrm{H}), 2.24(\mathrm{~s}, 3 \mathrm{H})$. 


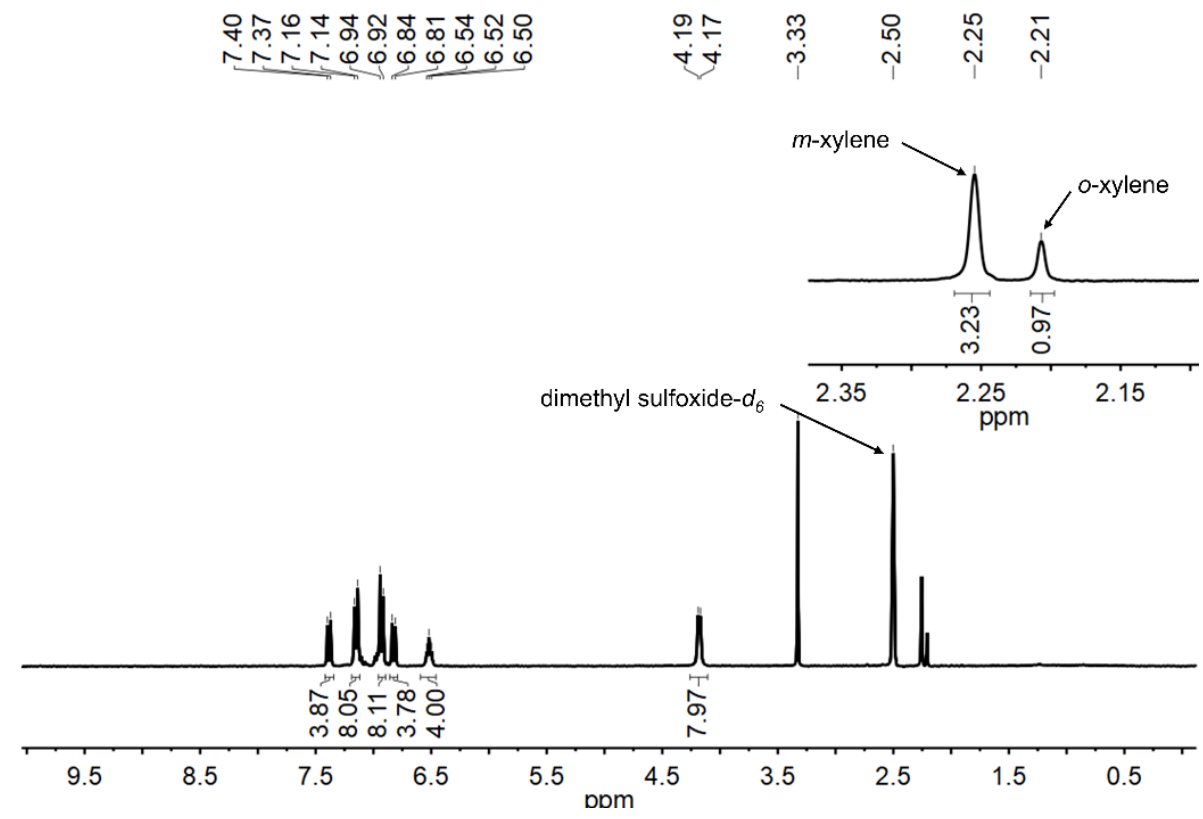

Figure S103. ${ }^{1} \mathrm{H}$ NMR taken on selective loading from a 1:1 $\mathrm{m}$-xylene/o-xylene mixture (4 mL) using $5 \mathrm{mg}$ of crystalline 1. $\delta 7.39(\mathrm{~d}, J=8.8 \mathrm{~Hz}, 4 \mathrm{H}), 7.15(\mathrm{~d}, J=8.4 \mathrm{~Hz}, 8 \mathrm{H}), 6.93(\mathrm{~d}, J=8.3 \mathrm{~Hz}, 8 \mathrm{H}), 6.82(\mathrm{~d}, J=8.8 \mathrm{~Hz}, 4 \mathrm{H}), 6.52(\mathrm{t}$, $J=6.2 \mathrm{~Hz}, 4 \mathrm{H}), 4.18(\mathrm{~d}, J=5.9 \mathrm{~Hz}, 8 \mathrm{H}), 2.25(\mathrm{~s}, 3 \mathrm{H}), 2.21(\mathrm{~s}, 1 \mathrm{H})$.
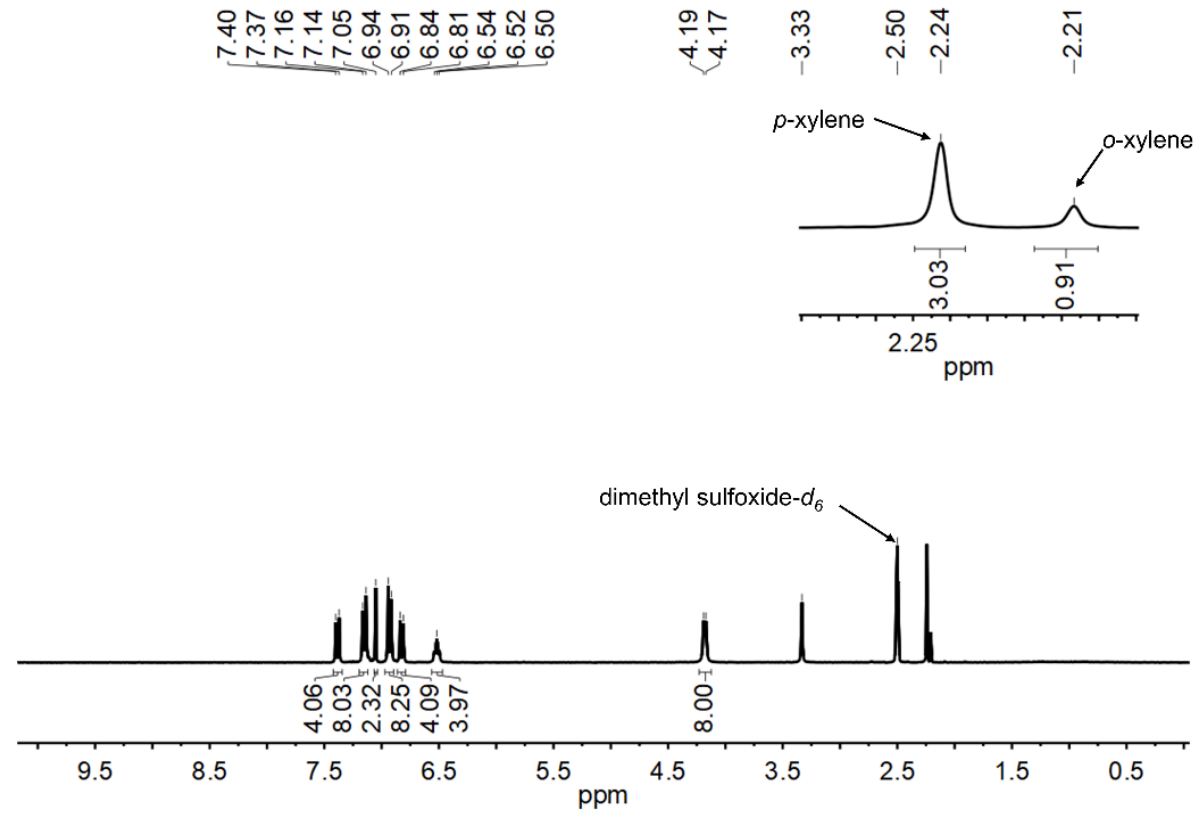

Figure S104. ${ }^{1} \mathrm{H}$ NMR taken on selective loading from a $1: 1 o$-xylene $/ p$-xylene mixture (4 mL) using $5 \mathrm{mg}$ of crystalline $1(300 \mathrm{MHz}$, DMSO) $\delta 7.39(\mathrm{~d}, J=8.8 \mathrm{~Hz}, 4 \mathrm{H}), 7.15(\mathrm{~d}, J=8.4 \mathrm{~Hz}, 8 \mathrm{H}), 7.05(\mathrm{~s}, 2 \mathrm{H}), 6.93(\mathrm{~d}, J=8.4 \mathrm{~Hz}, 8 \mathrm{H})$, $6.82(\mathrm{~d}, J=8.9 \mathrm{~Hz}, 4 \mathrm{H}), 6.52(\mathrm{t}, J=6.2 \mathrm{~Hz}, 4 \mathrm{H}), 4.18(\mathrm{~d}, J=6.1 \mathrm{~Hz}, 8 \mathrm{H})$. 


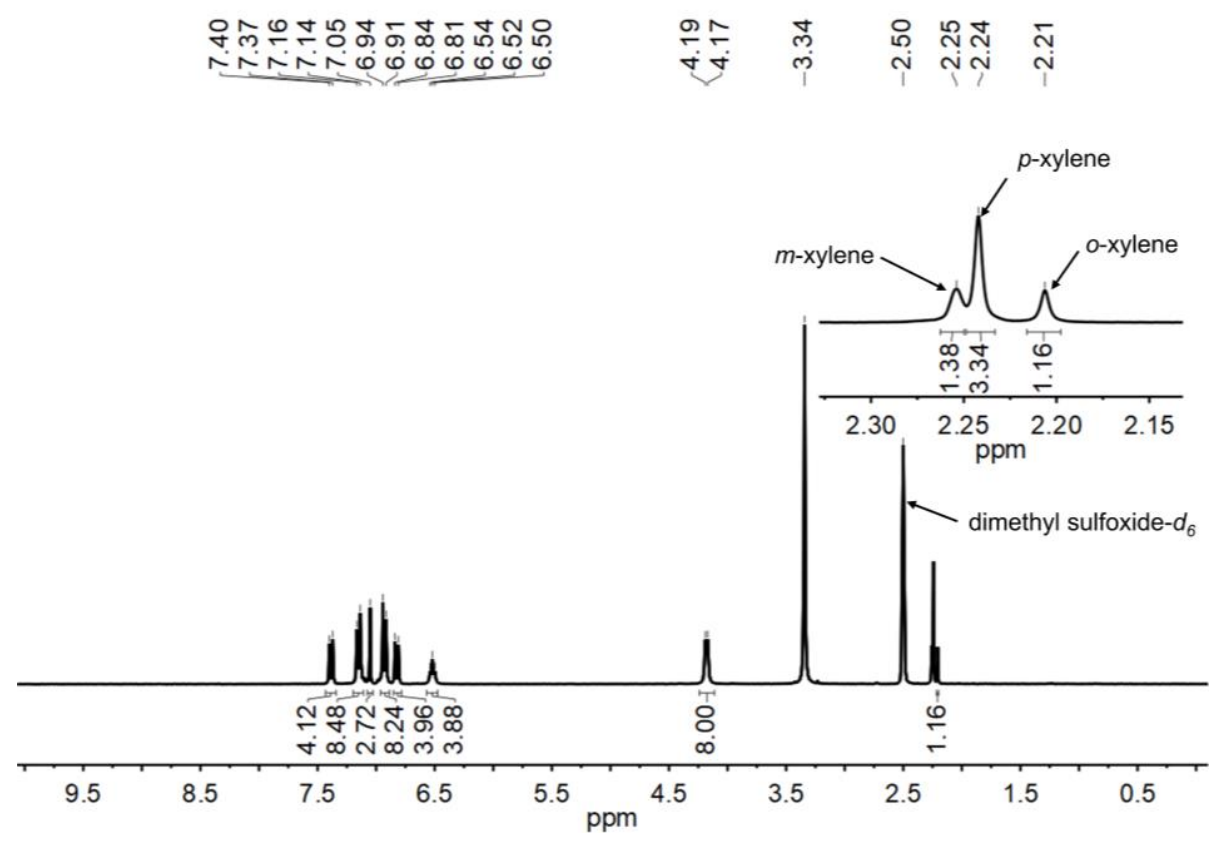

Figure S105. ${ }^{1} \mathrm{H}$ NMR taken on selective loading from a 1:1:1 $\mathrm{m}$-xylene/o-xylene/ $p$-xylene mixture (3 mL) using 5 mg of crystalline 1. ${ }^{1} \mathrm{H}$ NMR (300 MHz, DMSO) $\delta 7.38(\mathrm{~d}, J=8.8 \mathrm{~Hz}, 4 \mathrm{H}), 7.15(\mathrm{~d}, J=8.4 \mathrm{~Hz}, 8 \mathrm{H}), 7.05(\mathrm{~s}, 3 \mathrm{H}), 6.93(\mathrm{~d}$, $J=8.4 \mathrm{~Hz}, 8 \mathrm{H}), 6.82(\mathrm{~d}, J=8.9 \mathrm{~Hz}, 4 \mathrm{H}), 6.52(\mathrm{t}, J=6.2 \mathrm{~Hz}, 4 \mathrm{H}), 4.18(\mathrm{~d}, J=5.9 \mathrm{~Hz}, 8 \mathrm{H}), 2.21(\mathrm{~s}, 1 \mathrm{H})$.

\section{REFERENCES}

(1) Sindt, A. J.; Smith, M. D.; Berens, S.; Vasenkov, S.; Bowers, C. R.; Shimizu, L. S. Single-Crystal-to-Single-Crystal Guest Exchange in Columnar Assembled Brominated Triphenylamine Bis-Urea Macrocycles. Chem. Commun. 2019, 55 (39), 56195622.

(2) APEX3 Version 2018.1-0 and SAINT+ Version 8.38A. Bruker AXS, Inc., Madison, Wisconsin, USA, 2016.

(3) Krause, L.; Herbst-Irmer, R.; Sheldrick, G. M.; Stalke, D. Comparison of Silver and Molybdenum Microfocus X-Ray Sources for Single-Crystal Structure Determination. J. Appl. Crystallogr. 2015, 48, 3-10.

(4) Sheldrick, G. M. SHELXT - Integrated Space-Group and Crystal-Structure Determination. Acta Crystallogr., Sect. A: Found. Adv. 2015, A71, 3-8.

(5) Dolomanov, O. V.; Bourhis, L. J.; Gildea, R. J.; Howard, J. A. K.; Puschmann, H. OLEX2: A Complete Structure Solution, Refinement and Analysis Program. J. Appl. Crystallogr. 2009, 42, 339-341. 